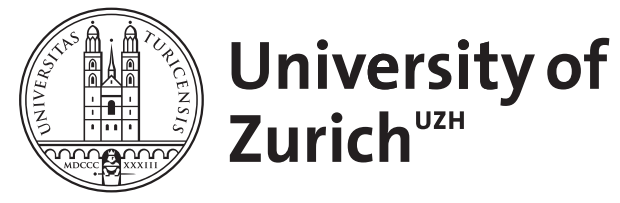

\title{
Zum Rechtsschutz von Fideikommissen im Prinzipat
}

Babusiaux, Ulrike

DOI: https://doi.org/10.1515/zrgr-2019-0007

Posted at the Zurich Open Repository and Archive, University of Zurich ZORA URL: https://doi.org/10.5167/uzh-181344

Journal Article

Published Version

Originally published at:

Babusiaux, Ulrike (2019). Zum Rechtsschutz von Fideikommissen im Prinzipat. Zeitschrift der SavignyStiftung für Rechtsgeschichte. Romanistische Abteilung, 136(1):140-213.

DOI: https://doi.org/10.1515/zrgr-2019-0007 


\title{
Zum Rechtsschutz von Fideikommissen im Prinzipat
}

\author{
Von \\ Ulrike Babusiaux*) \\ „Es wäre auch ein ganz aussichtsloses Beginnen, \\ wollten wir es versuchen, aus den wenigen unsicheren Andeutungen \\ der Quellen ein nur in den Grundzügen \\ zuverlässiges Bild des Fideikommißverfahrens zu entwerfen“l).
}

\begin{abstract}
Judicial protection of fideicommissa during the principate. The enforcement of fideicommissa via cognitio extra ordinem from the time of Augustus onwards has led much of the scholarship to neglect the evidence for agere per formulas in this field. The paper attempts to show that until the late Severan age, fideicommissa were enforced via both procedures. For fideicommissa hereditatis, it is shown that both the senatus consultum Trebellianum and the senatus consultum Pegasianum functioned with the formulary procedure and were therefore enacted by the ordinary praetor. The cognitio in this respect seems to have been limited to the determination of the existence, the content and the consequences of a fideicommissum. For pecuniary fideicommissa over singular items, a similar partition can be assumed. In fact, safeguarding the fideicommissum through cautio fideicommissorum servandorum causa and missio rei servandae causa was attributed to the ordinary praetor also in charge of the protection of legata: only the petitio fideicommissaria itself was left to the imperial officials and their cognitio.
\end{abstract}

Keywords: Fideicommissum, cognitio extra ordinem, agere per formulas, Severan Age

Inhalt: I. Einleitung; II. Rechtsschutz im Rahmen der cognitio extra ordinem; III. Das Verfahren bei Universalfideikommissen; IV. Zum Rechtsschutz des Einzelfideikommisses im Formularverfahren; V. Gesamtergebnis; VI. Zusammenfassung in Thesen

*) ulrike.babusiaux@rwi.uzh.ch. Für Kritik und Anmerkungen in verschiedenen Stadien der Entstehung danke ich Jakob F. Stagl (Santiago de Chile), Ulrich Manthe (Passau), Martin J. Schermaier (Bonn) sowie Wolfgang Kaiser (Freiburg i. Br.).

1) K. Salkowski, in: C.L. Arndt (Hg.), Ausführliche Erläuterung der Pandekten nach Hellfeld, Ein Commentar begründet von Christian Friedrich v. Glück, 49. Theil, Erlangen 1889, 609. 


\section{Einleitung}

Die Entwicklungsgeschichte der cognitio extra ordinem ${ }^{2}$ ) aus Fideikommissen im Verhältnis zum Formularverfahren muss nach wie vor als ungeklärt gelten, obgleich das Recht der formlosen Verfügungen von Todes wegen häufiger Gegenstand von Gesamtdarstellungen war ${ }^{3}$ ). Ein Grund für die fehlende Aufarbeitung der prozessualen Durchsetzung der Fideikommisse ist in der Quellenlage zu sehen. Da die cognitiones extra ordinem ${ }^{4}$ ) in der justinianischen Überlieferung nicht vom Formularverfahren getrennt sind, mag es müßig erscheinen, die Textzeugnisse der Digesten überhaupt auf das jeweils einschlägige Verfahren hin zu untersuchen. Hinzu kommt, dass auch die sonst für die Kenntnis des römischen Zivilprozessrechts überaus hilfreichen Institutionen des Gaius keinen Ansatzpunkt für Differenzierungen bieten, indem Gaius die cognitio zwar nennt, aber nur das Legisaktionenverfahren und das Formularverfahren eingehend behandelt ${ }^{5}$ ).

Angesichts dieser Ausgangslage hat sich die Forschung zum Rechtsschutz der Fideikommisse in der Regel darauf beschränkt, die Form- und Regellosigkeit der cognitio zu betonen und vorrangig einzelne Auslegungsprobleme erörtert, welche diese Art der letztwilligen Verfügung aufwirft. Dabei gerät allerdings aus dem Blick, dass es eine Reihe von Belegen gibt, welche Organe und Institute des Formularverfahrens auch im Zusammenhang mit Fideikommissen erwähnen ${ }^{6}$ ). Wenn überhaupt auf diesen Umstand eingegangen

$\left.{ }^{2}\right)$ Der Unterschied zwischen dem Sprachgebrauch der Quellen und der Forschung wird immer wieder hervorgehoben; vgl. nur Nachweise bei I. B uti, La ,cognitio extra ordinem' da Augusto a Diocleziano, in: ANRW II.14 (1982) 29-59, 30 Fn. 5; M. Kaser/K. Hack1, Römisches Zivilprozessrecht, München ${ }^{2} 1996$, 435f. Fn. 1 und Fn. 5. Im Folgenden wird von cognitio oder cognitio extra ordinem gesprochen werden.

$\left.{ }^{3}\right)$ D. Johnston, The Roman Law of Trusts, Oxford 1988; A. Murillo Villar, El fideicomiso de residuo en derecho romano, Valladolid 1989; F. Longchamps de Bérier, Il fedecommesso universale nel diritto romano classico, Warschau 1997; L. Desanti, Restitutionis post mortem onus: i fedecommessi da restituirsi dopo la morte dell'onerato, Mailand 2003. Eine Ausnahme bildet V. Giodice-Sabbatelli, Fideicommissorum persecutio, Contributo allo studio delle cognizioni straordinarie, Bari 2001, die ausdrücklich den verfahrensrechtlichen Aspekt untersucht.

$\left.{ }^{4}\right)$ Vgl. statt aller Kaser/Hack1 (Fn. 2) 436f., die zutreffend darauf verweisen, dass es sich um einen „Sammelbegriff“ für verschiedene Verfahrensarten handelt.

$\left.{ }^{5}\right)$ Gai. Inst. 2,278; Gai. Inst. 4,11-29 handelt von den legis actiones; Gai. Inst. 4,30-137 vom agere per formulas.

$\left.{ }^{6}\right)$ Vgl. die Beobachtung von R. Röhle, Praetor fideicommissarius, RIDA 15 (1968) 399-428, 405-411, dass Rechtsschutzfragen der Fideikommisse sowohl in den Monographien der Juristen zum Thema als auch in den Ediktskommentaren 
wird, so wird meist angenommen, praetor sei eine kürzende Interpolation für praetor fideicommissarius ${ }^{7}$ ); in ähnlicher Weise wird die in einigen Quellen aufscheinende parallele prozessuale Behandlung von Fideikommissen und Legaten als Anpassung im Sinne der justinianischen Reform zur Gleichstellung von legata und fideicommissa gedeutet (vgl. unten III.3a).

Nach dem heutigen Stand der Textkritik sind derartige Pauschalverdächtigungen, wie sie hier jedenfalls hineinspielen, zu hinterfragen; zudem existieren durchaus Indizien, die für eine stärkere Verschränkung von Formularprozess und cognitio extra ordinem sprechen. So ist zunächst daran zu erinnern, dass schon die Vorstellung der ermessensgeleiteten $\operatorname{cognitio}^{8}$ ) ihrerseits aus dem Formularverfahren stammt und die besonderen Befugnisse des Prätors bezeichnet, wenn dieser eine eigene Sachentscheidung trifft oder für die Erteilung oder Versagung eines Rechtsmittels weitergehende Nachforschungen anstellen muss ${ }^{9}$ ). Weiter belegen Walter Selbs Forschungen zum „formularen“ Denken, dass die Ablösung von der Klageformel schrittweise erfolgt sein muss und Traditionen des Formularverfahrens auch in der cognitio extra ordinem nachwirkten ${ }^{10}$ ). Diesen Eindruck bestätigen auch papyrologische Studien, die nahelegen, dass die Klageformel auch im Rahmen der Kognition Verwendung fand $\left.{ }^{11}\right)$; zuletzt ist daran zu erinnern,

erörtert werden. Er leitet hieraus allerdings einen Interpolationsverdacht gegen die Nennungen in den Ediktskommentaren ab.

$\left.{ }^{7}\right)$ So dezidiert Röhle (Fn. 6) 402-415.

${ }^{8)}$ M. W lassak, Römische Processgesetze, Ein Beitrag zur Geschichte des Formularverfahrens, Erste Abteilung, Leipzig 1888, 216-220; M. Lemosse, Cognitio, Étude sur le rôle du juge dans l'instruction du procès civil antique, Paris 1944, 142-147; G. Scherillo, Lezioni sul processo, Introduzione alla ,cognitio extra ordinem', Corso di diritto romano, Mailand 1960, 209-213.

9) Vgl. W. Kunkel/R. Wittmann, Staatsordnung und Staatspraxis der römischen Republik, Abschnitt 2: Die Magistratur, München 1995, 145f. Zu dieser Art der Gerichtsbarkeit, die dem Hausgericht ähnelt; vgl. H. Volkmann, Zur Rechtsprechung im Principat des Augustus, ${ }^{2} 1949,63-93$ (nicht nur zum Strafprozess).

$\left.{ }^{10}\right)$ W. Selb, Actiones in factum und Formeltechnik, Vorbemerkungen zu einer geplanten Untersuchung, in: G. Frotz/W. Ogris (Hgg.), Festschrift Demelius, Wien 1973, 223-235; W. Selb, Formulare Analogien in ,actiones utiles' und ,actiones in factum' am Beispiel Julians, in: Studi Biscardi III, Mailand 1982, 315-350; ders., Formulare Analogien in ,actiones utiles' und ,actiones in factum' vor Julian, in: Studi Sanfilippo V, Mailand 1984, 729-759.

11) Vgl. J. Mélèze Modrzejewski, Loi et coutume dans l'Égypte grecque et romaine, Warschau 2014, 288: „Il convient de rappeler cependant que la cognitio provinciale peut avoir recours aux formules de l'édit prétorien pour les utiliser comme modèle dans la rédaction des instructions adressées par le magistrat déléguant au juge délégué"; in der Sache bereits L. Wenger, s. v. formula, in: RE VI,2, Stuttgart 
dass die Durchführung vieler cognitiones extra ordinem in den Provinzen dem zweistufigen Verfahren des Formularprozesses äußerlich nahekommt, was eine Übertragung von formularen Vorgaben auf die Kognition erleichtert haben dürfte' ${ }^{12}$ ).

Die skizzierten Übereinstimmungen sprechen dafür, bei einer Neubetrachtung der Frage weder die Klageformel noch die Zweiteilung des Verfahrens als Differenzierungsmerkmal für die Quellenanalyse zu wählen, sondern cognitio und Formularprozess nach anderen kompetenz- und verfahrenstechnischen Elementen zu unterscheiden. Dabei ist auch mit Überschneidungen und Verschränkungen der beiden Verfahrensarten sowie mit schrittweisen Veränderungen ihres Verhältnisses, vor allem unter dem Einfluss der zunehmenden Zentralisierung der Rechtssetzung in den Händen des princeps, zu rechnen. Die Eigengerichtsbarkeit des princeps, die gerade im Bereich der letztwilligen Verfügungen viele Innovationen bereithält, wird aufgrund ihrer Besonderheiten allerdings auszuklammern sein ${ }^{13}$ ). Außer Betracht bleiben auch die Sonderfragen der fideikommissarischen Freilassung, deren prozessuale Besonderheiten unlängst ausführlich untersucht worden $\operatorname{sind}^{14}$ ). Vielmehr soll im Folgenden allein die verfahrensrechtliche Situation von vermögensrechtlichen Fideikommissen und ihr Verhältnis zum für das Testamentsrecht vorauszusetzenden Formularverfahren untersucht werden. Dabei wird die gut erforschte Entwicklung des materiellen Fideikommissrechts nur dann näher gewürdigt, wenn sie sich auf prozessualer Ebene auswirkt oder Folgen zeitigen könnte.

1909, Sp. 2859-2876, Sp. 2869f.; vgl. auch Buti (Fn. 2) 47 Fn. 101; ferner W. Turpin, Formula, cognitio and proceedings extra ordinem, RIDA 46 (1999) 499-574, 506-531.

$\left.{ }^{12}\right)$ Zum iudex pedaneus vgl. zuletzt S. Liva, Il iudex pedaneus nel processo privato romano: dalla procedura formulare alla cognitio extra ordinem, Mailand 2012.

${ }^{13}$ ) Zur Eigengerichtsbarkeit des princeps vgl. Kaser/Hackl (Fn. 2) 445-451; J.M. Kelly, Princeps iudex, Eine Untersuchung zur Entstehung und zur Grundlage der kaiserlichen Gerichtsbarkeit, Weimar 1957, der deren Grundlage in der auctoritas principis erblickt; zur politischen Funktion vgl. Buti (Fn. 2) 35f.; N. Palazzolo, Potere imperiale ed organi giurisdizionali nel II secolo d.C., L'efficacia processuale dei rescritti imperiali da Adriano ai Severi, Mailand 1974, 59-71 zu den Unterschieden zwischen decretum und rescriptum; aus historischer Sicht vgl. M. Peachin, Iudex vice Caesaris, Deputy Emperors and the Administration of Justice during the Principate, Stuttgart 1996, bes. 14-91; eine fundierte Analyse der decreta bei M. Rizzi, Imperator cognoscens decrevit, Profili e contenuti dell'attività giudiziaria imperiale in età classica, Mailand 2012.

${ }^{14}$ ) $\mathrm{Zu}$ den fideikommissarischen Freilassungen vgl. zuletzt F. M. Silla, La cognitio sulle libertates fideicommissae, Padua 2008. 
Mit dem so skizzierten Programm ist zunächst herauszuarbeiten, was über die petitio fideicommissaria und den Rechtsschutz von Fideikommissen in der cognitio extra ordinem ermittelt werden kann (II). Sodann ist der nicht auf die cognitio beschränkte Rechtsschutz für Erbschaftsfideikommisse (III) und Einzelfideikommisse (IV) zu analysieren, wobei auch die Frage zu streifen ist, ob und inwieweit die cognitio extra ordinem ihrerseits auf das Legatsrecht gewirkt haben könnte. Abschließend sind die Ergebnisse zusammenzuführen (V) und in Thesen vorzustellen (VI).

\section{Rechtsschutz im Rahmen der cognitio extra ordinem}

Mit Blick auf den Rechtsschutz der Fideikommisse im Rahmen der cognitio extra ordinem sind die allgemein für das Kognitionsverfahren zu beobachtenden Besonderheiten im Bereich der Ladung ${ }^{15}$ ), der Säumnis $\left(\right.$ contumacia $^{16}{ }^{16}$ und vor allem der Vollstreckung ${ }^{17}$ ) in Erinnerung zu rufen, die allerdings nur selten in der Entscheidungsfindung sichtbar werden. Ein weiterer Unterschied zum Formularverfahren ergibt sich aus der Stilisierung der in der cognitio getroffenen Entscheidung: Die vom Beamten erteilte pronuntiatio spricht formal nur das Bestehen oder Nichtbestehen des Fideikommisses aus $\left.{ }^{18}\right)$, weshalb nicht von einer eigentlichen Verurteilung (condemnatio) oder einem Freispruch (absolutio) gesprochen werden

${ }^{15)}$ Statt privater in ius vocatio eine denuntiatio oder evocatio vgl. R. Samter, Nichtförmliches Gerichtsverfahren, Weimar 1911, 95-99; knapp Buti (Fn. 2) 33, 44f.; Kaser/Hack1 (Fn. 2) 472-477.

$\left.{ }^{16}\right)$ Zur Möglichkeit, auch bei Abwesenheit einer Partei einen Entscheid zu treffen (contumacia); vgl. Sa mter (Fn. 15) 99-119; Buti (Fn. 2) 45f.; Ka ser/Hackl (Fn. 2) 477-481; zuletzt ausführlich A. Bellodi Ansaloni, Richerche sulla contumacia nelle cognitiones extra ordinem, Mailand 1998.

$\left.{ }^{17}\right)$ Condemnatio in ipsam rem statt condemnatio pecuniaria; vgl. Buti (Fn. 2) 33f. Hauptbeleg für die Fideikommisse ist D. 50,16,178,2 Ulp. 49 ad Sab. (...) ,Persecutionis"verbo extraordinarias persecutiones puto contineri, ut puta fideicommissorum et si quae aliae sunt, quae non habent iuris ordinarii exsecutionem; dazu Samter (Fn. 15) 73 Fn. 1 mwN.

$\left.{ }^{18}\right)$ Diese Unbestimmtheit findet sich sogar in den decreta des princeps vgl. D. 36,1,76pr. Paul. 2 decr. (...) pronuntiavit imperator fideicommissum ex hac scriptura deberi, (...): sic enim accipiendam eam scripturam, ac si hereditatem suam rogasset eam restituere. Daneben findet sich auch untechnisch der Begriff condemnatio; vgl. D. 42,1,5,1 Ulp. 59 ad ed. Si iudex aliquem sic condemnet, ut, quod habet ex testamento vel codicillis Maevii, restitueret Titio, sic accipiendum est, quasi quantitatem nominavit, quae testamento vel codicillis relicta est. sed et si fideicommissum sine scriptura pronuntiatum, idem erit probandum. 
$\mathrm{kann}^{19}$ ), wie sie in der formula vorgegeben sind. Dennoch wirkt die Feststellung als Befehl' ${ }^{20}$ ), verlangt also Handlungen des Beschwerten, welche die Anordnung des Erblassers vollziehen. Diese Erfüllung kann durch freiwillige Herausgabe, aufgrund vergleichsähnlicher Vereinbarungen zwischen dem Beschwertem und dem Fideikommissar ${ }^{21}$ ) erfolgen oder aber durch die Ausübung von Zwang durchgesetzt werden ${ }^{22}$ ).

Für vermögensrechtliche Fideikommisse lassen sich weitergehende Unterschiede zum Formularverfahren vor allem mit Blick auf die zuständigen Organe, Inhalt und Begründung der Entscheidung in der cognitio sowie ihrer Vollstreckung feststellen.

1. Die für die cognitio zuständigen Organe:

Die Forschung zur Gerichtsverfassung der Kaiserzeit ${ }^{23}$ ) hat herausgearbeitet, dass einmal zugewiesene Kompetenzen trotz der zunehmenden Machtfülle des princeps grundsätzlich respektiert wurden. Eine getrennte Zuständigkeitsordnung von Formularverfahren und cognitio extra ordinem ist mit Blick auf Fideikommisse offenbar nur in Rom selbst durchgeführt worden, während in den Provinzen schon seit dem 2. Jh. v. Chr. von einer einheitlichen Zuständigkeit des Statthalters ${ }^{24}$ ) auszugehen ist ${ }^{25}$ ). Spezialorgane zur Durchsetzung der Fideikommisse in Rom sind die Konsuln und der praetor fideicommissarius. Die Amtsgewalt (auctoritas) der Konsuln bildet nach dem Bericht in Justinians Institutionen den

$\left.{ }^{19}\right)$ Salkowski (Fn. 1) 609. Vergleichbares nimmt G. Impallomeni, Le manomissioni mortis causa, Studi sulle fonti autoritative romane, Padua 1963, 65 für die fideikommissarischen Freilassungen an.

${ }^{20}$ ) Vgl. Kaser/Hack1 (Fn. 2) 494f., die davon ausgehen, dass Leistungsurteile „die Regel bilden“. Interessant ist die Behandlung der pronuntiatio als iudicatum in D. 4,4,40pr. Ulp. 5 opin. Minor annis viginti quinque, cui fideicommissum solvi pronuntiatum erat, caverat id se accepisse et cautionem eidem debitor quasi creditae pecuniae fecerat. in integrum restitui potest, quia partam ex causa iudicati persecutionem novo contractu ad initium alterius petitionis redegerat.

${ }^{21)}$ Vgl. nochmals D. 4,4,40pr. Ulp. 5 opin.

${ }^{22}$ D. $42,1,15$ pr.-12 Ulp. 3 off. cons.; dazu vor allem D. Simon, Summatim cognoscere, Zwölf Exegesen, ZRG RA 83 (1966) 142-218, 151-158; vgl. ferner D. 42,1,31 Call. 2 cogn.; dazu Samter (Fn. 15) 144f.

23) Palazzolo (Fn. 13) bes. 274-277.

${ }^{24}$ ) Zur einheitlichen Zuständigkeit des praeses provinciae für cognitio extra ordinem und Formularverfahren vgl. auch Impallomeni, Manomissioni (Fn. 19) 65; Longchamps de Bérier (Fn. 3) 84f. (auch zu den iuridici in Italien).

${ }^{25}$ ) Zu Einzelheiten des Verhältnisses von cognitio extra ordinem und Formularverfahren in den Provinzen vgl. Buti (Fn. 2) 42f. 
Ausgangspunkt für die später eingerichtete iurisdictio aus Fideikommis$\left.\operatorname{sen}^{26}\right)$ :

Inst. 2,23,1 (...) postea primus divus Augustus semel iterumque gratia personarum motus, vel quia per ipsius salutem rogatus quis diceretur, aut ob insignem quorundam perfidiam iussit consulibus auctoritatem suam interponere. quod, quia iustum videbatur et populare erat, paulatim conversum est in adsiduam iurisdictionem: tantusque favor eorum factus est, ut paulatim etiam praetor proprius crearetur, qui fideicommissis ius diceret, quem fideicommissarium appellabant.

Der erste princeps, der selbst Fideikommisse gewissenhaft erfüllt habe (Inst. 2,25pr.), soll die Konsuln in besonders gelagerten Einzelfällen gebeten haben, ihre Amtsgewalt zur Durchsetzung von Fideikommissen einzusetzen. Als Beispiele für derartige Fälle nennt Justinian Fideikommisse zugunsten von dem Kaiser nahestehenden Personen (gratia personarum), Fideikommisse, bei denen die Bitte auf das Heil des Kaisers (per ipsius salutem rogatus) gelautet habe, sowie Situationen, in denen sich die Weigerung, ein Fideikommiss zu erfüllen, als besonders schwerwiegender Vertrauensbruch von Seiten des Beschwerten erwiesen habe ${ }^{27}$ ). Erst schrittweise soll sich das Eingreifen in Einzelfällen zu einer Regel verdichtet haben, nach welcher auch der formlos geäußerte Erblasserwille zu schützen und gegen den treuwidrigen Erben durchzusetzen sei. Die kaiserliche Maßnahme zum Schutz der Fideikommisse sei nämlich allgemein als gerecht angesehen worden und habe breite Zustimmung erhalten ${ }^{28}$ ).

Mit Blick auf die Zuständigkeitsordnung ist zu beachten, dass sich Oktavian nicht selbst als Richter über die Fideikommisse einsetzt, sondern die Konsuln zum Handeln aufforder ${ }^{29}$ ); zudem ist auffällig, dass zunächst nicht von

${ }^{26}$ ) Nachweise zum vielzitierten Text bei Longchamps de Bérier (Fn. 3 ) 23 Fn. 12; seitdem v.a. Giodice-Sabbatelli (Fn. 3) 42-60.

${ }^{27}$ ) Zur perfidia vgl. H. Krüger/M. Kaser, Fraus, ZRG RA 63 (1943) 117-174.

${ }^{28}$ ) Zur Kultur der exempla vgl. K.-J. Hölkeskamp, Exempla und mos maiorum, Überlegungen zum kollektiven Gedächtnis der Nobilität, in: H.J. Gehrke/A. Möller (Hgg.), Vergangenheit und Lebenswelt, Soziale Kommunikation, Traditionsbildung und historische Bewußtsein, Tübingen 1996, 301-328; J.-M. David, Maiorum exempla sequi, L'exemple historique dans les discours judiciaires de Cicéron, in: Ecole française de Rome (Hg.), Rhétorique et Histoire, L'exemplum et le modèle de comportement dans le discours antique et médiéval, Rom 1980, 67-86.

${ }^{29}$ ) Zum Bezug von auctoritatem suam interponere auf die Konsuln vgl. V. Giodice-Sabbatelli, La tutela giuridica dei fedecommessi fra Augusto e Vespasiano, Bari 1993, 99-119; ihr folgend auch A. Brieger, Die Jurisdiktion der römischen Konsuln von der frühen Republik bis zum 1. Jahrhundert n. Chr., Diss. Bonn 2007, 84-99. 
einer eigenen Gerichtsbarkeit der Konsuln die Rede ist. Vielmehr scheinen die Konsuln lediglich das ihnen als Höchstmagistraten zustehende Eintrittsrecht gegenüber allen Magistraten ausgeübt zu haben ${ }^{30}$ ). $\mathrm{Zu}$ diesem gehört, dass sie die cognitio, das heißt die Entscheidung über einen Einzelfall ${ }^{31}$ ), an sich ziehen können. Man wird die von Justinian geschilderte Situation zu Beginn des Prinzipats daher so auffassen müssen, dass die Konsuln ausnahmsweise (extra ordinem) bereit waren, den Fideikommissaren den Rechtsschutz zu gewähren, der vom Prätor verweigert worden war ${ }^{32}$ ). Erst in einem nächsten Schritt entstand hieraus - weil die Konsuln häufig in Anspruch genommen werden - eine ständige Gerichtsbarkeit (iurisdictio adsidua) ${ }^{33}$ ). Deren deutlichstes Anzeichen stellt die auch andernorts belegte Einführung einer Sonderprätur unter Claudius und Titius ${ }^{34}$ ) dar.

Dieser praetor fideicommissarius ist ein kaiserlicher Beamter, womit sich die Qualität der Jurisdiktion wandelt: Während die consules nach dem Bericht Justinians zwar auf Anweisung des Augustus hin tätig werden, aber die eigene Imperiumgewalt ausüben, stellt sich die iurisdictio des praetor fideicommissarius als delegierte kaiserliche Kompetenz (iurisdictio mandata) dar ${ }^{35}$ ). Dabei ist zu beachten, dass die Spezialprätur für Fideikommisse (praetor fideicommissarius) die Zuständigkeit der Konsuln nicht vollständig beseitigt zu haben scheint, sondern dass die Konsuln für Fideikommisse zugunsten von Senatoren und über große Vermögen zuständig blieben ${ }^{36}$ ).

${ }^{30}$ ) Zur Rolle der Konsuln unter Augustus vgl. F. Hurlet, Consulship and consuls under Augustus, in: H. Beck/A. Duplá/M. Jehne/F. Pina Polo (Hgg.), Consuls and res publica, Holding Office in the Roman Republic, Cambridge 2011, 319-335.

${ }^{31}$ ) Zur cognitio der Konsuln (im Zeitalter der Republik) vgl. F. Pina Polo, The consul at Rome, The Civil Functions of the Consuls in the Roman Republic, Cambridge 2011, 122-134.

32) J.M. Kelly, Roman Litigation, Oxford 1966, 94f. sieht hierin ein Anzeichen für den Verlust der Anpassungskraft des prätorischen Rechts.

${ }^{33}$ ) $\mathrm{Zu}$ dieser vgl. vor allem Giodice-Sabbatelli (Fn. 3) 60-68.

${ }^{34}$ ) Vgl. D. 1,2,2,32 Pomp. 1. s. ench. (...) post deinde divus Claudius duos praetores adicit qui de fideicommisso ius dicerent, ex quibus unum divus Titus detraxit (...).

${ }^{35}$ ) Zur iurisdictio mandata vgl. A. Steinwenter, s. v. iurisdictio mandata, in: RE X,1, Stuttgart 1918, Sp. 1157f.; für den Bereich der Fideikommisse vgl. Giodice-Sabbatelli (Fn. 3) 230-270.

${ }^{36)}$ Vgl. D. 1,9,8 Ulp. 6 fideicomm. Feminae nuptae clarissimis personis clarissimarum personarum appellatione continentur (...); D. 50,16,100 Ulp. 2 off. cons.; dazu O. Lenel, Palingenesia iuris civilis II, Leipzig 1889, Sp. 955 und Sp. 924 Fn. 2: Clarissimae personae non praetoris fideicommissarii, sed consulis iurisdictioni videntur subiectae fuisse. Die Argumente von P. Jörs, Untersuchungen 
Unterschiedlich gedeutet worden ist aber der Umfang der Spezialkompetenz des praetor fideicommissarius. Der zentrale Beleg ${ }^{37}$ ) zur Frage stammt aus den Institutionen des Gaius:

Gai. Inst. 2,278 praeterea legata per formulam petimus; fideicommissa vero Romae quidem apud consulem vel apud eum praetorem, qui praecipue de fideicommissis ius dicit, persequimur, in provinciis vero apud praesidem provinciae.

Im Rahmen seines Vergleichs von Legaten und Fideikommissen erwähnt Gaius auch die prozessualen Unterschiede zwischen beiden Vermächtnisarten: Während die Legate im Formularverfahren eingeklagt würden, könnten Fideikommisse in der Stadt Rom beim Konsul und dem praetor, qui praecipue de fideicommissis ius dicit durchgesetzt werden, in der Provinz beim Statthalter. Der Hinweis praecipue ist bisweilen so verstanden worden, dass der praetor fideicommissarius noch andere Zuständigkeiten in seiner Person vereint hätte ${ }^{38}$ ), die Fideikommisse also nur einen (vorrangigen) Teil seiner Befugnisse umfasst hätten. Diese Deutung übersieht, dass praecipue im Zusammenhang des Relativsatzes keine einschließende Bedeutung haben kann, sondern - in Abgrenzung zur umfassenden Kompetenz der für das Formularverfahren zuständigen Gerichtsmagistrate - auf eine beschränkte ${ }^{39}$ ) Zuständigkeit des Beamten weisen muss ${ }^{40}$ ): Der praetor fideicommissarius ist also zur Zeit des Gaius ausschließlich für Fideikommisse zuständig; es handelt sich um eine gegenständlich beschränkte Spezialprätur.

Auch das ius dicere hinsichtlich der Fideikommisse weist Besonderheiten auf, die sich auch in der Terminologie niederschlagen.

zur Gerichtsverfassung der Römischen Kaiserzeit, Leipzig 1892, 20f. gegen Lenels Deutung greifen m. E. nicht. Zur Abgrenzung der beiden Kompetenzen vgl. auch A. Dell' Oro, I libri de officio nella giurisprudenza romana, Mailand 1960, 59-61 mwN; L ongchamps de Bérier (Fn. 3) 85-87; zum Vermögensumfang vgl. Quint. 3,6,70; dazu Buti (Fn. 2) 37 mit Fn. 35.

${ }^{37}$ ) Nachweise $\mathrm{zu}$ den Deutungen von praecipue bei Giodice-Sabbatelli (Fn. 3) 144-153, die ebenfalls zu dem Schluss kommt, dass hier eine Gegenüberstellung der generellen Kompetenz des praetor urbanus zur Spezialzuständigkeit des imperialen Beamten beabsichtigt ist.

${ }^{38}$ ) So aber Jörs (Fn. 36) 41: „Zu Gaius Zeit scheint der Prätor gar nicht ausschliesslich mit Fideicommisssachen beschäftigt gewesen zu sein, denn es heisst (2,278): apud eum praetorem qui praecipue de fideicommissis ius dicit.“

${ }^{39}$ ) Zur ausschließenden Bedeutung von praecipue vgl. ThLL s. v. praecipue II vi separandi, excludendi A in universum; vgl. Cic. Sull. 82 (...) neque ego praecipue de consularibus disputo (...); Gai. Inst. 4,160.

$\left.{ }^{40}\right)$ Diese Deutung wird bestätigt durch Ulp. epit. 25,12. Fideicommissa non per formulam petuntur, ut legata, sed cognitio est Romae quidem consulum aut praetoris, qui , fideicommissarius" vocatur; in provinciis vero praesidum provinciarum.

ZRG RA 136 (2019) 
2. Zur Entscheidungsbegründung: fideicommissum deberi:

So wird die Klage auf das Fideikommiss, die petitio fideicommissaria ${ }^{41}$ ), bei Gaius nicht behandelt und in den Digesten nur beiläufig erwähnt ${ }^{42}$ ). Vielmehr sprechen die justinianischen Quellen davon, dass das Fideikommiss ,geschuldet' werde (fideicommissum debere/deberi) ${ }^{43}$ ). Dieser Sprachgebrauch belegt, dass die Entscheidung über Wirksamkeit, Inhalt und Umfang des Fideikommisses vorrangig aus dem materiellen Gesichtspunkt erfolgt, in welcher Weise und welchem Umfang der Erblasser sein Vertrauen investiert hat ${ }^{44}$ ), wobei sanktioniert wird, wenn sich der Beschwerte dieses Vertrauens nicht würdig erweist ${ }^{45}$ ).

${ }^{41}$ ) Zum Begriff actio fideicommissi vgl. Nachweise bei Sa mter (Fn. 15) 90 Fn. 1.

${ }^{42}$ Z Zum Sprachgebrauch vgl. L. Schnorr von Carols feld, s. v. petitio, in: RE XIX,1, Stuttgart 1937, Sp. 1153-1162 (allerdings mit zu weitreichenden Interpolationsannahmen).

$\left.{ }^{43}\right) \mathrm{Zu}$ fideicommissum debere/deberi vgl. D.29,4,6,2 Ulp. 50 ad ed. (...) quae secundum ea quae supra scripta sunt non offendit edictum, dicendum est contribui fideicommissa debere quasi exaequata; D.31,75pr. Pap. 6 resp. (...) fideicommissum deberi sorori constitit nec aliud probandum in cuiuslibet suprema voluntate; D. 31,88,16 Scaev. 3 resp. (...) respondi posse defendi fideicommissum deberi; D. 32,3pr. Ulp. 1 fideicomm. (...) sed et si mortis causa auxerit marito dotem vel in matrimonium eius mortis causa redierit, potest dici fideicommissum ab eo deberi; D. 32,41,6 Scaev. 22 dig. (...) quaesitum est, an, si quam suburbanam adiacentem possessionem haberet, haec quoque ex causa fideicommissi Maeviis debeatur (...) item quaesitum est, (...) an id quoque kalendarium propter verba supra scripta Maeviis ex causa fideicommissi deberetur (...); D. 33,7,27,1 Scaev. 6 dig. (...) respondit mancipia, de quibus quaereretur, secundum ea quae proponerentur ex causa fideicommissi deberi; D. 35,1,113 Paul. 2 imp. sent. in cogn. prolat. (...) rescriptum est fideicommissum deberi; D. 40,5,24,11 Ulp. 5 fideicomm. Ex testamento, quod adgnatione postumae ruptum esse constitit, neque directas libertates competere neque fideicommissarias deberi (...); D. 40,5,47,2 Iul. 42 dig. (...) atque ita pronuntiet libertatem ex causa fideicommissi deberi (...).

$\left.{ }^{44}\right)$ Maßgeblich ist die voluntas des Erblassers; vgl. auch D. 30,127 Paul. 1. s. de iur. cod. A fratris postumo fideicommissum dari potest: sola enim voluntas servatur in fideicommissis, et optinuit Galli sententia alienos quoque postumos legitimos nobis heredes fieri; zutreffend insoweit S. Ric c ob on o, Cognitio extra ordinem e caratteri del ius novum, RIDA 2 (1949) 277-293, $284 f$.

${ }^{45}$ ) Insoweit trifft hier erneut die Beschreibung der fides als Erwartungshorizont zu; vgl. dazu D. Nörr, Aspekte des römischen Völkerrechts, Die Bronzetafeln von Alcántara, München 1989, 145-153 mwN. Die „Neigung, einen gegebenen Streitstoff in umfassender Weise zu behandeln", sieht auch Samter (Fn. 15) 125f. als wesentliches Merkmal der cognitio extra ordinem an. 


\section{a. Zur Feststellung der Verpflichtung aus Fideikommissen:}

Zwar gibt es objektive Gründe, welche die Wirksamkeit von Fideikommissen beeinträchtigen können, wie etwa das Fehlen der Testierfähigkeit ${ }^{46}$ ) oder bestimmte in der Kaiserzeit aus dem Legatsrecht übernommenen Gestaltungsverbote ${ }^{47}$ ). In der Mehrzahl der hier $\mathrm{zu}$ untersuchenden Belege steht aber die Auslegungsoperation des cognoszierenden Beamten im Vordergrund, welche zur Ermittlung des Erblasserwillens, und damit zur Bestimmung der diesem Willen entsprechenden Rechtsfolgen dient. Aus der unübersehbaren Kasuistik seien hier beispielhaft nur zwei besonders illustrative Beispiele genannt. Das erste Fragment betrifft die Feststellung eines Familienfideikommisses ${ }^{48}$ ):

D. 32,11,9 Ulp. 2 fideicomm. Haec verba: ,te, fili, rogo, ut praedia, quae ad te pervenerint, pro tua diligentia diligas et curam eorum agas, ut possint ad filios tuos pervenire', licet non satis exprimunt fideicommissum, sed magis consilium quam necessitatem relinquendi, tamen ea praedia in nepotibus post mortem patris eorum vim fideicommissi videntur continere.

Der Erblasser hat seinem Sohn durch Fideikommiss auferlegt, die hinterlassenen Grundstücke so zu verwalten, dass sie später einmal auch an dessen eigene Kinder, das heißt die Enkel des Erblassers, gelangen könnten. Nach Ulpian soll diese Bitte gerade keine Herausgabepflicht des Sohnes zugunsten der Enkel begründen, sondern stelle eher einen Ratschlag dar, wie der Sohn die Weitergabe in der Generationenfolge sicherstellen könne. Dennoch gelangt der Jurist sodann zur Annahme eines Fideikommisses, nach welchem die Enkel die Grundstücke von den Erben des Vaters heraus verlangen können. Auf den ersten Blick steht diese Entscheidung im Widerspruch zu einer Vorgabe, die Ulpian selbst innerhalb der gleichen Katene formuliert hat. So soll nach D. 32,11,2 Ulp. 2 fideicomm. die bloße Empfehlung ,illum tibi commendo ${ }^{6}$ nicht als Fideikommiss angesehen werden können ${ }^{49}$ ); auch in D. 32,11,9 Ulp. 2 fideicomm. ist entsprechend von einem Ratschlag (consilium) und gerade nicht von einer verbindlichen Anordnung die Rede ${ }^{50}$ ). Es liegt nahe, den Grund für die Abweichung im Entscheidungskontext der Stelle zu sehen, namentlich in der Tatsache, dass der Großvater dem Vater

${ }^{46)}$ Vgl. D. 30,2 Ulp. 1 fideicomm.; D. 32,1pr.-5 Ulp. 1 fideicomm.

${ }^{47}$ ) Vgl. Gai. Inst. 2,285-288.

${ }^{48}$ ) Zum Text vgl. D. Johnston, Prohibitions and perpetuities, Family settlements in Roman law, ZRG RA 102 (1985) 220-290, 284; seitdem Desanti (Fn. 3) 43f. mwN.

${ }^{49}$ ) Weitere Nachweise zur Frage bei Johnston, ZRG RA 102 (Fn. 48) 282.

${ }^{50}$ ) Möglich ist auch, eine - wie Johnston ibid. 282-284 konstatiert - seit Marc Aurel zunehmende Tendenz zu Liberalität bei der Auslegung. 
den Erhalt von Familiengut in der Familie ,empfiehlt‘. So ist daran zu erinnern, dass zugunsten von Familienangehörigen auch in anderen Fällen eine freiere Auslegung gewählt wird, indem etwa Veräußerungsverbote als Familienfideikommisse ausgelegt werden, wenn dies dem Zweck des Verbotes entspricht ${ }^{51}$ ). Auch in dem hier zu entscheidenden Fall verfolgt der Ratschlag des Großvaters den Zweck, die Grundstücke in der Familie zu halten und seinen Enkeln zukommen zu lassen. Dieser Zweck kann - wenn der Vater den Ratschlag des Großvaters missachtet und ohne entsprechende Vorsorge verstorben ist - nur dadurch erreicht werden, dass die Enkel tatsächlich die Möglichkeit erhalten, gegen die Erben ihres Vaters vorzugehen und die Grundstücke herauszuverlangen.

Aus dem Wesen des vom Erblasser ausgesetzten Fideikommisses bestimmt sich auch der Umfang der Herausgabepflicht beim fideicommissum de residuo ${ }^{52}$ ):

D. 36,1,56 Pap. 19 quaest. Titius rogatus est, quod ex hereditate superfuisset, Maevio restituere. Quod medio tempore alienatum vel deminutum est, ita quandoque peti non poterit, si non interveniendi fideicommissi gratia tale aliquid factum probetur: verbis enim fideicommissi bonam fidem inesse constat. Divus autem Marcus cum de fideicommissaria hereditate cognosceret, his verbis: ,quidquid ex hereditate mea superfuerit, rogo restituas' et viri boni arbitrium inesse credidit: iudicavit enim erogationes, quae ex hereditate factae dicebantur, non ad solam fideicommissi deminutionem pertinere, sed pro rata patrimonii, quod heres proprium habuit, distribui oportere (...)

Beim fideicommissum de residuo erlegt der Erblasser dem Beschwerten auf, das nach einer Zeit oder am Ende des eigenen Lebens aus der Erbschaft Verbliebene ,herauszugeben'. Da der Beschwerte nur quod ex hereditate superfuisset herauszugeben hat, stellt sich die Frage, wie mit Ausgaben und Zuwächsen zu verfahren ist, insbesondere welche Abflüsse der Fideikommissar hinzunehmen hat. Papinian greift zur Klärung dieser Frage auf den

${ }^{51}$ ) Vgl. vor allem D. 30,114,14 Marcian. 8 inst. Divi Severus et Antoninus rescripserunt eos, qui testamento vetant quid alienari nec causam exprimunt, propter quam id fieri velint, nisi invenitur persona, cuius respectu hoc a testatore dispositum est, nullius esse momenti scripturam, quasi nudum praeceptum reliquerint, quia talem legem testamento non possunt dicere: (...). Die durch Auslegung entwickelte Begünstigung von Familienangehörigen aus enttäuschtem Vertrauen findet sich auch in D. 31,67,10 Pap. 19 quaest.; dazu zuletzt U. Babusiaux, Mentions emphatiques et louanges à l'intention du souverain, À propos d'une stratégie des jurisconsultes du temps des Sévères, in: Mélanges Coriat, Paris 2019, 1-20, $18 \mathrm{f}$.

${ }^{52}$ ) Zum Text vgl. Murillo Villar (Fn. 3) 64f.; G. Coppola, Osservazione sul regime dei frutti nel fedecommesso de residuo, in: Studi Campagna I, Mailand 1982, 185-222, 215-217; Desanti (Fn. 3) 147-151. 
Erblasserwillen und die bona fides zurück, die er aus dem besonderen Vertrauen, das der Erblasser in den Erben gelegt hat, ableitet ${ }^{53}$ ). In der Tat ist anzunehmen, dass der Beschwerte dem Fideikommissar nur die Aufwendungen und Verluste entgegenhalten kann, die er gutgläubig und ohne Schädigungsabsicht vorgenommen hat, denn dies entspricht seiner besonderen Treubindung ${ }^{54}$ ). Zur Bestätigung seiner Ansicht verweist Papinian auf eine cognitio des Marc Aurel, der für ein fideicommissum de residuo die Ansicht vertreten habe, dass Vermögensabflüsse von der Erbschaft nicht nur das Fideikommiss, sondern auch das eigene Vermögen des Erben beträfen ${ }^{55}$ ). Wie Murillo Villar gezeigt hat, ist damit eine Verbindungslinie zur hereditatis petitio (fideicommissaria) geschlagen, mit welcher der Erbschaftsfideikommissar die Herausgabe der Erbschaft verlangen kann. Klagegegner ist in diesem Fall der Erbe, der die Erbschaft angetreten und von ihr profitiert hat, oder der Erbeserbe, der die dem Fideikommissar vorbehaltene Erbschaft im Rahmen der Rechtsnachfolge an sich genommen hat ${ }^{56}$ ). Maßgeblich für die Bestimmung des Klageinhalts ist der geäußerte Testatorwille, nach welchem der Erbe die überlassene Erbschaft auch verkleinern oder aufbrauchen darf; die den Beschwerten treffende fides-Bindung führt allerdings dazu, dass die

$\left.{ }^{53}\right)$ Zur Beschränkung der Entscheidungsmacht des Beschwerten im Sinne des arbitrium boni viri vgl. D. 30,75pr. Ulp. 5 disp.; D. 32,11,7 Ulp. 2 fideicomm. Quamquam autem fideicommissum ita relictum non debeatur, si volueris', tamen si ita adscriptum fuerit: ,si fueris arbitratus' , si putaveris' , si aestimaveris' , si utile tibi fuerit visum'vel ,videbitur', debebitur: non enim plenum arbitrium voluntatis heredi dedit, sed quasi viro bono commissum relictum; zum arbitrium boni viri vgl. G. Brogg ini, Iudex Arbiterve, Prolegomena zum Officium des römischen Privatrichters, Köln 1957, 116-120 mwN; Murillo Villar (Fn. 3) 66-69.

$\left.{ }^{54}\right)$ Gleichsinnig Desanti (Fn. 3) 149f. mwN in Fn. 127.

$\left.{ }^{55}\right)$ Vgl. vor allem D. 5,3,25,16 Ulp. 15 ad ed. Quod autem quis ex hereditate erogavit, utrum totum decedat an vero pro rata patrimonii eius? Ut puta penum hereditarium ebibit: utrum totum hereditarii expensum feratur an aliquid et patrimonio eius? Ut in id factus locupletior videatur, quod solebat ipse erogare ante delatam hereditatem: ut si quid lautius contemplatione hereditatis impendit, in hoc non videatur factus locupletior, in statutis vero suis sumptibus videatur factus locupletior: utique enim etsi non tam laute erogasset, aliquid tamen ad victum cottidianum erogasset. Nam et divus Marcus in causa Pythodori, qui rogatus erat quod sibi superfuisset ex hereditate reddere, decrevit ea, quae alienata erant non minuendi fideicommissi nec pretium in corpus patrimonii Pythodori redisse, et ex proprio Pythodori patrimonio et ex hereditate decedere, non tantum ex hereditate (...); dazu Murillo Villar (Fn. 3) 69-73.

$\left.{ }^{56}\right)$ Diese Situation ist von den Fragen des Erbschaftsfideikommisses, wie sie im Rahmen des SC Trebellianum und SC Pegasianum geregelt werden, zu unterscheiden. 
erlittenen Vermögensverluste nicht nur von der Erbschaft abzuziehen sind, sondern auch das Eigenvermögen des Erben betreffen ${ }^{57}$ ). Mithin ist - wie schon für das Familienfideikommiss - auch für das fideicommissum de residuo der Erblasserwille als maßgebliches Kriterium für den Ausgang der cognitio festzuhalten. Der vom Erblasser gesetzte Zweck determiniert die Rechtsfolgen nach den Bedürfnissen des jeweiligen Einzelfalls. Sowohl das fideicommissum familiae relictum als auch das fideicommissum de residuo sind damit lediglich Erscheinungen einer spezifischen Auslegungspraxis, die sich aus der für die cognitio typischen Konzentration auf die Feststellung des tatsächlichen Willens des Erblassers erklärt ${ }^{58}$ ).

Auch die Grenzen der Verpflichtung sind aus den Umständen des Einzelfalls zu bestimmen; als eine allgemeine Richtlinie gilt, dass nur derjenige, der selbst einen Vorteil aus der Erbschaft erhalten hat, das Fideikommiss schuldet, also den empfangenen Vorteil ganz oder teilweise an einen anderen restituieren soll ${ }^{59}$ ).

\section{b. Zur restitutio fideicommissaria:}

Auch Umfang und Ausmaß dieser Restitutionspflicht liegen im Ermessen des Beamten, der den erblasserischen Willen ermittelt. Bei unklarer Sachlage kann dieser auch einen arbiter einsetzen ${ }^{60}$ ):

D. 42,2,7 Afr. 5 quaest. Cum fideicommissum peteretur, heres confessus est de-

${ }^{57}$ ) Die Problematik ist Folge der Möglichkeit, ein Fideikommiss auch auf den Tod des Beschwerten auszusetzen; vgl. dazu Gai. Inst. 2,269.

${ }^{58}$ ) Zur quaestio facti in der cognitio vgl. nur D. 31,64 Pap. 15 quaest. Cum proponebatur in scriptura fideicommissi, quod pluribus sub condicione fuerat relictum, per errorem omissam mutuam substitutionem, quam testator in secundis tabulis, cum eosdem substitueret, expressit: divi Marcus et Commodus imperatores rescripserunt voluntatem manifestam videri mutuae factae substitutionis. etenim in causa fideicommissi utcumque precaria voluntas quaereretur, coniectura potuit admitti; vgl. auch D. 32,11,19 Ulp. 2 fideicomm. (....) cum in fideicommissis praecipue spectanda servandaque sit testatoris voluntas.

${ }^{59}$ ) Diese Restitutionspflicht der cognitio extra ordinem ist wenig untersucht. Sie knüpft terminologisch an das bereits im Formularprozess bekannte restituere an. Zum Begriff des restituere vgl. M. Kaser, Restituere als Prozeßgegenstand, Die Wirkungen der litis contestatio auf den Leistungsgegenstand im römischen Recht, München ${ }^{2} 1968$, 42f., der auf die Parallelen zwischen Fideikommissen und bonae fidei iudicia verweist.

${ }^{60}$ ) H.-D. Spengler, Studien zur interrogatio in iure, München 1994, 69; vgl. ferner A. D'Ors, Las Quaestiones de Africano, Mursia 1997, 224f.; weiterführend Giodice-Sabbatelli (Fn. 3) 265-270 sowie I. Kroppenberg, Die Insolvenz im klassischen römischen Recht, Tatbestände und Wirkungen außerhalb des Konkursverfahrens, Köln 2001, 194-197. 
bere: arbiter ad restituendum datus comperit nihil deberi: quaesitum est, an possit absolvere. Respondi posse interesse, qua ex causa nihil debeatur. Nam si ob id, quod nullum fideicommissum fuerit, non debere eum absolvere: si vero quia testator forte solvendo non erat aut quod heres omne solutum esse apud praetorem dixerat et, cum controversia et computatio difficilior esset, arbiter datus fuerit, salvo officio eum absoluturum: has enim partes eius esse, ut, si in computatione nihil inveniatur, possit absolvere. Sed et ex superiore casu ad praetorem remittere debet, ut absolvatur.

Ein Erbe hat zugestanden, das Fideikommiss zu schulden ${ }^{61}$ ); dem vom Beamten eingesetzten arbiter obliegt es, den Inhalt und Umfang der restitutio zu bestimmen. Die Anfrage bezieht sich darauf, ob der arbiter, wenn er feststelle, dass das Fideikommiss nicht geschuldet werde, den Erben freisprechen könne oder die Sache zurückverweisen müsse, damit der praetor fideicommissarius den Erben freispreche ${ }^{62}$ ). Africanus hält fest, dass das officium des arbiter nicht umfasse, die Unwirksamkeit des Fideikommisses festzustellen; soweit aber behauptet werde, die Erbschaft sei überschuldet oder der Erbe habe das Fideikommiss bereits erfüllt, könne der arbiter den Erben freisprechen, wenn diese Behauptungen zuträfen ${ }^{63}$ ).

Die Auskunft des Juristen belegt, dass der Verweis an den arbiter nur zur Bestimmung des genauen Restitutionsumfangs erfolgt ist, wozu auch der Freispruch des Erben bei Überschuldung der Erbschaft gehört ${ }^{64}$ ); hingegen bleibt es dem praetor fideicommissarius vorbehalten, die Wirksamkeitsvoraussetzungen des Fideikommisses, also die Einhaltung der rechtlichen Vorgaben, festzustellen. Die hier vorgenommene Aufgabenteilung zwischen praetor fideicommissarius und arbiter lässt die unterschiedlichen Aspekte der Entscheidungsfindung über die Verpflichtung des mit dem Fideikommiss Beschwerten deutlich hervortreten: Einerseits sind Existenz, Inhalt und Umfang der fideikommissarischen Anordnung festzustellen, anderer-

$\left.{ }^{61}\right)$ Der Text war lange Anlass für die Annahme, erst die cognitio extra ordinem kenne einen Grundsatz confessus pro iudicato habere (vgl. auch D. 42,2,6 Ulp. 5 de omn. trib.); dazu Samter (Fn. 15) 154-156. Für diese Annahme besteht indes kein Anlass; vgl. zuletzt Y. Thom as, Les opérations du droit, Paris 2011, 239-254. $\mathrm{Zu}$ den sonstigen Fragen der confessio in iure in diesem Fall vgl. Kroppenberg (Fn. 60) 195 Fn. 105.

${ }^{62}$ ) Hier steht praetor tatsächlich für praetor fideicommissarius, weil auch die übrigen Details des Falls auf eine cognitio weisen; vgl. Salkowski (Fn. 1) 610-612; weitere Nachweise bei K roppenberg (Fn. 60) 195 Fn. 104.

$\left.{ }^{63}\right) \mathrm{Zu}$ dieser „rechnerischen“ Absolutionsgewalt des arbiter vgl. K roppenberg (Fn. 60) 196 mit Fn. 106.

${ }^{64)}$ Zum Verhältnis von Insolvenz und Verpflichtung des Erben, das Fideikommiss herauszugeben; vgl. Kroppenberg (Fn. 60) 196 sowie unten III.2.a. 
seits müssen beim Beschwerten entsprechende Mittel vorhanden sein, um die Restitutionspflicht aus dem Fideikommiss durchsetzen zu können. Beide Aspekte werden tatsächlich wie rechtlich umfassend gewürdigt; Maßstab ist das Ermessen des Beamten, das die Juristen in seiner Breite an die bonae fidei iudicia erinnert $\left.{ }^{65}\right)$.

3. Die missiones in der cognitio extra ordinem:

Der Gestaltungsfreiheit der cognitio äußert sich auch in den prozessualen Sicherungsmechanismen, die zugunsten des Fideikommissars geschaffen wurden. Nach dem Vorbild des Legatsrechts bot sich die missio rei servandae causa an, die als Zwangsmaßnahme zur Durchsetzung der cautio legatorum servandorum causa konzipiert war. Durch sie konnte der Legatar den Erben zwingen, die Erfüllung eines bedingten oder befristeten Legat mittels satisdatio zu sichern ${ }^{66}$ ). Auch zugunsten des Fideikommissars ist die Sicherheitsleistung als cautio fideicommissorum servandorum causa in den Digesten und im Codex belegt (s. u. III.1). Gleichzeitig aber finden sich - und diese Gemengelage ist als wesentliche Schwierigkeit der verfahrensrechtlichen Analyse der missiones anzusehen - Fragmente, die für eine eigene, dem unmittelbaren Zwang der cognitio verpflichtete missio sprechen ${ }^{67}$ ). In diesen Belegen stellt die cautio offensichtlich keine Sicherungs-, sondern eine Vollstreckungsmaßnahme dar, die - und auch dies widerspricht dem Legatsrecht - gegenüber Dritten Wirksamkeit entfalten kann. Erschwert wird die Differenzierung der unterschiedlichen Missionsarten dadurch, dass Justinian sich

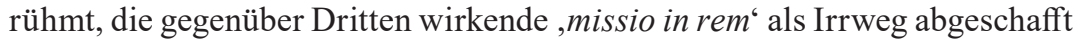
$\mathrm{zu}$ haben ${ }^{68}$ ), weshalb in diesem Bereich mit Interpolationen zu rechnen ist.

${ }^{65}$ ) S. Ric cobon o, L'arbitrium boni viri nei fedecommessi, in: Mélanges Cornil II, Paris 1926, 310-347; Kaser, Restituere (Fn. 59) 42f.

$\left.{ }^{66}\right)$ Satisdatio bedeutet Stipulation mit Bürgenbestellung; vgl. D. 2,8,1 Gai. 5 ad ed. prov.; zuletzt T. Finkenauer, Vererblichkeit und Drittwirkungen der Stipulation im klassischen römischen Recht, Tübingen 2010, 211f. Grundlegend zur missio in possessionem beim Legat vgl. F. Betancourt, La defensa pretoria del ,missus in possessionem', AHDE 52 (1982) 373-510, bes. 416-419 und 445-480; allgemein zur missio rei servandae causa P. Ramadier, Les effets de la missio in bona rei servandae causa, Paris 1911, 11f., 61-69 (custodia).

${ }^{67}$ ) Salkowski (Fn. 1) 619f. unterscheidet die missio in rem von der missio fideicommissorum servandorum causa, der missio Antoniniana und der translatio possessionis bei der appellatio, wie sie in D. 36,3,5,1 Pap. 28 quaest. zum Ausdruck kommt.

${ }^{68}$ ) C. $6,43,1$ pr.-1 Iust. (a. 529) pr. Cum ii, qui legatis vel fideicommissis honorati sunt, personalem plerumque actionem habere noscuntur, quis vel vindicationis vel sinendi modo aliorumque generum legatorum subtilitatem prono animo admittet, 
a. Exsequi oportere als Kriterium der exekutorischen missio:

Um angesichts dieser auch überlieferungsgeschichtlichen Schwierigkeiten ein Abgrenzungskriterium für unterschiedliche missiones entwickeln zu können, ist mit einem Fragment zu beginnen, das selbst eindeutig die unterschiedlichen Rechtsfolgen der missio in cognitio und Formularverfahren thematisiert:

D. 43,4,3pr. Ulp. 68 ad ed. Si quis missus fuerit in possessionem fideicommissi servandi causa et non admittatur, potestate eius inducendus est in possessionem, qui eum misit, aut si quis volet uti interdicto, consequens erit dicere interdictum locum habere. sed melius erit dicere extra ordinem ipsos iure suae potestatis exsequi oportere decretum suum, nonnumquam etiam per manum militarem.

Der Auszug aus dem 68. Buch von Ulpians Ediktskommentar ${ }^{69}$ ) betrifft das Interdikt ne vis fiat ei qui legatorum vel fideicommissorum servandorum causa in possessionem missus erit. Es schützt den Legatar und offenbar auch den Fideikommissar ${ }^{70}$ ), der vom Prätor in den Besitz eingewiesen wurde, nachdem der Erbe die Ableistung der cautio legatorum vel fideicommissorum servandorum causa verweigert hat. Dieser Interdiktenschutz entspricht der Logik des Formularverfahrens, denn der Prätor kann den Begünstigten nicht mit Gewalt in den Besitz einführen. Stattdessen verspricht er interdiktalen Schutz, der in diesem Fall sowohl prohibitorisch als auch restitutorisch ist, da er einerseits das Verbot beinhaltet, dem Eingewiesenen den erlangten (tatsächlichen) Besitz streitig zu machen, andererseits bei Missachtung der missio eine Verurteilung in quanti ea res erit eröffnet $^{71}$ ).

quam posteritas optimis rationibus usa nec facile suscepit nec inextricabiles circuitus laudavit? quis in rem missionis scrupulosis utatur ambagibus? 1 Rectius igitur esse censemus in rem quidem missionem penitus aboleri, omnibus vero tam legatariis quam fideicommissariis unam naturam imponere et non solum personalem actionem praestare, sed etiam in rem, quatenus eis liceat easdem res, vel per quodcumque genus legati vel per fideicommissum fuerint derelictae, vindicare in rem actione instituenda, et insuper utilem servianam (id est hypothecariam) super his quae fuerint derelicta in res mortui praestare; vgl. Röhle (Fn. 6) 410f.; G. Impallomeni, L'efficacia del fedecommesso pecuniario nei confronti dei terzi, BIDR 70 (1967) 1-104, 4-8; Johnston, Law of Trusts (Fn. 3) 250-252 mwN.

${ }^{69)}$ Lenel, Palingenesia II (Fn. 36) Sp. 1472.

$\left.{ }^{70}\right) \mathrm{Ob}$ dies eine spätere Erweiterung (interdictum utile) oder bereits ediktal ist, braucht an dieser Stelle nicht zu interessieren; für interdictum utile vgl. O. Lenel, Edictum Perpetuum, Leipzig ${ }^{3} 1927,455$; zur Diskussion vgl. Bet a nc ourt, AHDE 52 (Fn. 66) 375 Fn. 8, 422-429 mwN.

$\left.{ }^{71}\right)$ A. Berger, Miszellen aus der Interdiktenlehre, ZRG RA 36 (1915) 176-229, 198f., 212f. und L en e1, ${ }^{3} \mathrm{EP}$ (Fn. 70) 455 halten das Interdikt nur für prohibitorisch; vgl. aber D. 43,4,1pr. Ulp. 72 ad ed. Ait praetor: ,Si quis dolo malo fecerit, quo minus 
Im Rahmen der auf Fideikommisse anwendbaren cognitio extra ordinem ist hingegen nach Ulpian auch eine Naturalexekution manu militari möglich ${ }^{72}$ ), sofern der zuständige Beamte ein entsprechendes decretum erlassen hat $\left.^{73}\right)$. Da es keinen vernünftigen Grund gibt, diesen Verweis auf die Zwangsgewalt des in der cognitio tätigen Beamten als Interpolation anzusehen $^{74}$ ), scheint Ulpians Vergleich zwischen Interdikt und Naturalexekution gerade darauf abzuzielen, die Begrenztheit des prätorischen Rechtsschutzes gegenüber den weitergehenden Möglichkeit der cognitio extra ordinem darzulegen.

Für die hier untersuchte Abgrenzungsfrage ist damit gewonnen, dass eine

quis permissu meo eiusve, cuius ea iurisdictio fuit, in possessionem bonorum sit, in eum in factum iudicium, quanti ea res fuit, ob quam in possessionem missus erit, dabo; zur Frage nun umfassend B et a n court, AHDE 52 (Fn. 66) 486f.

${ }^{72}$ ) Die Interpolationsverdächtigungen gegen manu militari beruhen allesamt auf der parallelen Formulierung in D. 6,1,68 Ulp. 51 ad ed. Vgl. dazu etwa Lene1, Palingenesia II (Fn. 36) Sp. 739 und Sp. 2987 mit Fn. 2, der die Inskription auf 51 ad Sab. abändert und den Teil ab haec sententia bis locum habet für interpoliert hält; radikaler F. Schulz, Einführung in das Studium der Digesten, Berlin 1916, 79; aus der neueren Lit. vgl. aber S. Schipani, Responsabilità del convenuto per la cosa oggetto di azione reale, Turin 1971, 124f. Vor dem Hintergrund der hier angestellten Überlegungen wird man den palingenetischen Bezug auf die actio ex testamento nochmals zu prüfen haben. Auch andere Fragmente des Buches weisen auf die Möglichkeit des unmittelbaren Zwangs, was sich zu den severischen Anpassungen des Legatsrechts durchaus fügen würde.

$\left.{ }^{73}\right)$ Mit dieser Bedingung wird das Prinzip angesprochen, dass der kaiserliche Beamte selbst für die Vollstreckung zuständig ist; vgl. D. 42,1,15pr. Ulp. 3 off. cons. A divo Pio rescriptum est magistratibus populi Romani, ut iudicum a se datorum vel arbitrorum sententiam exsequantur hi qui eos dederunt; dazu zuletzt im hiesigen Zusammenhang Johnston, Law of Trusts (Fn. 3) 225f. mit Fn. 18. Das Fragment stammt aus dem Werk über die Amtspflichten der Konsuln und leitet eine längere Darstellung der Vollstreckung mittels Pfandrechts ein, bezieht sich also auf die $\mathrm{co}$ gnitio extra ordinem; gleichsinnig A. Pernice, Parerga, ZRG 5 (1884) 1-135, 31; abweichend Scherillo, Lezioni 1960, 211f., der annimmt, dass es sich um allgemeine prozessuale Angaben handele, die sowohl für die cognitio als auch für das Formularverfahren Geltung beanspruchten. Im hiesigen Kontext interessiert nur die Tatsache, dass die Vollstreckung durch den Konsul oder praetor fideicommissarius überwacht wird. $\mathrm{Zu}$ dem „Prinzip, daß der Urteilende auch die Vollstreckung bestimme“; vgl. Nachweise bei R. Knütel, Papinian D. 2,14,40, ZRG RA 111 (1994) 438-443, 440 Fn. 10.

${ }^{74}$ ) Manu militari gilt hier - wie in D. 6,1,68 Ulp. 51 ad ed. - als interpoliert. Die Annahme hat für dieses Fragment indes keine Berechtigung, weil ja schon Ulpian den Gegensatz von cognitio und Formularverfahren betont, also offenbar selbst auf die unterschiedlichen Zwangsbefugnisse hinwies. 
missio im Rahmen der cognitio extra ordinem den unmittelbaren Sachzugriff erlaubt, während eine missio rei servandae causa nur interdiktalen prätorischen Rechtsschutz eröffnet. Damit ergibt sich jedenfalls für den Rechtsschutz des missus ein klares Unterscheidungskriterium für die Zuordnung zum ordentlichen Verfahren oder zur cognitio extra ordinem: Erhält der Berechtigte unmittelbaren und auch mit Gewalt durchgesetzten Sachzugriff, ist von einer cognitio auszugehen; lediglich prohibitorische und restitutorische Schutzmaßnahmen sprechen hingegen eher für die formulare missio rei servandae causa, wobei allerdings zu beachten ist, dass die Terminologie der possessio - wie schon von den römischen Juristen gerügt - in diesem Kontext bisweilen mehrdeutig ist ${ }^{75}$ ), da sie sowohl die vorläufige Situation des rei servandae causa eingewiesenen Vermächtnisnehmers bezeichnen kann, als auch die definitive, vollstreckungsrechtliche Einweisung des Fideikom$\operatorname{missars}^{76}$ ).

Als Besonderheit der cognitio ist eine gegenüber Dritten wirkende missio in rem angesehen worden ${ }^{77}$ ).

\section{b. Die sog. missio in rem:}

So hat Impallomeni gegen frühere Interpolationsverdächtigungen betont, dass Fideikommissen auch im Recht der Prinzipatszeit Drittwirkung zukommen könne ${ }^{78}$ ). Allerdings räumt Impallomeni selbst ein, dass in den Digesten kein Beleg für eine prozessuale Begründung dieser missio in rem zu finden ist. Er erklärt dies aus der justinianischen Abschaffung dieser Art der mis-

${ }^{75}$ ) Zur possessio bei der missio vgl. D. 42,4,12 Pomp. 23 ad Q. Muc. Cum legatorum vel fideicommissi servandi causa, vel quia damni infecti nobis non caveatur, bona possidere praetor permittit, vel ventris nomine in possessionem nos mittit, non possidemus, sed magis custodiam rerum et observationem nobis concedit. Zur Frage vgl. umfassend Betancourt, AHDE 52 (Fn. 66) 445-480.

${ }^{76}$ ) Zur missio rei servandae causa vgl. D. 30,114,12 Marcian. 8 inst.; D. 36,4,5pr. Ulp. 52 ad ed.; C. 6,54,5 Alex. (a. 224).

${ }^{77}$ ) Die Bezeichnung missio in rem findet sich in C. 6,43 sowie in Paul. sent. 4,1,15; neben Impallomen i, BIDR 70 (Fn. 68) 1-104 vgl. bereits F. Kling müller, Ius ad rem? ZRG RA 44 (1924) 211-223; S al kow sk i (Fn. 1) 618-660; zur Wirkung der fideikommissarischen Freilassung erga omnes vgl. Impallomeni, Manomissioni (Fn. 19) 71-76.

${ }^{78}$ ) Impallomeni, BIDR 70 (Fn. 68) 94 mit der Annahme einer Übernahme aus dem prätorischen Edikt; wie hier F. De Robertis, Di una pretesa innovazione di Antonino Caracalla, La ,missio in possessionem in bona heredis' e la portata effettiva dell'intervento imperiale (Paul. sent. 3,9 e 4,1,17; D. 36,4,5,16 Ulp. 52 ad ed.), Bari 1938, jetzt auch in: ders., Scritti varii di diritto romano, IV: Miscellanea, Bari 2000, 32f., der aus der cognitio extra ordinem die vollkommene Freiheit des entscheidenden Beamten ableitet. 
$\left.s i O^{79}\right)$; zu bedenken ist aber auch, dass die Entscheidungen über Fideikommisse allgemein ,materiellrechtlich` begründet sind (vgl oben I.2). Zu dieser Annahme fügt sich, dass alle Belege, die Impallomeni für die sog. missio in rem präsentiert, Familienfideikommisse betreffen, also Veräußerungsverbote, die einen oder mehrere Gegenstände gleichsam aus der verfügbaren Erbmasse herausnehmen ${ }^{80}$ ). Die effektive Durchsetzung derartiger Verbote setzt Drittwirkung voraus, weshalb sich auch diese letztlich aus der Ermessensfreiheit des Beamten ableiten lässt, die ihrerseits auf der Auslegung der letztwilligen Verfügung beruht. Hiermit lässt sich der schwierige Hauptbeleg aus Impallomenis Material durchaus klären:

D. 30,109,1 Afr. 6 quaest. Heres, cuius fidei commissum erat, ut mihi fundum aut centum daret, fundum Titio vendidit: cum electio ei relinquitur utrum malit dandi, ut tamen alterum solidum praestet, praetoris officio convenire existimo, ut, si pecuniam Titius offerat, inhibeat fundi persecutionem. Ita enim eadem causa constitueretur, quae futura esset si alienatus fundus non fuisset, quando etiam adversus ipsum heredem officium praetoris sive arbitri tale esse deberet, ut, si fundus non praestaretur, neque pluris neque minoris quam centum aestimaretur.

Dem Erben ist zugunsten des Ego ein Wahlfideikommiss auf die Übereignung eines Grundstücks oder der Zahlung von hundert auferlegt worden ${ }^{81}$ ). Nachdem der Erbe das Grundstück an Titius veräußert hat, verlangt es der Fideikommissar von diesem heraus. Africanus entscheidet, Titius könne die persecutio fundi des Fideikommissars durch Zahlung von hundert abwenden, setzt also voraus, dass der Dritte überhaupt aufgrund des Fideikommisses belangt werden kann. Vom Erben selbst, dem ja als Schuldner der Wahlobligation die electio zusteht, könne der Fideikommissar nur das Geld verlangen, ganz so, als habe der Schuldner sein Wahlrecht durch die Veräußerung ausgeübt.

Von Interesse ist hier, dass Africanus die Rechtslage zwischen Titius und dem Fideikommissar ohne weiteres so deutet, als sei der Einzelrechtsnachfolger Titius mit Blick auf das Grundstück als Verpflichteter anzusehen (si alienatus fundus non fuisset). Die Drittwirkung selbst problematisiert der Jurist nicht; sie scheint sich bereits aus der Auslegung des Fideikommisses, nämlich aus der Verpflichtung des Erben, dem Fideikommissar die vom Erblasser verlangte Leistung (real) zuzuwenden, zu ergeben. Relevant wird diese Auslegung für das Ablösungsrecht des Dritten. Dieser wird von Africanus

\footnotetext{
${ }^{79}$ ) Impallomeni, BIDR 70 (Fn. 68) 85-88.

${ }^{80}$ ) Dies gilt namentlich für die bei Impallomeni ibid. 15-34 genannten Belege.

$\left.{ }^{81}\right)$ Zum Text vgl. Impallomeni ibid. bes. 13-15; zuletzt Giodice-S abbatelli (Fn. 3) 187-189.
} 
nämlich so behandelt, als habe er - genau wie der verpflichtete Erbe - die Wahl, das Grundstück oder die Summe zu leisten (cum electio ei relinquitur utrum malit dandi).

Man könnte geneigt sein, diese Entscheidung als Interpolation im Sinne der justinianischen Reform zur Abschaffung der missio in rem anzusehen, denn diese verbietet die Veräußerung der betroffenen Sache und erteilt dem Legatar wie dem Fideikommissar die rei vindicatio auch gegenüber Dritten ${ }^{82}$ ). Hiergegen lässt sich allerdings einwenden, dass das Fragment keineswegs von einer dinglichen Wirkung des Fideikommisses spricht, sondern lediglich von einer persecutio fundi, was auf die persecutio fideicommissi weist. Genau für diese aber erwähnt Justinian in Nov. 39 praef. selbst die gegen Dritte

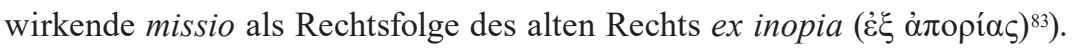
Man kann diesen Hinweis so verstehen, dass die missio gegenüber Dritten nur bei Uneinbringbarkeit der Sache beim Beschwerten für zulässig befunden wurde. Unter dieser Prämisse kann die Entscheidung Africans als eine Präzisierung der inopia im Falle des Wahlfideikommisses angesehen werden: Soweit der Dritte zur Zahlung in der Lage ist, kann er die Naturalexekution abwenden ${ }^{84}$ ). Die Rechtslage gegenüber diesem Dritten wird - genauso wie alle anderen Rechtsfolgen - aus dem Inhalt der fideikommissarischen Anordnung und damit aus dem Erblasserwillen durch Auslegung bestimmt.

Mit dieser Herleitung der missio in rem aus der vollstreckungsrechtlichen Besonderheit der cognitio lässt sich auch ein viel behandeltes Fragment aus einer längeren Erläuterung Papinians zum Familienfideikommiss erklären ${ }^{85}$ ):

D. 31,69,1 Pap. 19 quaest. Praedium, quod nomine familiae relinquitur, si non vo-

${ }^{82}$ ) Vgl. C. 6,43,3,2a und C. 6,43,3,3b Iust. (a. 531) Quod similiter censemus in huiusmodi legatis, quae sive pure sive sub die certo sive sub condicione sive sub incerta die relicta sint: sed in his omnibus casibus legatario quidem vel fideicommissario omnis licentia pateat rem vindicare et sibi adsignare, nullo obstaculo ei a detentatoribus opponendo; in diesem Sinne O. Lenel, Afrikans Quästiones, Versuch einer kritischen Palingenesie, ZRG RA 51 (1931) 1-53, 23. Wie hier J o h n st on, Law of Trusts (Fn. 3) 227, der betont, dass der Erfolg einer petitio fideicommissaria nicht als ,real effect" anzusehen ist, sondern: „It means merely that where the trustee was in possession of the property under trust, he could be ordered to make it over."

$\left.{ }^{83}\right)$ Nov. praef. 39 (a. 536) (ed. Schö11/Krol1) (...) Et introducebantur etiam fideicommissi persecutiones et ex inopia in rem missiones, et plurimi illi et varii et insolubiles paene praedictae in rem missionis circuli (...); dazu Impallomen $\mathrm{i}$, BIDR 70 (Fn. 68) 8f.

${ }^{84)}$ So auch Impallomeni ibid. 15. Zur Auslegung der Nov. 39 vgl. bereits G. Marezoll, Zu der Lehre von den Vermächtnissen, Zeitschr. f. Civilrecht und Prozessrecht 9 (1836) 247-310, 309.

$\left.{ }^{85}\right)$ Zum Fragment vgl. S. Solazzi, Il concorso die creditori nel diritto romano 
luntaria facta sit alienatio, sed bona heredis veneant, tamdiu emptor retinere debet, quamdiu debitor haberet bonis non venditis, post mortem eius non habiturus quod exter heres praestare cogeretur.

Papinian handelt von der Durchsetzung eines Familienfideikommisses im Rahmen einer venditio bonorum: Finde aufgrund der Überschuldung des Erben der Vermögensverkauf statt, könne der emptor bonorum die fideikommissarisch hinterlassene Sache genauso lange behalten, wie sie der Beschwerte ohne Verkauf innegehabt hätte. In jedem Fall müsse er sie herausgeben, wenn der Beschwerte versterbe, weil auch dieser die Sache nach seinem Tod an den Fideikommissar herauszugeben hätte. Der hypothetische Vergleich zwischen bonorum emptor und Beschwertem zeigt, dass sich die Rechtsfolgen des Einzelfideikommisses auch in der Insolvenz nach dem Willen des Erblassers bestimmen ${ }^{86}$ ): Der bonorum emptor wird insoweit als Rechtsnachfolger des Beschwerten angesehen, sodass ihn die Herausgabepflicht gegenüber dem Fideikommissar genauso trifft, als wäre er selbst mit dem Fideikommiss beschwert gewesen. An dieser Stelle spricht Papinian vom unmittelbaren Zwang, der gegen den Erben anzuwenden wäre (quod exter heres praestare cogeretur), was man als Hinweis auf die Naturalvollstreckung der cognitio ansehen kann. Der Umfang - und damit auch die Drittwirkung - der so vollstreckten Verpflichtung richten sich nach dem Erblasserwillen, sind also Gegenstand der Auslegung des zuständigen Organs im Rahmen der cognitio.

Mit dieser Annahme lässt sich schließlich auch die vieldiskutierte ,Grenze“ des Familienfideikommisses, wie sie namentlich in einem Reskript des Septimius Severus und des Caracalla ausgesprochen wird, erklären:

D. 30,114,14 Marcian. 8 inst. Divi Severus et Antoninus rescripserunt eos, qui testamento vetant quid alienari nec causam exprimunt, propter quam id fieri velint, nisi invenitur persona, cuius respectu hoc a testatore dispositum est, nullius esse momenti scripturam, quasi nudum praeceptum reliquerint, quia talem legem testamento non possunt dicere: (...).

Die von Marcian zitierte Konstitution greift ein bereits bei Scaevola angesprochenes Argument gegen die Drittwirkung von Fideikommissen im Einzelfall auf: Es dürfe sich nicht um ein nudum praeceptum, also ein blo-

III, Neapel 1940, 196f.; Desanti (Fn. 3) 288; weitere Nachweise bei U. Babusia ux, Papinians Quaestiones, München 2011, 239f.

${ }^{86}$ ) Etwas abweichend Solazzi, Concorso III (Fn. 85) 199: „Il giureconsulto classico attribuisce al fedecommissario solamente una preferenza concorsuale, se l'oggetto del fedecommesso esista ancora nel patrimonio venduto al bon. emptor $(\ldots)^{\prime}$, der das Fragment als Ausdruck der Rechtsnachfolge des bonorum emptor in die Position des Erben ansieht. 
ßes Veräußerungsverbot, handeln, das keinen spezifischen Begünstigten kennt $^{87}$ ). Definiert man das Fideikommiss als Bitte des Erblassers, einen aus der Erbschaft erhaltenen Gegenstand einer anderen Person herauszugeben, so stellt die Intention der Begünstigung eine zentrale Wirksamkeitsbedingung des Institutes dar. Fehlt es mithin an einer begünstigten Person oder ist nicht erkennbar, aus welchem Grund die Verfügung über die Sache verboten wurde, ist die für das Fideikommiss konstitutive Interessenlage nicht gegeben, sodass ein solches fehlt. Die Hauptschwierigkeit des Familienfideikommisses liegt mithin nicht darin, ob es Drittwirkung entfaltet, sondern ob der Erblasser nachweislich eine Begünstigung intendiert hat oder lediglich Vermögensbestandteile Gläubigern oder dem Fiskus ${ }^{88}$ ) vorenthalten wollte ${ }^{89}$ ). Steht fest, dass der Erblasser Familienangehörige bedenken wollte, kann dieser Zweck mit den Mitteln der cognitio durchgesetzt werden und damit auch Dritten entgegengesetzt werden. Gerade diese Rechtsfolge ist als Besonderheit und als Vorteil der cognitio extra ordinem gegenüber der mit dem Formularverfahren verbundenen condemnatio pecuniaria anzusehen ${ }^{90}$ ).

Die Beispiele zeigen, dass die cognitio extra ordinem in ihrer Suche nach einer bestmöglichen Realisierung des erblasserischen Willens nicht nur die Naturalexekution zulässt, sondern überhaupt die Rechtsfolgen nach dem vom Beamten ermittelten Zweck der letztwilligen Verfügung abhängig macht. Unter dieser Prämisse ist abschließend nach dem Zweck der sog. missio Antoniniana zu fragen.

${ }^{87}$ ) Vgl. D. 32,38pr. Scaev. 19 dig.; dazu auch Desanti (Fn. 3) 269-273. Zum Familienfideikommiss und seinen Entwicklungen vgl. zuletzt Johnst on, ZRG RA 102 (Fn. 48) bes. 272-281 zu den severischen Reformen in diesem Bereich (allerdings mit zu weitgehender Textkritik).

${ }^{88}$ ) $\mathrm{Zu}$ dieser Umgehungsfunktion von Fideikommissen vgl. zuletzt U. Babusia u x, Il Valore della Terra e il Fideicommissum Familiae Relictum, Una Configurazione Giuridica motivata da Fattori Economici? in: Atti dell'Accademia Romanistica Costantiniana, Perugia 2017, 405-435 mwN.

${ }^{89}$ ) Es sei hervorgehoben, dass auch das Verbot, die erbrechtliche Begünstigung nicht für sachfremde Zwecke zu nutzen, nicht erst in der cognitio entwickelt wurde, sondern etwa bereits im Verbot, Legate strafweise auszusetzen, einen Niederschlag findet. Zum legatum poenae relictum vgl. Gai. Inst. 2,243; dazu C. Paulu s, Auf der Suche nach Unsterblichkeit: Zur mentalitätsgeschichtlichen, sozialen und rechtlichen Bedeutung des Testaments in Rom, Berlin 2018, $125 \mathrm{f}$.

${ }^{90}$ ) Zur condemnatio pecuniaria vgl. die Diskussion und die Nachweise bei M. Pennitz, Der „Enteignungsfall“ im römischen Recht der Republik und des Prinzipats, Eine funktional-rechtsvergleichende Problemstellung, Wien 1991, 249-323. 


\section{c. Zur sog. missio Antoniniana:}

Die missio Antoniniana wird in Ulpians Ediktskommentar zur cautio legatorum servandorum causa im Rahmen eines Exkurses präsentiert:

D. 36,4,5,16 Ulp. 52 ad ed. ${ }^{91}$ ) Imperator Antoninus Augustus rescripsit certis ex causis etiam in propria bona heredis legatarios et fideicommissarios esse mittendos, si post sex menses, quam aditi pro tribunali fuerint hi quorum de ea re notio est, in satisfactione cessatum est, inde fructus percepturos, quoad voluntati defunctorum satisfiat. Quod remedium servaretur et adversus eos, qui ex qua causa fideicommisso moram faciunt.

Ulpian zitiert ein Reskript des Caracalla ${ }^{92}$ ), nach dem Legatare und Fideikommissare ex certis causis auch in die eigenen Güter des Erben eingewiesen werden können. Voraussetzung dieser missio sei, dass seit der Durchführung eines Gerichtsverfahrens (pro tribunali) über das Vermächtnis sechs Monate ohne Befriedigung (satisfactio) des Vermächtnisnehmers vergangen seien. Ziel der missio sei es, die Früchte aus dem Vermögen des Erben zu ziehen, bis das Vermächtnis als erfüllt anzusehen sei ${ }^{93}$ ). Abschließend hebt der Jurist hervor, diese missio gelte auch für den Fall der mora ex causa fideicommissi.

Welche Innovation die missio Antoniniana ausmacht, ist in der Literatur umstritten ${ }^{94}$ ): Einige sehen hierin eine Ausweitung der missio in rem, die nunmehr nicht nur die Erbschaft, sondern das Vermögen des Erben betref-

${ }^{91}$ ) Grundlegend De Robertis (Fn. 78) 13-42; Palazzolo (Fn. 13) 157-161; nur sehr knapp zuletzt J.D. Harke, Actio utilis, Anspruchsanalogie im römischen Recht, Berlin 2016, 95-97.

${ }^{92}$ ) Zur Urheberschaft Caracallas vgl. De Robertis (Fn. 78) 18-20.

93) Die Zuordnung zur cognitio extra ordinem ergibt sich aus dem ersten Teil der lemmatischen Kommentierung Ulpians. So präsentiert er zunächst eine Begriffsdeutung des Wortes satisfactio (§ 17), das er als Synonym für exsolutio, also ,Erfüllung', ansieht, eine Rechtsfolge, die nur im Rahmen der cognitio extra ordinem vorstellbar ist. In $\S 18$ geht es sodann um die Anwendbarkeit der missio Antoniniana trotz remissio satisdationis durch den Erben, was ebenfalls zeigt, dass diese Einweisung in den Besitz nicht der Sicherung, sondern der Vollstreckung dient. Vor allem aber belegt D. 36,4,5,19 Ulp. 52 ad ed., dass sich die Entscheidung wohl im Rahmen der cognitio extra ordinem vollzieht, denn die Berechnung nach continuum tempus, non sessionum entspricht dem bereits bei Gaius mitgeteilten Unterschied, dass Fideikommisse (im Rahmen der cognitio) jederzeit, Legate (im Rahmen des Formularverfahrens) aber nur an den Gerichtstagen eingeklagt werden können.

${ }^{94)}$ Rekonstruktionsversuche des Textes auf der Grundlage weitreichender Interpolationsannahmen bleiben hier außer Betracht, da sie alle willkürlich sind. Vgl. etwa die sich widersprechenden Annahmen von Pernice (Fn. 73) 135-192, 154 mit Fn. 4, der meint, dass der Hinweis auf die Legate eingeschoben worden sei, weil es doch in Wahrheit um Fideikommisse gehe, und von De Robertis (Fn. 78) 31f., der umgekehrt davon ausgeht, der Bezug auf Fideikommissare sei eingefügt worden. 
$\mathrm{fe}^{95}$ ); andere meinen hingegen, der Schwerpunkt der Anordnung liege darin, die außerordentliche Form der Vollstreckung auch auf Legate auszuweiten ${ }^{96}$ ). Angesichts dieser Widersprüche ist zunächst festzuhalten, dass die missio Antoniniana offensichtlich von dem Verfahren der cognitio extra ordinem ausgeht; hierfür spricht nicht nur die Terminologie (pro tribunali, notio, remedium), sondern auch die satisfactio als Ziel dieser Besitzeinweisung ${ }^{97}$ ). Vor allem aber ist zu berücksichtigen, dass Schwerpunkt der Regelung der Fruchtersatz (bei Legat und Fideikommiss) bzw. die Verzinsung (bei Fideikommissen) ist (vgl. auch III.4) ${ }^{98}$ ). Führt man sich weiter vor Augen, dass die cognitio beim Einzelfideikommiss regelmäßig zu einem direkten Zugriffsrecht auf die vermachte Sache führt (vgl. II.3.b), lässt sich die missio Antoniniana als Ergänzung dieser Einzelvollstreckung deuten: Hat der Fideikommissar nicht nur ein Recht auf die Sache selbst, sondern auch auf die bereits vom Erben gezogenenen Früchte, kann der Wille des Erblassers allein durch den Sachzugriff nicht realisiert werden ${ }^{99}$ ). Dem Wesen der cognitio entspricht es, hier nicht nur entsprechende Zahlungen vom Erben zu verlangen, sondern unmittelbaren Zwang anzudrohen, wenn der Erbe die Erfüllung verweigert oder verzögert. Genau hier setzt die Maßnahme Caracallas an: Das Vermögen des Erben wird dem Begünstigten solange zur Verfügung gestellt, bis dieser sich hinsichtlich der Früchte befriedigt hat.

Mit dieser Deutung ist auch die von Ulpian vorgenommene Erstreckung auf die mora des aus Fideikommiss Verpflichteten einleuchtend, die oftmals als unnötige Redundanz angesehen wird ${ }^{100}$ ), in Wahrheit aber die ulpianische Übertragung der Lösung des Reskriptes auf einen verwandten Fall darstellt:

${ }^{95}$ ) Röhle (Fn. 6) 424f.; gleichsinnig F. Arcaria, ,Missio in possessionem e ,cognito“ fedecommissaria, BIDR 89 (1986) 245-304, 257f. mwN in Fn. 59 und 60.

${ }^{96)}$ Vgl. De Robertis (Fn. 78) 25f.

$\left.{ }^{97}\right)$ Palazzolo (Fn. 13) 157f. Zur Umschreibung für Organe der cognitio mittels cuius de ea re notio est vgl. Nachweise und Diskussion bei Giodice-Sabbatelli (Fn. 3) 169-171.

$\left.{ }^{98}\right)$ Im zweiten Teil der lemmatischen Kommentierung ( $\left.\$ \S 24-25\right)$ definiert Ulpian den Maßstab der durch die missio Antoniniana angestrebten Befriedigung quoad voluntati defunctorum satisfiat (\$24) und betont, dass die missio auch auf diejenigen Anwendung finde, a quibus utiliter fideicommissum relictum est (\$25). Letzteres wird man so verstehen müssen, dass hier ein Fideikommiss gemeint ist, das nicht einem Erben (quamvis heredes non sint), sondern einem Legatar oder einem Fideikommissar selbst auferlegt worden ist (sekundäres Fideikommiss). Dieses wird auch in $\S 28$ aufgegriffen und in den Schutzbereich der missio Antoniniana einbezogen.

$\left.{ }^{99}\right)$ Vgl. M.F. Lepri, Note sulla natura giuridica delle missiones in possessionem, Florenz 1939, 124-128.

${ }^{100}$ ) Anders L. Mitteis, Zur Interpolationenforschung, ZRG RA 33 (1912) 
Wie gesehen behandelt das Reskript die Früchte und damit auch die Zinsen der Geldschuld, die vom Erblasser ausdrücklich oder stillschweigend angeordnet wurden, jedenfalls aber ihre Grundlage im Willen des Erblassers haben. Die von Ulpian vorgenommene Erweiterung betrifft hingegen eine allein für das Fideikommiss geltende Sonderregel, die auch in Gai. Inst. $2,280^{101}$ ) genannt wird. Danach sind für Fideikommisse schon ab dem Zeitpunkt der mora Zinsen zu zahlen, während für Legate der Zinslauf erst mit der litis contestatio beginnt ${ }^{102}$ ). Die hier beschriebene Differenz zwischen Legaten und Fideikommissen beruht nicht auf dem Willen des Erblassers, sondern ergibt sich aus der Rechtsnatur des Fideikommisses, ist also einer „gesetzlichen“ Zinspflicht vergleichbar. Da Caracallas Reskript sich - wie alle Maßnahmen der cognitio extra ordinem im Rahmen von Fideikommissen - auf den Erblasserwillen stützt, der auch der Maßstab für Inhalt und Umfang der satisfactio bildet, leuchtet es ein, dass diese Regelung für die „gesetzlichen“ Zinsen nur entsprechend herangezogen werden kann. Nichts anderes sagt im Übrigen die ebenfalls oftmals wegen ihre Unbestimmtheit gerügte Ausdrucksweise certis ex causis für den Anlass der Einweisung ${ }^{103}$ ): Sie verweist darauf, dass eine Fruchtziehungspflicht, welche die missio Antoninia auslöst, nur in besonderen Fällen anzunehmen ist ${ }^{104}$ ), wobei auch

180-211, 205, der den letzten Satz für interpoliert hält, da er nicht zum Anfang des Fragments passe.

101) Gai. Inst. 2,280 Item fideicommissorum usurae et fructus debentur, si modo moram solutionis fecerit, qui fideicommissum debebit; legatorum vero usurae non debentur, idque rescripto divi Hadriani significatur. scio tamen Iuliano placuisse in eo legato, quod sinendi modo relinquitur, idem iuris esse quod in fideicommissis; quam sententiam et his temporibus magis optinere video; vgl. auch Frg. Vat. 65 Papinianus VII responsorum. Equis per fideicommissum relictis ut fructus post moram fetus quoque praestabitur (...); zur Frage vgl. Kas er, Restituere (Fn. 59) 42f.; Coppola (Fn. 52) 195; allgemein zuletzt F. Zuccotti, Fruges Fructusque, Studio esegetico su D. 50,16,77, Per una ricerca sulle origine della nozione di ,frutto', Mailand 2000, 113 Fn. 176 mwN.

$\left.{ }_{102}\right)$ Vgl. C. 6,47,1pr. Sev./Ant. (a. 199) Legatorum seu fideicommissorum usuras ex eo tempore, quo lis contestata est, exigi posse manifestum est. sed et fructus rerum et mercedes servorum, qui ex testamento debentur, similiter praestari solent. $\mathrm{Zu}$ beachten ist, dass die litis contestatio nicht generell zum Verzug führt; vgl. Kaser, Restituere (Fn. 59) 1f.

$\left.{ }^{103}\right) \mathrm{Zu}$ certis ex causis vgl. auch D. 43,4,3,1 Ulp. 68 ad ed. Constitutum est ab Antonino, ut etiam in bona heredis quis admittatur certis modis (...). $\mathrm{Zu}$ diesem Fragment vgl. III.4.c.

${ }^{104}$ ) Allgemein zur Frage der Früchte beim fideicommissum de residuo vgl. Coppola (Fn. 52) 185-222.

ZRG RA 136 (2019) 
diesbezüglich von einer Auslegungsfrage, die nach dem Willen des Erblassers entschieden wird, auszugehen ist. Aus der Kasuistik sei neben der ausdrücklichen Anordnung der Fruchtherausgabe auf die bei Papinian überlieferte Auslegung des fideicommissum de residuo auf quidquid ex bonis supererit verwiesen ${ }^{105}$ ), namentlich beim heres fiduciarius, der die Sache nur für den eigentlich Berechtigten verwaltet $\left.{ }^{106}\right)$. Allgemeiner formuliert Pomponius, dass sich bei allen befristeten oder bedingten Fideikommissen ${ }^{107}$ ) die Frage stelle, ob der Zeitablauf zugunsten des Beschwerten oder des Begünstigten intendiert sei. Dies ist - wie jegliche Frage der Wirksamkeit des Fideikommisses - unter Berücksichtigung des Gesamtzusammenhangs der Begünstigung zu ermitteln.

Nach alldem ist die Besonderheit der missio Antoniniana somit darin zu sehen, dass sie die Einzelvollstreckung der cognitio extra ordinem mit Blick auf die Früchte ergänzt. Auch diese missio ist exekutorisch, dient also nicht der Sicherung, sondern der Vollstreckung der Verpflichtung (satisdatio) ${ }^{108}$ ).

\section{Fazit:}

Für den Rechtsschutz des Fideikommissars im Rahmen der cognitio extra ordinem ist festzuhalten, dass sich dessen Besonderheiten namentlich im Bereich der Vollstreckung manifestieren, da die Durchsetzung des Erblasserwillens auch die Einzelvollstreckung sowie ein Folgerecht gegenüber Dritten rechtfertigt $\left.{ }^{109}\right)$. Die Schaffung einer Sonderzuständigkeit der Konsuln und

$\left.{ }^{105}\right)$ D. 22,1,3,2 Pap. 20 quaest. Nonnumquam evenit, ut, quamquam fructus hereditatis aut pecuniae usura nominatim relicta non sit, nihilo minus debeatur. ut puta si quis rogetur post mortem suam quidquid ex bonis supererit Titio restituere (...) ita quod ex fructibus supererit iure voluntatis restitui oportebit; dazu M. B a r to še k, Il senato consulto Trebelliano, in: Scritti Ferrini III, Mailand 1948, 308-336, 313 Fn. 1 (der das Fragment aber für interpoliert hält); weiterführend De s a nti (Fn. 3) 162-173 (auch zum Verhältnis zu D. 36,1,60 Pap. 9 resp.); weitere Nachweise bei B abu siau x, Papinians Quaestiones (Fn. 85) 238.

$\left.{ }^{106}\right)$ D. 22,1,3,3 Pap. 20 quaest. (...) praefectis praetorii suasi fructus, qui bona fide a Pollidio ex bonis defunctae percepti essent, restitui debere, sive quod fundum ei tantum praelegaverat sive quod lubrico tutelae fideicommissi remedium mater praetulerat. Zum heres fiduciarius vgl. nun U. Babusiaux, D. 36,1,48 Iavolenus 11 epistularum, Römischrechtliche Bemerkungen zum textlichen Ausgangspunkt der französischen fiducie à cause de mort, in: M. Storck (Hg.), Mélanges Claude Witz, Paris 2018, 41-59.

${ }^{107)}$ D. 31,43,2 Pomp. 3 ad Q. Muc.; dazu auch Desanti (Fn. 3) 130-132.

${ }^{108}$ ) Vgl. auch De Robertis (Fn. 78) 37-39, der namentlich auf die Formulierung quoad voluntati defunctorum satisfiat verweist.

$\left.{ }^{109}\right)$ Gleichsinnig A. Polaček, Denegare actionem im späteren römischen und im justinianischen Zivilprozeß, ZRG RA 63 (1943) 406-414, 407 Fn. 10. 
sodann des praetor fideicommissarius dient aus dieser Perspektive dazu, die mit der Feststellung des Erblasserwillens verbundenen Auslegungsoperationen zu vereinheitlichen.

Es ist aber als offene Frage anzusehen, ob sich der Rechtsschutz für Fideikommisse mit dieser sowohl vom Prüfungsgegenstand als auch von der Rechtsfolge her beschränkten cognitio extra ordinem tatsächlich erschöpft. Eine unmittelbare Konkurrenz und auch ein Spannungsverhältnis zum Formularverfahren ergeben sich in jedem Fall beim Erbschaftsfideikommiss, denn hier tritt der Fideikommissar in die Rechtsnachfolge des Erblassers nach dem Erben ein ${ }^{110}$ ). Im Folgenden ist daher die Frage des einschlägigen Verfahrens für den Rechtsschutz eines Universalfideikommissars zu untersuchen.

\section{Das Verfahren bei Universalfideikommissen}

Das Universalfideikommiss zeichnet sich durch ein Konkurrenzverhältnis zwischen Erbschaftsfideikommissar und Erbe aus, das ursprünglich kautelarjuristisch durch Annahme eines Erbschaftskaufs ${ }^{111}$ ) gelöst wurde, der sodann durch Übertragung der Erbschaft mittels in iure cessio ${ }^{112}$ ) erfüllt wurde. Da auf diese Weise nur die körperlichen Gegenstände der Erbschaft übertragen werden konnten, bedurfte es zusätzlich des Abschlusses wechselseitiger Stipulationen (stipulationes emptae et venditae hereditatis) ${ }^{113}$ ), um auch mit Blick auf die Forderungen für und gegen die Erbschaft eine Art Rechtsnach-

$\left.{ }^{110}\right)$ Entsprechend gibt es hier eine interrogatio in iure, ob die Erbschaft restituiert worden sei; vgl. D. 11,1,9,7 Ulp. 22 ad ed. Denique Iulianus scribit eum quoque, cui est hereditas restituta, debere in iure interrogatum respondere, an ei hereditas sit restituta; dazu Spengler (Fn. 60) 48f., der diese interrogatio auf die Folgen des SC Trebellianum zurückführt. Es gibt freilich keinen Grund, dies nicht auch auf den erzwungenen Antritt des SC Pegasianum auszudehnen. Zum kautelarjuristischen Charakter vgl. Bar to šek (Fn. 105) 310-312, der daher vom vertraglichen Charakter der Restitution spricht; zum Erbschaftsfideikommiss in den Quellen vgl. die Übersicht bei Longchamps de Bérier (Fn. 3) 59-79.

$\left.{ }^{111}\right)$ Gai. Inst. 2,252 (...) nummo uno eam hereditatem dicis causa venire (...); zur Funktion des Erbschaftskaufs vgl. Th. Mayer-Maly, Rez. Amando Torrent, Venditio hereditatis, La venta de herencia en derecho romano, ZRG RA 85 (1968) 535-539, bes. 537; im hiesigen Kontext vgl. Longchamps de Bérier (Fn. 3) 94f.

112) Vgl. H.W. Nels on/U. Manthe, Gai Institutiones III 1-87, Intestaterbfolge und sonstige Arten von Gesamtnachfolge, Berlin 1992, 207-212 mwN; anders M. Kaser, Römisches Privatrecht II, ${ }^{2} 1975,762$ Fn. 5; so auch noch M. Kaser/R. Knütel/S. Lohsse, Römisches Privatrecht, ${ }^{21} 2017, \S 78$ Rn. 3. Ich danke Ulrich Manthe für den Hinweis auf die verbreitete Fehldeutung.

113) Zu ihrer Herkunft vgl. Bartošek (Fn. 105) $309 f$. 
folge von der Person des Erben auf den Erbschaftsfideikommissar zu erreichen $\left.^{114}\right)$. Im Rahmen dieser Stipulationen versprach der Erbschaftsverkäufer, dem Käufer alle Rechte und Vorteile aus der Erbschaft zu garantieren; umgekehrt erklärte der Erbschaftskäufer, den Verkäufer von aller Haftung und allen Nachteilen aus der Erbschaft freizuhalten ${ }^{15}$ ).

Das skizzierte Vorgehen ist durchaus praktikabel, denn die Restitution der Erbschaft aufgrund eines Erbschaftsfideikommisses lässt sich ohne weiteres als in iure cessio der Erbschaft konzipieren; die Schwierigkeit dieser Lösung lag aber darin, dass die Parteien Einvernehmen erzielen mussten. Zudem konnte der Erbschaftsfideikommissar seine Rechte nur geltend machen, wenn der Erbe die Erbschaft überhaupt antrat. Weigerte sich der Erbe, die Erbschaft zu übernehmen, kam es zum Eintritt der Intestaterbfolge. Zwar konnte spätestens seit der Mitte des 2. Jh. n. Chr. auch einem Intestaterben ein Fideikommiss auferlegt werden ${ }^{116}$ ); auch diesem stand aber die Möglichkeit offen, die Erbschaft auszuschlagen, sodass es schließlich gegen den Fiskus durchgesetzt werden musste, falls sich dieser der Erbschaft annahm ${ }^{17}$ ).

Aus verfahrensrechtlicher Sicht stellt sich der Konflikt zwischen Erbe und Erbschaftsfideikommissar als Abgrenzungsproblem zwischen cognitio und Formularverfahren dar, da der nach ius civile berufene Erbe seine Position im Formularverfahren durchsetzen muss ${ }^{118}$ ), während der Erbschaftsfidei-

${ }^{114}$ ) Vgl. bereits F. Kniep, Der Rechtsgelehrte Gaius und die Ediktskommentare, Jena 1910, 266, der allerdings noch von der mancipatio ausgeht. Zu den Implikationen des Erbschaftsantritts und der Möglichkeit für Intestaterben, die Erbschaft vor dem Antritt zu verkaufen; vgl. Gai. Inst. 3,85 mit Manthe/Nels on (Fn. 112) $207 f$.

$\left.{ }^{115}\right)$ Einzelheiten zum Erbschaftskauf und zum Inhalt der Stipulationen bei U. Manthe, Das senatus consultum Pegasianum, Berlin 1989, 26-31, sowie F. Erxleben, Translatio iudicii, Der Parteiwechsel im römischen Formularprozess, München 2017, 147f.

${ }^{116)}$ Vgl. nur Gai. Inst. 2,270; D. 30,114,2 Marcian. 8 inst.; zur Praxis der Intestatfideikommisse vgl. den Überblick über die reichhaltige Kasuistik bei John st on, Law of Trusts (Fn. 3) 117-145.

$\left.{ }^{117}\right)$ Der Fiskus stand insofern einem Privaten gleich, als er eine vindicatio bonorum zu erheben hatte; vgl. G. Prover a, La vindicatio bonorum, Contributo allo studio del processo fiscale romano, Turin 1964. Die fiskale Komponente des Erbrechts bedarf neuer Untersuchung, bleibt hier aber außer Betracht. Es zeigt sich jedenfalls, dass auch der die Erbschaft übernehmende Fiskus die ausgesetzten Fideikommisse zu erfüllen hatte; vgl. nur D. 30,96,1 Iul. 39 dig.; D. 49,14,3,4 Call. 3 de iur. fisc.; D. 49,14,48,1 Paul. 2 decr. Hierin könnte ein wesentliches Motiv für die Praxis des Familienfideikommisses zu erblicken sein; vgl. Babusiaux, ARC 2017 (Fn. 88) 405-435.

${ }^{118}$ ) Indem er zum Beispiel die hereditatis petitio gegen den Erbschaftsbesitzer 
kommissar die auf Fideikommiss gestützte Herausgabe der Erbschaft nur im Rahmen der cognitio extra ordinem erreichen kann. Die frühkaiserzeitlichen Senatsbeschlüsse zur Frage, das heißt sowohl das SC Trebellianum als auch das SC Pegasianum, lassen sich als Antworten auf diese Zuständigkeitsfrage lesen.

1. Der Aktionentransfer nach dem SC Trebellianum:

Das SC Trebellianum von 55 n. Chr. ${ }^{119}$ ) versucht das Verhältnis von Erbe und Erbschaftsfideikommissar dadurch zu klären, dass es die wechselseitigen Stipulationen durch einen unmittelbaren Aktionentransfer ersetzt: Sobald der Erbe die Erbschaft herausgegeben hat, soll der Erbschaftsfideikommissar aktiv- und passivlegitimiert hinsichtlich der erbschaftlichen Klagen $\left.\operatorname{sein}^{120}\right)$. Diese Anordnung ist auch verfahrensrechtlich von Relevanz: Indem das SC Trebellianum den Erbschaftsfideikommissar, dem die Erbschaft herausgegeben worden ist, loco heredis stellt ${ }^{121}$ ), verweist es auf das Formularverfahren $^{122}$ ):

Gai. Inst. 2,253 ... per quod senatus consultum desierunt illae cautiones in usu haberi; praetor enim utiles actiones ei et in eum, qui recepit hereditatem, quasi heredi et in heredem dare coepit, eaeque in edicto proponuntur.

Nach dem Wortlaut von Gai. Inst. 2,253 steht die Erteilung der actiones utiles dem ordentlichen praetor $\mathrm{zu}^{123}$ ), weshalb schon Lenel - jedenfalls für das hadrianische Edikt - eine eigene Rechtsschutzverheißung für die hereditatis petitio fideicommissaria ${ }^{124}$ ) rekonstruierte. Ebenso wird man anneh-

erhebt, um die Erbschaft zu erlangen. In jedem Fall ist ihm der Antrag auf Einweisung in den Nachlassbesitz (bonorum possessio secundum tabulas) beim Prätor zu empfehlen, der ihm dann das Rechtsmittel des Interdikts quorum bonorum zur Verfügung stellt, mit dem er bei jedem Besitzer Sachen aus der Erbschaft herausverlangen kann.

119) Vgl. Manthe (Fn. 115) 35 Fn. 1; zum Inhalt des SC Trebellianum vgl. D. 36,1,1,1-2 Ulp. 3 fideicomm.; dazu Long champs de Bérier (Fn. 3) 98-102.

$\left.{ }^{120}\right)$ Das SC Trebellianum ist vermutlich ursprünglich auf die hängigen Prozesse beschränkt. In der severischen Rechtsliteratur findet es sich allerdings in verallgemeinerter Form wieder; vgl. Einzelheiten bei Manthe (Fn. 115) 36f.; ihm folgend Erxleben (Fn. 115) 148f.

${ }^{121}$ ) Impallomeni, BIDR 70 (Fn. 68) 88 konstatiert denn auch zutreffend: „il fedecommissario era equiparato all'erede“.

122) Zur Rekonstruktion der Formel in einem solchen Fall vgl. nun umfassend und grundlegend Erxleben (Fn. 115) 152-172 mwN.

${ }^{123}$ ) Abweichend aber Jörs (Fn. 36) 42f., der eine Zuständigkeit des praetor fideicommissarius behauptet.

${ }^{124)}$ Vgl. Lenel, ${ }^{3} \mathrm{EP}$ (Fn. 70) 183; vgl. ferner Bartošek (Fn. 105) 316f. 
men müssen, dass dieser Ediktsabschnitt auch vorsah, dass den Erbschaftsfideikommissar alle für und gegen die Erbschaft zustehenden Klagen treffen konnten. Im Ergebnis steht der Erbschaftsfideikommissar, dem die Erbschaft herausgegeben wurde, somit nicht anders da als ein bonorum possessor, der ebenfalls durch prätorische Anordnung eine erbenähnliche Stellung erhält ${ }^{125}$ ). Die Regelung des SC Trebellianum bedeutet mithin nichts anderes, als dass die Erbschaftsgläubiger auch gegen den Erbschaftsfideikommissar im ordentlichen Verfahren zu prozessieren haben. Damit erreicht der Aktionentransfer des SC Trebellianum eine Verfahrensvereinfachung und stellt gleichzeitig klar, dass in der cognitio nur über Existenz, Inhalt und Wirksamkeit des Fideikommisses entschieden wird (vgl. II.2), während die übrigen erbschaftlichen Klagen im ordo iudiciorum abgewickelt werden ${ }^{126}$ ). Ein weiteres Indiz für diese Deutung findet sich in der Beschreibung der Rechtsfolgen bei teilweiser Restitution nach dem SC Pegasianum, das insoweit das SC Trebellianum in Kraft belässt:

Gai. Inst. 2,255 Ergo si quidem non plus quam dodrantem hereditatis scriptus heres rogatus sit restituere, tum ex Trebelliano senatus consulto restituitur hereditas, et in utrumque actiones hereditariae pro rata parte dantur, in heredem quidem iure civili, in eum uero, qui recipit hereditatem, ex senatus consulto Trebelliano (...)

Die hier relevante Modifikation des SC Trebellianum durch das SC Pegasianum betrifft das Quartrecht: Soweit die Erbschaft ganz oder jedenfalls zu $3 / 4$ freiwillig herausgegeben wird, bleibt es beim Aktionentransfer, der bei Zuerkennung der Quart zu einer Aufteilung der Erbenstellung nach prätorischem Recht führt. Gaius beschreibt diese Situation mit den Worten, dass der Erbe die Erbschaft nach ius civile erhalte, der Erbschaftsfideikommissar hingegen die Erbenstellung ex senatus consulto Trebelliano ${ }^{127}$ ). Diese Ausdrucksweise belegt, dass der Senatsbeschluss als Grundlage der Zuweisung der Klagen an den Erbschaftsfideikommissar angesehen wird; gleichzeitig wird deutlich, dass die senatorische Anordnung prätorischer Umsetzung bedurfte ${ }^{128}$ ), womit in der Verfassungsordnung des 1. Jh. n. Chr. nur der praetor urbanus oder peregrinus gemeint sein kann.

$\left.{ }^{125}\right)$ So schon H. Krüger, Verweisungsedikte im prätorischen Album, ZRG RA 37 (1916) 230-316, 297f. zu Gai. Inst. 2,253. Als ius honorarium bezeichnet dies Longchamps de Bérier (Fn. 3) 101f. Zur Ähnlichkeit der Stellung von missus in possessionem (= Erbschaftsfideikommissar) und bonorum possessor vgl. bereits Ramadier (Fn. 66) 38f.

126) So bereits Bartošek (Fn. 105) 104f.; Longchamps de Bérier (Fn. 3) 113.

${ }^{127}$ ) Vgl. D. 36,1,41pr. Paul. 20 ad ed.; dazu Longchamps (Fn. 3) 103-105.

${ }^{128}$ ) Zur Umsetzung von Senatsbeschlüssen durch den Prätor vgl. Kun kel/ Wit tmann (Fn. 9) 244f. 
Während über die skizzierte Zuweisung des SC Trebellianum zum Formularverfahren Konsens herrscht, gehen die meisten Autoren für das knapp zwanzig Jahre später ergangene SC Pegasianum ${ }^{129}$ ) von einer Anordnung zur Ausgestaltung der cognitio extra ordinem aus.

2. Der Antrittszwang nach dem senatus consultum Pegasianum:

Die Hauptinnovationen des SC Pegasianum liegen einerseits im Quartrecht des Erben ${ }^{130}$ ), das über die lex Falcidia hinaus auch auf Erbschaftsfideikommisse erstreckt wird, andererseits in der Schaffung eines Antrittszwangs $^{131}$ ), mit dem der Erbe im Interesse des Fideikommissars zur aditio hereditatis und zur Restitution gezwungen werden kann. Dieser Antrittszwang steht im SC Pegasianum als dritte Alternative neben einer freiwilligen, dem Erblasserwillen vollständig entsprechenden Herausgabe durch den Erben (erste Alternative) und dem Zwischenfall, dass sich der freiwillig antretende Erbe entgegen dem erblasserischen Willen auf sein Quartrecht beruft, das ausgesetzte Fideikommiss also schmälert (zweite Alternative). Während der erste Fall durch Fortgeltung des Aktionentransfers des SC Trebellianum gelöst wird, womit auch hier vom Formularverfahren auszugehen ist, wird namentlich der Antrittszwang (dritte Alternative) als typisches Instrument der cognitio extra ordinem des praetor fideicommissarius angesehen ${ }^{132}$ ). Gegen diese Annahme spricht bereits, dass in der für beide Senatsbeschlüsse wichtigsten Quelle, den Institutionen des Gaius, der praetor fideicommissarius erst in Gai. Inst. 2,278 eingeführt wird, mithin in den vom SC Pegasianum handelnden Kapiteln Gai. Inst. 2,258-259 noch gar nicht bekannt ist. Daher liegt es näher, auch für den Antrittszwang des SC Pegasianum von der Zuständigkeit des ordentlichen Gerichtsmagistraten auszugehen $^{133}$ ):

Gai. Inst. 2,258 Sed si recuset scriptus heres adire hereditatem ob id, quod dicat eam sibi suspectam esse quasi damnosam, cauetur Pegasiano senatus consulto, ut desiderante eo, cui restituere rogatus est, iussu praetoris adeat et restituat, proin-

${ }^{129}$ ) Zur Datierung siehe Manthe (Fn. 115) 41f.; Longchamps de Bérier (Fn. 3) 116f.

${ }^{130}$ ) Zu diesem Aspekt des SC Pegasianum vgl. Manthe (Fn. 115) 76-84, $213 f$.

$\left.{ }^{131}\right)$ Auch der Aktionentransfer als Rechtsfolge des Zwangs kann außer Betracht bleiben; vgl. Gai. Inst. 2,258.

${ }^{132}$ ) So schon Jörs (Fn. 36) 42 und Lenel, ${ }^{3} \mathrm{EP}$ (Fn. 70) 353; nunmehr auch Manthe (Fn. 115) 91; Longchamps de Bérier (Fn. 3) 119f.

${ }^{133}$ ) So auch Bartošek (Fn. 105) 103-110; Giodice-Sabbatelli (Fn. 29) 186-190. 
deque ei et in eum, qui receperit, actiones dentur, ac iuris esset ex senatus consulto Trebelliano (...)

Nach Gaius ist der Vorgang des Antrittszwangs wie folgt zu rekonstruieren: Auf Antrag des Erbschaftsfideikommissars befiehlt der praetor dem Erben mittels Dekret ${ }^{134}$ ), die Erbschaft anzutreten und an den Antragsteller herauszugeben; der Erbe wird allerdings dadurch geschützt, dass auch auf den zwangsweisen Antritt der Aktionentransfer des SC Trebellianum sinngemäß Anwendung findet (qui receperit, actiones dentur, ac iuris esset ex senatu consulto Trebelliano). Dabei weist die Formulierung als Fiktion darauf, dass diese Rechtsfolge nicht dem Senatsbeschluss selbst entnommen werden kann, sondern auf einer prätorischen Rechtsfortbildung beruht.

Die Zuweisung dieses Verfahrens an den ordentlichen Gerichtsmagistraten ist aber nicht nur terminologisch naheliegend, sondern lässt sich auch sachlich herleiten. Während die Befürworter einer Sonderkompetenz des praetor fideicommissarius darauf verweisen, dass hier das Fideikommiss durchgesetzt werde, weshalb es sich um ein Verfahren der cognitio extra ordinem handeln müsse, lassen sich die offensichtlichen Parallelen des Antrittszwangs zur venditio bonorum zugunsten einer Zuständigkeit des ordentlichen praetor anführen.

a. Die Anlehnung an die venditio bonorum:

Einen ersten Anknüpfungspunkt für einen prätorisch begründeten Antrittszwang bildet die Regelung des Edikts de iure deliberandi ${ }^{135}$ ):

Gai. Inst. 2,167 (...) Solet praetor postulantibus hereditariis creditoribus tempus constituere, intra quod, si velit, adeat hereditatem, si minus, ut liceat creditoribus bona defuncti vendere.

Nach dieser Bestimmung ${ }^{136}$ ) können die Gläubiger, wenn der Erbe ${ }^{137}$ ) auch

${ }^{134}$ ) Longchamps de Bérier (Fn. 3) 117 mit Fn. 254, der allerdings 119f. von der Zuständigkeit des praetor fideicommissarius ausgeht.

$\left.{ }^{135}\right)$ D. 36,1,11,2 Ulp. 4 fideicomm. (...) Cum autem possit, inquit, evenire, ut ante decedat ea, cui fideicommissaria libertas et hereditas relicta est, nec oporteat damno adfici eum, qui rogatus adit hereditatem, remedium dedit, ut, si quid horum contigerit, perinde permittatur venumdari bona Antistiae, ac si heres ei non exstitisset (...); dazu P. Voci, Diritto ereditario romano, II: Successione ab intestato, Successione testamentaria, Mailand ${ }^{2} 1963$, 354-362; K.P. Müller-Eis elt, Divus Pius constituit, Kaiserliches Erbrecht, Berlin 1982, 314; vgl. auch D. 36,1,46pr. Marcell. 15 dig.

136) D. 28,8,1,1 Ulp. 60 ad ed. Ait praetor: ,Si tempus ad deliberandum petet, dabo; zur Zugehörigkeit zum Edikt vgl. bereits Kn iep (Fn. 114) 268 und 321f.

$\left.{ }^{137}\right)$ Das Edikt de iure deliberandi gilt für den Außenerben. Gleichsinnig kann der Hauserbe eine Ausschlagung (beneficium abstinendi) geltend machen; vgl. Lenel, 
nach Ablauf der auf ihren Antrag gesetzten Frist hin die Erbschaft nicht antritt, die Güter des Verstorbenen verkaufen (bonorum venditio) ${ }^{138}$ ). Zur Durchführung des Verkaufs werden die Gläubiger in den Besitz eingewiesen und können sodann durch Wahl eines magister zum Verkauf schreiten.

Die erste Übereinstimmung mit dem SC Pegasianum besteht darin, dass der praetor auch im Rahmen des edictum de iure deliberandi Druck auf den antrittsunwilligen Erben ausübt, um den Gläubigern eine Durchsetzung ihrer Forderungen zu erlauben ${ }^{139}$ ); die zweite Parallele ergibt sich daraus, dass der Erbschaftsfideikommissar schon vor dem SC Pegasianum als „Erbschaftskäufer" behandelt wurde, also offenbar demjenigen gleichsteht, der die überschuldete Erbschaft im Rahmen der venditio bonorum erwirbt $\left.\mathrm{t}^{140}\right)$. Da der Erbschaftsfideikommissar eine Forderung gegen den Erben hat (vgl. II.2.a), liegt es durchaus auf der Hand, ihn als Gläubiger der Erbschaft anzusehen. Die einzige Besonderheit besteht darin, dass der Erbschaftsfideikommissar - anders als andere Gläubiger - die gesamte Erbschaft erhalten will, also nicht nur eine Einzelsache oder eine Geldsumme verlangt. Aufgrund dieser Besonderheit wird der Erbschaftsfideikommissar - anders als sonstige Gläubiger - nicht nur vorläufig in den Besitz eingewiesen, sondern erhält die Erbschaft auf Dauer. Während also bei einer sonstigen venditio bonorum der bonorum emptor erst durch den Verkauf Inhaber der Erbschaft wird, tritt der Erbschaftsfideikommissar schon dadurch, dass der zum Antritt gezwungene Erbe die Erbschaft an ihn herausgibt ${ }^{141}$ ), die Rechtsnachfolge des Erben an.

${ }^{3} \mathrm{EP}$ (Fn. 70) 417f., der das Edikt als Anhang zum Edikt cui heres non extabit ansieht. Eine moderne Darstellung des ius deliberandi fehlt; nur knapp hierzu Spengler (Fn. 60) 71-73. Aus der gemeinrechtlichen Lit. vgl. A. Dedekind, Das Deliberationsrecht des Erben und die Interrogationes in jure faciendae, Eine civilistische Abhandlung, Braunschweig 1870, bes. 6-11.

${ }^{138}$ ) Zur bonorum venditio vgl. S. Solazzi, Il concorso dei creditori nel diritto romano I, Neapel 1937, 35f.; zuletzt M. del Pilar Pérez Álvarez, La bonorum venditio, Estudio sobre el concurso de acreedores en Derecho Romano clásico, Madrid 2000, die allerdings das Edikt de iure deliberandi nicht behandelt.

${ }^{139}$ ) Zur Ausübung des Zwangs vgl. K rüger (Fn. 125) 298, der allerdings einfach apodiktisch behauptet: „Daß der Prätor zwingen soll, hat der Senat bestimmt, und der prätorische Zwang läßt sich ohne Edikt nicht denken.“

$\left.{ }^{140}\right)$ Zum bonorum emptor und zur venditio hereditatis vgl. zuletzt del Pilar Pérez Álvarez (Fn. 138) bes. 227-328 mwN.

$\left.{ }^{141}\right)$ Die aditio hereditatis mit restitutio ist auch in den Digesten mehrfach belegt; vgl. D. 36,1,2 Cels. 21 dig. Qui quadringenta reliquit, Titio trecenta legavit, heredis fidei commisit, ut tibi hereditatem restitueret, isque suspectam iussu praetoris adiit et restituit (...); D. 36,1,17,3 Ulp. 4 fideicomm. Inde quaeritur, si quis hereditatem rogatus sit restituere deducto aere alieno vel deductis legatis, an suspectam dicens 
Diese Deutung des Antrittszwangs lässt sich durch verschiedene Digestenstellen bestätigen und vertiefen.

b. Der Erbschaftsfideikommissar als Rechtsnachfolger des Erben:

Die Stellung des Erbschaftsfideikommisars als Rechtsnachfolger des Erblassers führt dazu, dass er für die Schulden der Erbschaft haftet und insbesondere Legate und Fideikommisse zu erfüllen hat:

D. 36,1,2 Cels. 21 dig. Qui quadringenta reliquit, Titio trecenta legavit, heredis fidei commisit, ut tibi hereditatem restitueret, isque suspectam iussu praetoris adiit et restituit: quaerebatur, quid legatario dare deberes. dicendum est, quia praesumptum est voluisse testatorem cum onere legatorum fideicommissum restitui, tota trecenta te dare Titio debere: nam heres hoc rogatus intellegi debet, ut te suo loco constituat (...)

Das Fragment betrifft die Berechnung der lex Falcidia beim erzwungenen Antritt, wobei Details dieser Berechnung an dieser Stelle außer Betracht bleiben können ${ }^{142}$ ). Von Interesse ist lediglich, dass die dem Erben auferlegten Legate auch vom Erbschaftsfideikommissar zu erfüllen sind, dem die Erbschaft herausgegeben wurde. Zur Begründung dieser translatio legati ${ }^{143}$ ) verweist Celsus auf den Willen des Erblassers: quia praesumptum est voluisse testatorem cum onere legatorum fideicommissum restitui. Der Erbschaftsfideikommissar soll also aufgrund des zu vermutenden Willens, auch in dieser Hinsicht die Nachfolge des eingesetzten Erben antreten. Mit dieser Begründung erweist sich die Entscheidung des SC Pegasianum, den Erbschaftsfideikommissar als emptor bonorum zu behandeln, ohne dass es zu einem Verkauf der Erbschaft kommen muss, als vom Willen des Erblassers getragene und auch für die Interessen der Legatare angemessene Lösung: Sie erhalten einen neuen Schuldner für ihre Forderung gegen die Erbschaft, sofern der Erblasser nicht ausnahmsweise abweichend bestimmt hat.

Diese Funktion des Erbschaftsfideikommisses - und dies ist eine wichtige Bestätigung der Vergleichbarkeit von venditio bonorum und Antrittszwang -

cogi possit adire et restituere hereditatem, quia vi ipsa magis id, quod superest ex hereditate, quam ipsam hereditatem restituere sit rogatus (...); D. 36,1,46pr. Marcell. 15 dig. Postulante Sticho, qui eodem testamento libertatem et fideicommissam hereditatem acceperat, heres suspectam adiit.

$\left.{ }^{142}\right) \mathrm{Zu}$ den Einzelheiten dieser Berechnung vgl. Manthe (Fn. 115) 92 (zum Text); V. Mannino, Il calcolo della ,quarta hereditatis' e la volontà del testatore, Neapel 1989, bes. 23 Fn. 54; D. S ch a nbacher, Ratio legis Falcidiae, Die falzidische Rechnung bei Zusammentreffen mehrerer Erbschaften in einer Hand, Berlin 1995, 39-80.

$\left.{ }^{143}\right) \mathrm{Zu}$ den einzelnen Tatbeständen und Voraussetzungen vgl. M. Tala manca, Revoca testamentaria e ,translatio legati‘, in: Studi Emilio Betti IV, Mailand 1962, 181-346. 
beschränkt die Gestaltungsmöglichkeiten des Erblassers, der den Erbschaftsfideikommissar von der Haftung befreien will:

D. 36,1,17,3 Ulp. 4 fideicomm. Inde quaeritur, si quis hereditatem rogatus sit restituere deducto aere alieno vel deductis legatis, an suspectam dicens cogi possit adire et restituere hereditatem, quia vi ipsa magis id, quod superest ex hereditate, quam ipsam hereditatem restituere sit rogatus. et sunt qui putent, ut Maecianus, inutilem esse hanc deductionem: nec enim posse ex iure deduci quantitatem, non magis quam si fundum quis deducto aere alieno vel deductis legatis restituere sit rogatus: neque enim recipit fundus aeris alieni vel legati minutionem. sed Iulianum existimare refert Trebelliano senatus consulto locum esse et, ne dupliciter fideicommissarius oneretur, et cum heres aes alienum vel legatum deducit et cum convenitur a creditoribus et legatariis, restituta sibi ex Trebelliano hereditate debere aut deductionem eum non pati ab herede aut cavere illi heredem defensum iri eum adversus legatarios ceterosque.

Ulpian untersucht, ob der Antrittszwang aus dem SC Pegasianum auch dann besteht, wenn das Erbschaftsfideikommiss so ausgestaltet ist, dass der Erbe die Erbschaft unter Abzug von Schulden und Legaten herausgeben muss, und konstatiert eine Meinungsverschiedenheit zwischen Maecian und Julian. Maecian hält die Konstruktion für unzulässig, weil eine Erbschaft ebensowenig wie ein Grundstück von Schulden befreit vermacht werden könne. Sei das Fideikommiss umgekehrt so zu verstehen, dass der Erbe nur eine quantitas schulde, also einen Restbetrag aus der erbschaftlichen Vermögensmasse, liege kein Universalfideikommiss vor, sodass der Fideikommissar keinen Antrittszwang auslösen könne' $\left.{ }^{144}\right)$. Demgegenüber vertritt Julian eine differenzierte Lösung, die er in der überkommenen Textfassung auf das SC Trebellianum stützt, vermutlich aber zum SC Pegasianum formuliert wurde ${ }^{145}$ ). Auch dieser Jurist hält es für nicht möglich, den Erbschaftsfideikommissar von der erbschaftlichen Haftung zu befreien. Er schlägt aber vor, die Anordnung des Erblassers, die Schulden und Legate vor der Herausgabe abzuziehen, im Sinne einer Abwicklungsregel zu verstehen, nach welcher der Erbe die Lasten der Berechnung und Auszahlung von Gläubigern und Legataren zu tragen habe, bevor er die Erbschaft herausgebe, sodass der Erbschaftsfideikommissar nur für die verbleibenden Schulden hafte. Beide von Ulpian zitierten Juristen stimmen mithin darin

${ }^{144}$ ) Manthe (Fn. 115) 100 Fn. 73 zur Stelle sieht dies eher als Ausdruck der Regel, dass aus dem Vermächtnis einer quantitas kein Antrittszwang abgeleitet werden kann.

${ }^{145}$ ) Da es gerade um den Antrittszwang geht, der ausweislich des gaianischen Zeugnisses nicht dem SC Trebellianum, sondern dem SC Pegasianum entstammt, ist hier eine Interpolation überaus wahrscheinlich. $\mathrm{Zu}$ den Interpolationen von $S C$ Trebellianum für SC Pegasianum vgl. Manthe (Fn. 115) 73 mit Fn. 42. 
überein, dass das Gegenstück des Antrittszwangs (und der Herausgabe) die Eigenhaftung des Universalfideikommissars ist, der insoweit die Rechtsnachfolge des Erblassers übernimmt. Ziel des Antrittszwangs ist damit nicht nur die Durchsetzung des Erbschaftsfideikommisses, sondern auch die Überleitung der erbschaftlichen Haftung auf den Fideikommissar, was der Funktion der venditio bonorum, die den bonorum emptor in die Schuldnerstellung einweist, entspricht.

c. Zur technischen Bedeutung des Einwands der hereditas suspecta:

Die so herausgearbeitete Parallele zur venditio bonorum ${ }^{146}$ ) erklärt, warum der Erbe im Rahmen des Antrittszwangsverfahrens die Erbschaft - wie in Gai. Inst. 2,258 erwähnt - als suspecta oder quasi damnosa bezeichnet (quod dicat eam sibi suspectam esse quasi damnosam) ${ }^{147}$ ), was die bisherige Forschung meist als untechnischen Hinweis abgetan hat ${ }^{148}$ ). Dagegen ist zunächst darauf hinzuweisen, dass die Behauptung der Überschuldung der Erbschaft bei der Beschwer mit einem Erbschaftsfideikommiss durchaus zutrifft, da ja dem Erben nach der Herausgabe nichts aus der Erbschaft verbleibt und er die ihn treffenden Erbschaftsschulden daher aus dem eigenen Vermögen tilgen müsste ${ }^{149}$ ). Zudem ist zu beachten, dass der Einwand der Überschuldung bei Legaten (und Einzelfideikommissen) durchaus zu hören wäre, weil der Erbe diese nicht zu erfüllen bräuchte, wenn sie den Wert des

${ }^{146}$ ) Trotz der ,freiwilligen' Restitution besteht kein Anlass für die Annahme einer cessio bonorum; vgl. dazu M. Wlassak, s. v. cessio bonorum, in: RE III,2, Stuttgart 1899, Sp. 1995-2000; F. v. Woeß, Personalexekution und cessio bonorum im römischen Reichsrecht, ZRG RA 43 (1922) 485-529, 520; zuletzt knapp W. Forster, Konkurs als Verfahren, Francisco Salgado de Somoza in der Geschichte des Insolvenzrechts, Köln 2009, 90-108, sowie K roppenberg (Fn. 60) 261f., 270.

$\left.{ }^{147}\right)$ Zur hereditas damnosa vgl. auch Ulp. epit. 25,16 Si heres damnosam hereditatem dicat, cogitur a praetore adire et restituere totam, ita ut ei et in eum, qui recipit hereditatem, actiones dentur, proinde atque si ex Trebelliano senatus consulto restituta fuisset; D. 50,16,119 Pomp. 3 ad Q. Muc. ,Hereditatis' appellatio sine dubio continet etiam damnosam hereditatem: iuris enim nomen est sicuti bonorum possessio.

${ }^{148}$ ) Keine Erklärung bei Manthe (Fn. 115) 85 Fn. 6, der festhält: „Die Berufung auf die Überschuldung war rein formal (...) An einer wirklich überschuldeten Erbschaft hätte der Erbschaftsfideikommissar auch kaum Interesse gehabt.“ Auch Kroppenberg (Fn. 60) 185 übernimmt diese Argumentation zum SC Pegasianum, obgleich sie 191-197 die Bedeutung der Überschuldung für die Unterscheidung von Einzel- und Universalfideikommiss treffend herausarbeitet.

${ }^{149}$ ) Dieser Einwand wäre bei einem Legat (wie beim Einzelfideikommiss) durchaus relevant, wird aber gerade beim Universalfideikommiss nicht gehört; vgl. D. 35,2,66,1 Ulp. 18 ad leg. Iul. et Pap.; dazu Kroppenberg (Fn. 60) 190f. 
Nachlasses überstiegen ${ }^{150}$ ). Zwar greift diese Verteidigung gegenüber dem Erbschaftsfideikommiss nicht durch ${ }^{151}$ ), weil der Erbschaftsfideikommissar - wie gesehen - als Rechtsnachfolger des Erblassers angesehen wird. Auch in dieser Hinsicht ist aber der Einwand nicht gegenstandslos, da er eine Einlassung auf die Sache darstellt und somit dem Erben ermöglicht, die Folgen einer Indefension zu vermeiden, die nicht nur zur venditio bonorum, sondern auch zur Personalexekution führen kann ${ }^{152}$ ).

\section{d. Der Schutz des zum Antritt gezwungenen Erben:}

Auch die übrigen Details des bei Gaius geschilderten SC Pegasianum lassen sich gut mit der Annahme einer abgewandelten venditio bonorum vereinbaren. Dies gilt zunächst für den Schutz des Erben nach der Herausgabe der Erbschaft:

Gai. Inst. 2,258 (...) quo casu nullis stipulationibus opus est, quia simul et huic, qui restituit, securitas datur, et actiones hereditariae ei et in eum transferuntur, qui receperit hereditatem.

Im Fall des zwangweisen Antritts nach dem SC Pegasianum sollen nach Gaius die stipulationes emptae et venditae hereditatis nicht zur Anwendung kommen; vielmehr würden zugunsten und gegen den Erbschaftsfideikommissar die erbschaftlichen Klagen erteilt und der Erbe werde durch eine „Sicherheitsleistung“ (securitas) vor einer Inanspruchnahme durch die Erbschaftsgläubiger geschützt. Dieser Schutz lässt sich durch Hinweise in den Digesten konkretisieren. So spricht Ulpian in seiner Monographie de fideicommissis mehrfach davon, dass der Erbe auf das Risiko des beantragenden Erbschaftsfideikommissars (suo periculo), die Erbschaft antrete ${ }^{153}$ ). Andere Fragmente aus dem Werk zeigen, dass der Fideikommissar mit dem Antrag auf Zwangsantritt oftmals eine Kaution (indemnitatis cautio) abgibt ${ }^{154}$ ), wel-

$\left.{ }^{150}\right)$ Kroppenberg (Fn. 60) 190-220, die auch den Unterschied zwischen ultravires-Verfügungen und lex Falcidia herausarbeitet.

$\left.{ }^{151}\right)$ Der Erbe vermeidet zudem den Vorwurf der Indefension. Zum Verhältnis von Insolvenz und Indefension vgl. auch Kroppenberg (Fn. 60) 286 Fn. 9 (allerdings zur lebzeitigen Insolvenz).

${ }^{152}$ ) Zur Rechtsfolge der Personalexekution bei actiones in personam vgl. Ka ser/ Hack1 (Fn. 2) 277f. Dass diese nicht nur als theoretische Möglichkeit anzusehen ist, beweist F. Klinck, Die persönliche Haftung des filius familias, ZRG RA 132 (2015) 126-153 mit Blick auf Haussöhne.

$\left.{ }^{153}\right) \mathrm{Zu}$ suo periculo adire vgl. D. 36,1,4pr. Ulp. 4 fideicomm.; D. 36,1,17,7-8 Ulp. 4 fideicomm.

${ }^{154)}$ Vgl. zum Beispiel D. 36,1,15,6 Ulp. 4 fideicomm. Quare si fideicommissum pecuniarium alicui fuerit relictum, cessat compulsio, tametsi indemnitatis cautio offeratur; D. 36,1,17,14 Ulp. 4 fideicomm. Idem quaerit, si quis paratus sit domino 
che Schadloshaltung zusagt ${ }^{155}$ ). Es liegt daher nahe, die von Gaius erwähnte securitas als eine Sicherheitsleistung zu deuten, die der Erbschaftsfideikommissar gegenüber dem praetor abzugeben hat, wenn er den zwangsweisen Antritt vom Erben verlangt. Vergleichbare Sicherheitsleistungen sind auch vom Erben und von Erbschaftsprätendenten bezeugt, wenn sie die Prozessführung für eine in ihrer Solvenz zweifelhafte Erbschaft übernehmen wollen $\left.{ }^{156}\right)$.

Eine interessante Kombination aller bisherigen Details des Antrittsverfahrens findet sich schließlich in einem Fragment aus Marcians Monographie über Fideikommisse:

D. 36,1,73 Marcian. 10 fideicomm. Omnes qui de hereditate deliberant desiderante eo, qui suo periculo velit adiri hereditatem, coguntur adire, sed non statim restituere, sed ut completo tempore deliberationis, si expedire sibi compererint hereditatem, sentiant commodum testamenti eo iure, quo si sponte adissent, sin vero contra onerosam crediderint, restituta ea exonerentur actionibus hereditariis.

Marcian betont, dass alle Miterben während der Deliberationsfrist (vgl. III.2.a) auf Antrag des Erbschaftsfideikommissars gezwungen werden können, auf dessen Risiko anzutreten. Die Restitution der Erbschaft an den Erbschaftsfideikommissar finde aber erst dann statt, wenn die Deliberationsfrist abgelaufen sei. Während der Bedenkzeit könne sich nämlich herausstellen, dass die Erbschaft trotz des Fideikommisses vorteilhaft sei; gelangten die Erben aber zu dem Schluss, dass die Erbschaft überschuldet sei, könnten sie diese an den Erbschaftsfideikommissar herausgeben und würden im Gegenzug von den erbschaftlichen Klagen befreit. Das bisher vermutete Geschehen wird hier plastisch: Der Erbschaftsfideikommissar verlangt beim praetor den zwangsweisen Erbschaftsantritt und bietet als Sicherheit die Kaution zur Schadloshaltung an; da eine missio erst nach Ablauf der Deliberationsfrist zulässig ist, muss der Erbschaftsfideikommissar abwarten, bis für alle Miterben diese Frist abgelaufen ist. Den Erben bleibt also das prätorische Wahlrecht, ob sie die Erbschaft antreten, auch nach dem erzwungenen Antritt erhalten. Das Risiko des Antrittszwangs liegt - wie gesehen - beim Erbschaftsfideikommissar, der die wegen Überschuldung ausgeschlagene Erb-

cavere de indemnitate, an possit cogi adire hereditatem, maxime et si pretium servi offeratur. et recte ait non oportere sub incerto cautionis committere se aditioni hereditatis.

$\left.{ }^{155}\right)$ Zur promissio indemnitatis bei der Tutel vgl. E.C. Silveira Marchi, Concurso de Credores e pactum ut minus solvatur, Lecce ${ }^{2} 1999,38$ f.

${ }^{156)}$ Vgl. Gai. Inst. 4,102; dazu K rop penberg (Fn. 60) 287f.; J. Plats chek, Studien zu Ciceros Rede für P. Quinctius, München 2005, 113-121; Er x leb en (Fn. 115) 187f. mit Fn. 365. 
schaft im Wege der Rechtsnachfolge übernehmen muss. An dieser Stelle wird weiter die verfahrensrechtliche Vergleichbarkeit von fideikommissarischer Restitution und venditio bonorum deutlich, da Marcian auf eine missio verweist, die der Erbschaftsfideikommissar gegen Sicherheitsleistung gegenüber dem Erben beantragen kann. Genau diese Besitzeinweisung der Gläubiger ist auch Kennzeichen des mehrstufigen Vollstreckungsverfahrens (s. o. III.2.a).

Die hier vorgeschlagene Deutung des Antrittszwangs als Teil eines ordentlichen Verfahrens über die erbrechtliche Nachfolge vor dem praetor erlaubt es zuletzt, auch die durch das SC Pegasianum vollzogene Rückkehr zu den stipulationes emptae et venditae hereditatis treffender zu würdigen, die bisher meist als Fehlentscheid des Senats angesehen wurde (s. u. III.3).

3. Die Rückkehr zu den stipulationes emptae et venditae hereditatis:

Diese Stipulationen kommen - im Gegensatz zum Antrittszwang, der den Aktionentransfer auslöst - bei der freiwilligen Übernahme einer mit einem Erbschaftsfideikommiss belasteten Erbschaft durch den Erben zum Tragen (Alternative 1, s.o. III.2.a):

Gai. Inst. 2,257 Sed is, qui semel adierit hereditatem, si modo sua voluntate adierit, sive retinuerit quartam partem sive noluerit retinere, ipse universa onera hereditaria sustinet. Sed quarta quidem retenta quasi partis et pro parte stipulationes interponi debent tamquam inter partiarium legatarium et heredem; si vero totam hereditatem restituerit, ad exemplum emptae et venditae hereditatis stipulationes interponendae sunt.

Wie sich die Stipulationen auf das Verhältnis von Erbschaftsfideikommissar und Erbe auswirken, ist von Manthe ausführlich beschrieben und gewürdigt worden ${ }^{157}$ ). Ungeklärt erscheint aber die Funktion der Stipulationen für den Erbschaftsantritt, also im Rahmen der Deliberationsfrist des Erben. Dabei ist nicht nur an den Zwangsverkauf, sondern auch an die Möglichkeit zu denken, dass die Gläubiger den Erben zum Antritt überreden oder ihm in einer Vereinbarung entsprechende Vorteile versprechen ${ }^{158}$ ), wenn er die Erbschaft übernimmt und ihnen damit als Klagegegner zur Verfügung steht. Ein Beispiel für eine derartige Absprache findet sich in einer Erörterung Julians zur actio mandati ${ }^{159}$ ):

${ }^{157}$ ) Manthe (Fn. 115) 64-75.

158) $\mathrm{Zu}$ einer derartigen Gestaltung vgl. D. 31,89,4 Scaev. 4 resp.; dazu Impallomen i, BIDR 70 (Fn. 68) 24-27, der allerdings von einer missio in rem ausgeht, die m. E. hier nicht vorliegt.

${ }^{159}$ ) Zur notwendigen Fremdnützigkeit des Mandats vgl. J.-H. Miche1, Gaius et le mandat mea, tua ou aliena gratia, RIDA 44 (1997) 293-309. 
D. 17,1,32 Iul. 3 ad Urs. Feroc. Si hereditatem aliter aditurus non essem quam cautum mihi fuisset damnum praestari et hoc mandatum intercessisset, fore mandati actionem existimo. si quis autem mandaverit alicui, ne legatum a se repellat, longe ei dissimile esse: nam legatum adquisitum numquam illi damno esse potuit: hereditas interdum damnosa est (...)

Der Jurist unterscheidet ${ }^{160}$ ): Während der Auftrag, eine Erbschaft anzutreten, nicht nur im eigenen Interesse des Beauftragten liege, da eine Erbschaft auch ,gefährlich` (damnosa) sein könne ${ }^{161}$ ), sei der Erwerb des Legates immer vorteilhaft, womit mangels Fremdnützigkeit kein mandatum im Rechtssinne vorliegen kann. Der haftungsrechtliche Unterschied zwischen Rechtsnachfolge und Einzelerwerb von Todes wegen wirkt sich hier auf die Qualifikation des Rechtsverhältnisses zwischen Gläubiger und Begünstigtem aus. Bei Vorliegen eines Universalfideikommisses ist ein Auftrag der Erbschaftsgläubiger an den Erbschaftsfideikommissar und damit eine rechtliche Gestaltung des Verhältnisses vorstellbar. Der Inhalt derartiger Absprachen lässt sich aus einem Fragment Ulpians zur exceptio doli erschließen:

D. 44,4,4pr. Ulp. 76 ad ed. Apud Celsum quaeritur, si, cum Titio mandassent creditores hereditarii, ut adiret hereditatem, unus non mandasset decipiendi eius causa, mandaturus alioquin, si non foret hic aditurus, deinde agat, an exceptione repellatur: et ait Celsus doli eum exceptione repellendum.

Ein Gläubiger hatte sich an einem an Titius gerichteten Auftrag zum Antritt, der von den meisten Erbschaftsgläubiger getragen wurde, nicht beteiligt, weil er plante, umgekehrt den Auftrag zum Nichtantritt zu erteilen ${ }^{162}$ ). Celsus entscheidet, der Gläubiger sei mit der exceptio doli zurückzuweisen, wenn er seine Erbschaftsforderung nach dessen Antritt von Titius einklage. Das Fragment belegt zunächst, dass ein Auftrag aller Erbschaftsgläubiger zum Erbschaftsantritt möglich, wenn nicht gar üblich war. Aus der Tatsache, dass Celsus dem Gläubiger, der sich nicht am Auftrag beteiligt hat, die Klage gegen den Erben versagt, ergibt sich weiter, dass diese Absprache dazu diente, den Erben für die Schulden der Gläubiger haftbar zu machen.

Geht man nach dem vorangehenden Überlegungen davon aus, dass der Erbschaftsfideikommissar ebenfalls den Erbschaftsgläubigern haftet, sind Erbe und Erbschaftsfideikommissar als zwei alternative Haftungslösungen

$\left.{ }^{160}\right)$ Zum Text vgl. zuletzt Silveira Marchi (Fn. 155) 26-33 sowie A. Calzada González, Una aproximación a la aditio mandato creditorum, in: Estudios Reimundo Yanes I, Burgos 2000, 60-71.

$\left.{ }^{161}\right) \mathrm{Zu}$ recht betont N. Tanaka, Zur vertraglosen Haftung des Ratgebers, in: D. Nörr/S. Ni shi mura (Hgg.), Mandatum und Verwandtes, Berlin 1993, 193-206, 194 Fn. 8, dass es sich um ein mandatum mea et tua gratia handele.

$\left.{ }^{162}\right) \mathrm{Zu}$ D. 44,4,4pr. Ulp. 76 ad ed. vgl. Silveira Marchi (Fn. 155) 33-37. 
für die Gläubiger anzusehen, wobei diese auch nach dem Wohlstand oder der Solvenz des jeweiligen Eigenvermögens eine Präferenz für den einen oder den anderen haben werden. In dieser Situation bietet das SC Pegasianum den Gläubigern weitergehende Gestaltungsmöglichkeiten, indem der „freiwillige“ Antritt des Erben vom zwangsweisen Antritt unterschieden wird. Während es beim zwangsweisen Antritt zum Aktionentransfer, das heißt zum Eintritt des Erbschaftsfideikommissars kommt, bleibt der Erbe beim „freiwilligen“ Antritt in der Schuldnerposition, obgleich er vom Erbschaftsfideikommissar mittels den Stipulationen Regress nehmen kann; eine direkte Klage der Gläubiger gegen den Erbschaftsfideikommissar - wie unter Geltung des SC Trebellianum - ist aber in diesem Fall nicht möglich: Nur der Erbe haftet den Gläubigern und trägt damit das Risiko, die von ihm getätigten Ausgaben nicht mehr vom Erbschaftsfideikommissar ersetzt zu erhalten. In diesem Ausfallrisiko liegt die von Papinian angesprochene „Verfänglichkeit“ der Stipulationen ${ }^{163}$ ); aus Sicht der Erbschaftsgläubiger ist der Weg über die Stipulationen hingegen wünschenswert, wenn sie den Erben für einen besseren Schuldner halten als den Erbschaftsfideikommissar.

Es sei erwähnt, dass die von Justinian auf Papinians Äußerung gestützte Kritik und Aufhebung des SC Pegasianum ${ }^{164}$ ) aus Sicht des justinianischen Rechts ihre Berechtigung hat. Mit der Einführung des beneficium inventarii kann der Erbe seine Haftung auf den Nachlass beschränken ${ }^{165}$ ); gleichzeitig etabliert Justinian eine Rangfolge, nach welcher die Gläubiger befriedigt werden sollen und beschränkt die Deliberationsmöglichkeiten des Erben ${ }^{166}$ ). Vor diesem Hintergrund sind Vereinbarungen zwischen Erbschaftsgläubigern und Erben über die Schuldenhaftung oder einen einvernehmlichen Erb-

${ }^{163)}$ Inst. 2,23,7 Sed quia stipulationes ex senatusconsulto Pegasiano descendentes et ipsi antiquitati displicuerunt et quibusdam casibus captiosas eas homo excelsi ingenii Papinianus appellat (...)

$\left.{ }^{164}\right)$ C. 1,17,2,6a Iust. (a. 533) Cumque nihil tam peculiare fuerat, quam ut legatis quidem legis Falcidiae narratio, fideicommissis autem senatus consulti Trebelliani, singulis libris utrique eorum adplicatis tota pars quinta in novem libros coadunata est. solum autem senatus consultum Trebellianum ponendum esse existimavimus: captiosas etenim et ipsis veteribus odiosas Pegasiani senatus consulti ambages et utriusque senatus consulti ad se tam supervacuas quam scrupulosas diversitates respuentes totum ius super his positum Trebelliano senatus consulto adiudicavimus.

$\left.{ }^{165}\right)$ C. 6,30,22 Iust. (a. 531); dazu G. Wesener, Beschränkungen der Erbenhaftung im römischen Recht: separatio bonorum und beneficium inventarii, in: M. J. Schermaier/Z. Végh (Hgg.), Festschrift Waldstein, 1993, 401-416, bes. $410-416$.

$\left.{ }^{166}\right)$ M. Kaser, RPR ${ }^{2} I I($ Fn. 112) 544. 
schaftsantritt entbehrlich. In einem System grundsätzlich unbeschränkter Erbenhaftung, wie sie für das Recht der Prinzipatszeit anzunehmen ist ${ }^{167}$ ), liegen Vereinbarungen zwischen Gläubigern und Erben dagegen im beiderseitigen Interesse und können dazu beitragen, die nicht immer günstigen Folgen der venditio bonorum zu vermeiden. Aus Sicht der Erbschaftsgläubiger ist die Regelung des SC Pegasianum mithin kaum zu kritisieren. Vor allem aber ist für die hier untersuchte Abgrenzungsfrage festzuhalten, dass sich die Entscheidung des SC Pegasianum, die stipulationes emptae et venditae hereditatis wieder einzuführen, als prozessual relevante Maßnahme darstellt, die eindeutig Gestaltungsmöglichkeiten des Formularverfahrens (Deliberation, bonorum venditio) voraussetzt.

4. Zum Zusammenspiel von Formularverfahren und cognitio:

Verfolgt man die hier vertretene Auffassung der formularen Durchsetzung des Antrittszwangs weiter, stellt sich die Frage, wie sich die cognitio extra ordinem über Bestehen, Inhalt und Umfang des Fideikommisses (II.2) zu dem hier angenommen Antrittsverfahren verhält. Dass diese Fragestellung überhaupt in den Digesten erörtert wird, kann dabei als Indiz für die Richtigkeit der hier angenommenen Verfahrensspaltung gelten:

D. 36,1,13,3 Ulp. 4 fideicomm. Quid ergo si de viribus fideicommissi tractetur? Haec quaestio praetori praetermittenda non erit. Sed quid si qui fideicommissarius dicat: ,Adeat prius et sic de hoc quaeratur?' Credo interdum audiendum fideicommissarium, si cognitio prolixiorem tractatum habeat: finge enim verba fideicommissi de longinquo petenda et iustam deliberationem de quantitate fideicommissi incidere: dicendum erit compellendum eum adire, ne prius heres decedens fideicommissarium decipiat.

Im vorangehenden Fragment hat Ulpian betont, dass der zum Antritt gezwungene Erbe mit Argumenten gegen die Wirksamkeit des Testaments nicht gehört werde ${ }^{168}$ ), wenn er die Erbschaft für verdächtig erklärt habe (si suspectam sibi hereditatem dicat $)^{169}$ ). Verfahrensrechtlich ist also ein Sta-

$\left.{ }^{167}\right)$ Kroppenberg (Fn. 60) 173-181 mwN.

$168)$ D. 36,1,13,2 Ulp. 4 fideicomm. Si de testamento aliquid quaeratur, heres non debet audiri, si suspectam sibi hereditatem dicat: nam et si maxime dicatur vel ius testandi non habuisse eum qui testatus est vel de viribus testamenti vel de sua condicione, non erit audiendus.

$\left.{ }^{169}\right)$ Auch die cessio bonorum knüpft an den Eid bonam copiam iurare an, verlangt also das Eingeständnis der Insolvenz; vgl. For ster (Fn. 146) 90f.; anders noch L. Guen oun, La cessio bonorum, Thèse Paris 1920, 5-18, der die Formulierung als Eid über die Zahlungsfähigkeit auslegt. Der einschlägige Text - D. 42,3,8 Ulp. 26 ad ed. Qui cedit bonis, antequam debitum adgnoscat, condemnetur vel in ius con- 
dium erreicht, in dem der Erbe als nicht mehr zuständig für die Erbschaft angesehen wird, weil er den Antritt verweigert hat. Im hier interessierenden Teil wirft Ulpian die Frage auf, wie - im Gegensatz zu Einwänden gegen die Validität des Testaments - mit Bedenken hinsichtlich der Wirksamkeit des Fideikommisses zu verfahren ist. Er hält fest, dass der im Rahmen des Antrittszwangs tätige praetor die Frage nicht außer Acht lassen dürfe; vor allem aber betont der Jurist, dass der Erbe ausnahmsweise auch dann zum Antritt gezwungen werden könne, wenn die cognitio über das Fideikommiss langwierige Abklärungen erwarten lasse ${ }^{170}$ ). Dann nämlich gebiete es der Schutz des Fideikommissars möglichst rasch Zugriff auf die Erbschaft zu erhalten, um Schaden durch Zeitablauf abzuwenden. Es liegt nahe, Ulpians Differenzierung als Ausdruck einer prätorischen causae cognitio im Formularverfahren anzusehen ${ }^{171}$ ): In deren Rahmen kann der praetor prüfen, ob das Fideikommiss offensichtlich nicht besteht; sind für diese Frage längere Abklärungen in der cognitio extra ordinem notwendig, kann der praetor des Formularverfahrens den Fideikommissar trotzdem schützen, indem er einen zwangsweisen Antritt anordnet ${ }^{172}$ ).

Ein weiteres Indiz für die Annahme einer zwischen Gerichtsmagistrat und praetor fideicommissarius geteilten Zuständigkeit, bietet das unmittelbar anschließende Fragment, das den Antrittszwang aus der Perspektive der Zuständigkeitsordnung behandelt173):

D. 36,1,13,4 Ulp. 4 fideicomm. Tempestivum est requirere, per quem quis cogatur adire et restituere hereditatem: veluti si praetor aut consul fuerit heres institutus suspectamque hereditatem dicat, an cogi possit adire et restituere? Et dicendum est praetorem quidem in praetorem vel consulem in consulem nullum imperium habere: sed si iurisdictioni se subiciant, solet praetor in eos ius dicere. Sed et si ipse praetor heres institutus suspectam dicat, ipse se cogere non poterit, quia triplici officio fungi non potest et suspectam dicentis et coacti et cogentis. Sed in his omnibus casibus atque similibus principale auxilium implorandum est.

fiteatur, audiri non debet - ist in seiner Deutung sehr umstritten; zuletzt Forster (Fn. 146) 94f.; wie hier M.A.v. Beth man n-Hollweg, Grundriss zu Vorlesungen über den gemeinen Civilprocess, Berlin ${ }^{2} 1825,547,688$ mit Fn. 113; S. S e g u ra, La cessio bonorum, Etude comparée de droit romain et de droit suisse, Genf 2005, 26: „Le système de la cessio bonorum oblige le débiteur de facto à admettre la prétention du créancier poursuivant.“

$\left.{ }^{170}\right) \mathrm{Zu}$ verba fideicommissi vgl. Johnston, Law of Trusts (Fn. 3) 168 Fn. 21.

$\left.{ }^{171}\right)$ Zur allgemeinen Qualifizierung vgl. R. Martini, Il problema della causae cognitio pretoria, Mailand 1960, 15-50.

${ }^{172}$ ) Man könnte geneigt sein, hier an eine Parallele zur Prüfung der calumnia vor der Kautionserteilung zu denken; vgl. unten III.1.b.

173) Kniep (Fn. 114) 269f. 
Ulpian fragt, wer überhaupt den Zwang anordnen könne, wenn der Erbe die Erbschaft für verdächtig erklärt und den Antritt verweigert hat. Der Jurist spitzt diese Frage zu, indem er einen praetor oder Konsul als eingesetzten und beschwerten Erben unterstellt. Dass mit praetor auch hier der ordentliche Gerichtsmagistrat und gerade nicht der praetor fideicommissarius gemeint sein muss, ergibt sich aus der im Fortgang erwähnten Jurisdiktionsgewalt ${ }^{174}$ ). Dagegen steht der Konsul - in Anlehnung an die augusteische Regelung - für die Spezialbeamten, welchen die cognitio extra ordinem für Fideikommisse obliegt. Die Bemerkung, dass mangels gegenseitiger Imperiumsgewalt weder der Konsul noch der praetor vom Amtskollegen zum Antritt gezwungen werden könnten ${ }^{175}$ ), dient der Vorbereitung der zentralen Textaussage, nach welcher sich sowohl der praetor als auch der Konsul der Gerichtsbarkeit (iurisdictio) eines (anderen) praetor unterwerfen könnten. Damit ist gemeint, dass ein praetor über den sich unterwerfenden Konsul ebenso Recht sprechen kann wie über einen als Erben eingesetzten anderen praetor, woraus folgt, dass der die Jurisdiktionsgewalt innehabende Magistrat beide auch zum Antritt zwingen kann. Diese Argumentation wird durch die Bemerkung abgerundet, dass sich der praetor selbst nicht zum Antritt zwingen könne, da er nicht „drei Rollen“ einnehmen könne, indem er sowohl als ,verdächtig Erklärender“, als „Erzwingender“ und als „Gezwungener" auftrete. Das Argument ist trotz seiner offensichtlichen Übertreibung - der Erbe erklärt die Erbschaft für verdächtig und wird gezwungen; der praetor übernimmt also nur zwei Rollen - schlagend, denn es illustriert auf paradoxe Weise Ulpians Ansicht, dass ein praetor Jurisdiktionsgewalt auch über andere Amtsträger ausüben kann, sofern diese in „,privater“ Funktion (als Erbe) auftreten, sich also nicht im Rahmen ihrer Amtsbefugnisse bewegen $^{176}$ ).

Für die hier interessierende Frage der Zuständigkeit in Verfahren aus Fideikommissen belegen diese Ausführungen zunächst, dass Ulpian offensichtlich zwischen den im Rahmen der cognitio extra ordinem zuständigen

$\left.{ }^{174}\right)$ Anders Jörs (Fn. 36) 42, der das Fragment als Beleg für die Zuständigkeit des praetor fideicommissarius anführt; insofern übereinstimmend auch Kniep (Fn. 114) 269, obgleich er zu Recht die iurisdictio im Fortgang dem praetor urbanus zuweist; zu iurisdictio und imperium mit Blick auf die missio vgl. bereits R a ma die r (Fn. 66) 15-22.

175) Zur Imperiumgewalt der Magistrate vgl. Kunkel/Wittmann (Fn. 9) 22-28.

$\left.{ }^{176}\right)$ Dies ist gegenüber dem Konsul umso bedeutsamer, als sich der praetor an sich der maior potestas des Konsuls fügen musste; vgl. Kun kel/Wittmann (Fn. 9) $201 f$.

ZRG RA 136 (2019) 
Konsuln und dem praetor als Gerichtsmagistrat unterscheidet. Vor allem wird deutlich, dass der Antrittszwang eine Prärogative des ordentlichen Gerichtsmagistraten darstellt ${ }^{177}$ ), die sogar gegenüber dem Konsul durchgesetzt werden kann.

5. Fazit:

Nach alldem ist entgegen der herrschenden Ansicht, sowohl für das SC Trebellianum wie für das SC Pegasianum von einer Zuständigkeitsteilung zwischen Formularverfahren und cognitio auszugehen. In dieser Verfahrensspaltung bestimmt die cognitio extra ordinem nur über die Wirksamkeit und Durchsetzung des Fideikommisses, während die Rechtsnachfolge des Erbschaftsfideikommissars nach dem Erblasser dem ordentlichen Gerichtsmagistraten vorbehalten bleibt. Die Annahme einer zwischen ordo und cognitio geteilten Zuständigkeit ist auch deshalb glaubhaft, weil sie die in den justinianischen Quellen kaum lösbare Interdependenz beider Verfahrensarten plausibel erklären kann: Das Formularverfahren war auch für die Rechtsfolgen aus der Restitution von Fideikommissen und zur Erzwingung der Restitution anwendbar.

Vor dem Hintergrund der so definierten Kompetenzordnung ist nun die Durchsetzung von vermögensrechtlichen Einzelfideikommissen im Formularverfahren zu analysieren.

\section{Zum Rechtsschutz des Einzelfideikommisses im Formularverfahren}

Das Einzelfideikommiss, das heißt die Bitte an den Erben, Vermächtnisnehmer oder Fideikommissar, einen einzelnen Gegenstand oder eine Summe Geld an eine Person ,herauszugeben', steht strukturell dem Legat na$\mathrm{he}^{178}$ ). Aus den Institutionen des Gaius ist jedoch zu erfahren, dass sich die Regeln zur Durchsetzung von Fideikommissen und Legaten unterschieden: So konnten Legate nur im Formularverfahren, Fideikommisse hingegen vor dem praetor fideicommissarius, consul oder dem praeses provinciae ${ }^{179}$ ) eingeklagt werden (Gai. Inst. 2,278); zudem sei die Klage aus Fideikom-

${ }^{177}$ ) Andere Ansicht Jörs (Fn. 36) 10f., der das Fragment als Beleg für die Zuständigkeit der Konsuln zum Antrittszwang anführt.

$\left.{ }^{178}\right)$ Dies kommt namentlich im Recht der Anwachsung zum Tragen; vgl. Frg. Vat. 85 (...) In fideicommisso autem id sequimur quod in damnatione; dazu M. Wimmer, Das Prälegat, Wien 2004, 245 Fn. 1376; S. Lohsse, Ius adcrescendi, Wien 2008, 148 und 213 Fn. 587.

$\left.{ }^{179}\right)$ Gai. Inst. 2,278; vgl. ferner Paul. sent. 4,4,2; dazu z. B. Johnston, Law of Trusts (Fn. 3) 222f. 
missen jederzeit, aus Legaten nur an Gerichtstagen zulässig ${ }^{180}$ ); schließlich gebe es Unterschiede mit Blick auf den Haftungsumfang für Zinsen und Früchte $\left.{ }^{181}\right)$. Vor allem aus Gaius' erster Bemerkung wird pauschal gefolgert, dass für Fideikommisse die cognitio, für die Legate hingegen das Formularverfahren zuständig gewesen sei. Durchmustert man die justinianischen Quellen nach dem Rechtsschutz für Fideikommisse neben der petitio fideicommissaria, lassen sich hingegen Anhaltspunkte dafür finden, dass auch der Schutz von Einzelfideikommissen teilweise über das Formularverfahren erfolgte ${ }^{182}$ ).

1. Cautio fideicommissorum servandorum causa:

Die Einschlägigkeit des Formularverfahrens gilt vor allem für das wichtigste prätorische Rechtsmittel zum Schutz des Legatars, die cautio legatorum servandorum causa und die an sie geknüpfte missio in possessionem ${ }^{183}$ ), die spätestens seit dem hadrianischen Edikt auch für Fideikommisse gilt ${ }^{184}$ ). $\mathrm{Ob}$ man dabei von einer ausdrücklichen Klausel im edictum perpetuum für Fideikommisse ausgehen kann ${ }^{185}$ ) oder ob die Erstreckung lediglich auf einer

180) Gai. Inst. 2,279; dazu nur Kas er/Hack1 (Fn. 2) 202 Fn. 12.

$\left.{ }^{181}\right)$ Gai. Inst. 2,280; dazu bereits oben II.3.c.

182) Zur Zuständigkeit des praetor bei Indefension des Erben vgl. vor allem C. 2,12,3 Sev./Ant. (a. 204) pr. Eum, qui res agit heredum, a quibus tibi deberi fideicommissum dicis, evoca ad praetorem virum clarissimum, qui aut respondere tibi cogetur aut administratione negotiorum secundum formam iurisdictionis prohibebitur. 1 Deliberabit autem praetor, si non defendat heredes, debeatne te mittere in possessionem, secutus iurisdictionem, quae exerceri adversus indefensos solet; dazu vor allem Arcaria (Fn. 95) 265-269; anders noch Ramadier (Fn. 66) 156-158. Zum Verhältnis von venditio bonorum und Indefension vgl. allgemein Johannes Böhm, Die missio in bona cum effectu venditionis als Folge der einfachen absentia sine defensione gegenüber der Prozeßeinleitung nach klassischem, römischem Rechte, Diss. Heidelberg, Berlin 1908, 26-38; Kroppenberg (Fn. 60) 286 Fn. 9. Zum Begriff forma iurisdictionis vgl. M. Kase r, ,Ius publicum“ und ,ius privatum', ZRG RA 103 (1986) 1-101, 94 Fn. 397: ,gefestigte Rechtsbildung“.

$\left.{ }^{183}\right)$ D. 36,3,1pr.-8 Ulp. 79 ad ed.; zur cautio legatorum servandorum causa vgl. zuletzt Finkenauer (Fn. 66) 300-306; Y. González Roldán, Dolo desinere possidere fra editto del pretore e scienza giuridica, Bari 2010, 246.

$\left.{ }^{184}\right)$ D. 36,3,14pr. Ulp. 79 ad ed. Haec stipulatio et in fideicommissis locum habet, sive pure fideicommissum sit relictum sive ex die certa vel incerta vel sub condicione, sive res aliqua sive hereditas sive ius aliquod relictum est; dazu zuletzt knapp Longchamps de Bérier (Fn. 3) 197. Die Erstreckung muss schon vor Ulpian stattgefunden haben; vgl. bereits Solazzi, Concorso I (Fn. 138) 23 Fn. 1; zur Frage vgl. schon P. Lotmar, Zur Geschichte des Interdictum Quod legatorum, ZRG RA 31 (1910) 89-158, 124f.

185) Vgl. Arcaria (Fn. 95) 288-290. 
interpretativen Verbreiterung des Anwendungsbereichs der Kautionspflicht beruht, kann nicht entschieden werden. Sicher ist lediglich, dass die nachhadrianische Rechtsliteratur den prätorischen Schutz von Fideikommissen und Legaten in einem Atemzug nennt ${ }^{180}$ ) und dabei einheitlich von einem ediktalen und daher prätorischen Rechtsschutz ausgeht. Im Folgenden ist zu prüfen, welche Organe und Verfahren für die cautio rei fideicommissorum servandorum causa und die dazu gehörige missio zuständig sind, und wie sie sich zu den Rechtsfolgen der cognitio (vgl. oben II.2/3) verhalten.

2. Zum Schutz des Fideikommisses durch den praetor urbanus:

Dazu ist zunächst zu klären, ob die cautio fideicommissorum servandorum causa ein Institut der cognitio extra ordinem oder eine Maßnahme des Formularverfahrens darstellt. Die bisherige Literatur geht vorrangig von einer Zuständigkeit der Beamten in der cognitio aus. In einer eingehenden Untersuchung hat allerdings Arcaria die gegenteilige These vertreten ${ }^{187}$ ), indem er darlegt, dass die missio in possessionem fideicommisorum servandorum causa ursprünglich durch den praetor urbanus angeordnet ${ }^{188}$ ) und erst unter den späten severischen Kaisern auf die Organe der cognitio extra ordinem übertragen worden sei. Arcarias Annahme hat den Vorzug ${ }^{189}$ ), dass sie die offensichtlich lang andauernde Koexistenz von Formularverfahren und cognitio in der Kaiserzeit berücksichtigt und grundlose Interpolationsannahmen, etwa die Behauptung, praetor stehe immer für praetor fideicommissarius, vermeiden $\left.k n_{n}{ }^{190}\right)$. Den Hauptbeleg für Arcarias These bildet eine Erörterung aus Papinians Quaestiones, die ein Reskript Marc Aurels zur Kautionspflicht bei der Appellation zitiert $\left.{ }^{191}\right)$ :

D. 36,3,5,1 Pap. 28 quaest. (a) Imperator Marcus Antoninus Iulio Balbo rescripsit

${ }^{186)}$ Vgl. D. 28,7,8,2 Ulp. 50 ad ed.; D. 29,1,29,2 Marcell. 10 dig. (Erstreckung auf das Militärtestament).

$\left.{ }^{187}\right)$ Arcaria (Fn. 95) 261-290.

188) Ein wichtiges Indiz bildet D. 2,12,2 Ulp. 5 ad ed. zur oratio divi Marci; dazu Arcaria (Fn. 95) 263f.; vertiefend jetzt ders., Oratio Marci, Giurisdizione e processo nella normazione di Marco Aurelio, Turin 2003, bes. 151-158.

$\left.{ }^{189}\right)$ Brieger (Fn. 29) 116f. Zur Stabilität der Institutionen der Republik bis in die Prinzipatszeit hinein vgl. F. Hurlet, Les origines de la juridiction impériale, Imperator Caesar Augustus iudex, in: R. Haensch (Hg.), Recht haben und Recht bekommen im Imperium Romanum, Das Gerichtswesen der römischen Kaiserzeit und seine dokumentarische Evidenz, Warschau 2016, 5-39,14f.

$\left.{ }^{190}\right)$ So zum Beispiel Röhle (Fn. 6) 402-405; anders Arcaria (Fn. 95) 259-263.

191) Zum Text vgl. Salkowski (Fn. 1) 619f.; Arcaria (Fn. 95) 270-274; Babusiaux, Papinians Quaestiones (Fn. 85) 36-40. 
eum, a quo res fideicommissae petebantur, cum appellasset, cavere vel, si caveat adversarius, ad adversarium transferri possessionem debere. (b) Recte placuit principi post provocationem quoque fideicommissi cautionem interponi: quod enim ante sententiam, si petitionis dies moraretur, fieri debuit, amitti post victoriam dilata petitione non oportuit (...)

Anlass des Reskriptes ist die vor einem kaiserlichen Beamten stattfindende Appellation ${ }^{192}$ ), der beim Kaiser um Rechtsrat anfragt ${ }^{193}$ ), um über die Berufung zu entscheiden. Thema der Anfrage ist, wie bei der Berufung des Erben gegen ein obsiegendes Urteil des Fideikommissars zu verfahren sei. Der Kaiser entscheidet, der Erbe müsse zum Zweck der Berufung Sicherheit mit Blick auf die vom Fideikommiss erfassten Sachen leisten (Kaution); leiste hingegen der Fideikommissar als Berufungsgegner Sicherheit, sei dieser in den vorläufigen Besitz der Sachen einzuweisen (a). Papinian deutet den ersten Teil der kaiserlichen Antwort als Hinweis auf die im Edikt vorgesehene Sicherungskaution für den Fideikommissar und problematisiert, ob diese auch nach Einlegung der Appellation (post provocationem) zur Anwendung kommen kann (b). Sowohl das Reskript als auch Papinian bejahen dies, während Ulpian in seinem Ediktskommentar betont ${ }^{194}$ ), dass die cautio legatorum servandorum causa entfalle, wenn die litis contestatio stattgefunden habe. Die Ansicht Ulpians für die cautio legatorum servandorum causa entspricht der sichernden Funktion dieses prätorischen Mittels im Formularverfahren: Es soll verhindern, dass der Legatar seinen Vorteil durch Zwischenverfügungen oder Vermögensverfall des Erben verliert. Der Eintritt der litis contestatio hat nicht nur die Überführung der Legatsforderung in eine Judizialforderung (obligatio in iudicium deducta) zur Folge, sondern beinhaltet auch eine Haftungsverschärfung für den Untergang der Sache oder Zwischenverfügungen des Erben ${ }^{195}$ ). Obgleich Ulpian seine Lösung explizit auch auf Fideikommisse erstreck ${ }^{196}$ ), spricht sich Papinian in Folge des Reskriptes für eine Fortgeltung der Kaution auch nach dem Urteil

${ }^{192}$ ) Kaser/Hackl (Fn. 2) 504; zur Person vgl. O. Groag, s. v. Iulius (Balbus), in: RE 10,1, Stuttgart 1918, Sp. 175 Nr. 112, der vermutet, dass dieser als praetor fideicommissarius tätig war.

$\left.{ }^{193}\right)$ T. Kipp, s.v. Appellatio (in Civilsachen), in: RE II,1, Stuttgart 1895, Sp. 194-208, bes. 198.

194) D. 36,3,1,9 Ulp. 79 ad ed. Plane si quis omissa stipulatione litem de legato contestatus est, probandum est cessare debere stipulationem.

${ }^{195}$ ) $\mathrm{Zu}$ den Funktionen und Wirkungen der litis contestatio vgl. G. Jahr, Litis contestatio, Streitbezeugung und Prozeßbegründung im Legisaktionen- und im Formularverfahren, Köln 1960, 120-147.

$\left.{ }^{196}\right)$ D. 36,3,1,10 Ulp. 79 ad ed. Idemque in fideicommissis quoque probandum est. 
aus, da er es jedenfalls im Rahmen der (aufschiebend wirkenden) Appellation für sachgerecht hält' ${ }^{197}$ ), den Begünstigten zu schützen.

Im Fortgang des Fragmentes nimmt Papinian das Reskript zum Anlass, ausführlicher die Kautionen des Appellationsverfahren ${ }^{198}$ ) mit der cautio legatorum vel fideicommissorum causa zu vergleichen. An diesem Punkt stellt sich nun die in der Literatur durchaus gegensätzlich beantwortete Frage, ob beide Arten von Kautionen in ein und demselben Verfahren oder aber vor einem Gericht des Formularverfahrens und einem Organ der cognitio (Appellation) abzugeben waren. Theoretisch kann sich die Antwort des Reskriptes (a) in ihrem ersten Teil (eum, a quo res fideicommissae petebantur, cum appellasset, cavere), sowohl auf eine Sicherungskaution vor dem praetor urbanus als auch auf eine freilich so nicht belegte Kaution vor dem praetor fideicommissarius beziehen; sicher ist allein, dass sie in ihrem zweiten Teil (vel, si caveat adversarius, ad adversarium transferri possessionem debere) das Appellationsverfahren, also ein Verfahren der cognitio, betrifft. Die von Papinian zur Abgrenzung vorgetragenen Argumente deuten freilich daraufhin, dass der Vergleichspunkt für die Appellationskautionen die Kautionspflicht des Formularverfahrens ist ${ }^{199}$ ):

${ }^{197}$ ) Die Appellation hat aufschiebende Wirkung; vgl. Kaser/Hack1 (Fn. 2) 509 mwN.

198) Zur cautio de exercendae provocatione vgl. auch C. 7,62,6,6 Diocl./Maxim. (s.a.); dazu Kipp (Fn. 193) 208.

199) Vor allem der quare-Satz gilt seit dem Humanismus als interpoliert; vgl. dazu Nachweise bei Babusiaux, Papinians Quaestiones (Fn. 85) 38 Fn. 192. Zur Vereinfachung des hier vorgezogenen Verständnisses, das auf die Emendation cavente bei Cujas zurückgreift, ein Übersetzungsvorschlag: ,.... (c) Aber warum hat er reskribiert, dass, wenn der Berufungskläger die Kaution hinsichtlich des Fideikommisses nicht abgegeben hatte, der Besitz, wenn der Gegner die Kaution leistete, auf ihn zu übertragen sei, obwohl die Rechtslage nach dem Edikt eine andere ist? (d) Denn vom Legatar wird nicht verlangt, wechselseitig Kaution zu leisten, sondern ihm wird zur Bewahrung der vorläufige Besitz zum Schutz eingeräumt. Und derjenige, der obsiegt hat, wird durch den praetor oder praeses in den Besitz eingewiesen. (e) Aber der praetor erlaubt zwar, dass er zum Schutz des Fideikommisses im Besitz aller Sachen sei, welche in jedem Fall in der Erbschaft verbleiben; der Kaiser aber hat mit Blick auf diejenigen Sachen, über die ein Urteil gesprochen worden war, gegenseitige Kautionsleistungen zugelassen, genauso, wie wenn der emanzipierte Sohn, nachdem er den Erbschaftsbesitz erhalten hat, hinsichtlich der Einwerfung seiner Sachen nicht die Kaution leisten kann. (f) Weil wir ihm ja die Klagen verweigern, geht die Pflicht zur Kautionsleistung nach der Vorschrift des Jurisdiktionsediktes auf die Brüder über, dass sie zurückerstatten werden, was sie als Erbteil des Bruders erhalten haben, sobald er begonnen hat, eigenes Vermögen einzuwerfen (...). Für philologischen Rat in dieser Sache danke ich Frau lic. phil. Thamar Xandry (Zürich). 
D. 36,3,5,1 Pap. 28 quaest. (...) (c) sed quare non caverat de fideicommisso qui provocaverit, si caveret adversarius, ad eum possessionem esse transferendam rescripsit, cum alia sit edicti condicio? (d) non enim exigitur a legatario vice mutua cautum, sed vicaria custodiae gratia possessio datur et qui optinuit in possessionem per praetorem aut praesidem inducitur. (e) sed praetor quidem in omnium rerum possessione, quae in causa hereditaria permanent omnimodo, fideicommissi servandi gratia esse permittit: princeps autem earum rerum nomine, de quibus fuerat iudicatum, mutuas admisit cautiones: sicuti, cum de bonis suis conferendis filius accepta possessione cavere non potest, (f) quia denegamus ei actiones, defertur condicio cavendi fratribus ex forma iurisdictionis, quod ex portione fratris fuerint consecuti, cum bona propria conferre coeperit, se restituturos (...)

Ausgangspunkt des Vergleichs ist die konsternierte Frage, warum nicht der in Berufung gehende Erbe die Kaution abgegeben hat, um die Besitzeinweisung des Fideikommissars zu verhindern (c). Der Fragesteller ist offensichtlich darüber verwundert, dass der Fideikommissar nur dann in den Besitz eingewiesen werden kann, wenn er selbst Sicherheit geleistet hat, denn das prätorische Edikt bestimmt, dass die missio als Zwangsmittel gegen den Erben schon dann eingreift, wenn der Erbe keine Kaution leistet (d). Papinian beantwortet diese Frage, indem er die vor dem princeps zu leistenden Kautionen von der Kautionspflicht des prätorischen Edikts (praetor) unterscheidet: So hält er zunächst fest, dass die cautio legatorum vel fideicommissorum servandorum causa das gesamte Vermögen erfasse, während sich die Kautionspflicht im Rahmen der Appellation nur auf die streitbefangene Sache beziehe $\left.{ }^{200}\right)$. Sodann erläutert der Jurist die Funktion der mutuae cautiones, die er durch Hinweis auf die Kautionen der collatio bonorum erklärt: Anders als die cautio rei servandae causa, welche die Erfüllung des Fideikommisses sichern solle, dienten die Kautionen der collatio wie der appellatio dazu, die Rückgabe einer hingegebenen Sache zu sichern (f) ${ }^{201}$ ). Aus dieser (abwei-

${ }^{200}$ ) Zur Rechtfertigung der kaiserlichen Regelung verweist Papinian auf das prätorische Edikt zur collatio bonorum des emanzipierten Haussohnes. Auch hier gehe es um gegenseitige Verpflichtungen (des emancipatus und der Hauskinder), die durch wechselseitige Kautionen gesichert würden; anders als bei der cautio legatorum vel fideicommissorum servandorum causa könne auch nach diesem Edikt die Besitzeinweisung nur erfolgen, wenn der Betreffende (Haussohn oder emancipatus) entsprechend Sicherheit geleistet habe (f). Unterbleibe im Rahmen der collatio bonorum emancipati eine Kaution von beiden Seiten, müsse das Vermögen von einem Sequester verwahrt werden.

${ }^{201}$ ) Der Verweis auf certa forma iurisdictionis meint das prätorische Edikt. Nicht begründet ist die Annahme von Giodice-Sabbatelli (Fn. 3) 167, die hierin eine Tendenz erkennen will, den kognitionalen Beamten Jurisdiktionsgewalt zuzuerkennen: „la tendenza di qualificare in senso giurisdizionale le attività dei magistrati specializzati in giudizi cognitori“. 
chenden) Funktion der cautio im Rahmen der Appellation rechtfertigt Papinian auch den Mechanismus der wechselseitigen Kautionspflicht: Sie treffe - genau wie bei der collatio bonorum des emancipatus - jeweils diejenige Partei, welche die im Streit befindliche Sache erhalten habe und daher deren Rückgabe versprechen müsse ${ }^{202}$ ). Dieser Funktion entspreche die Lösung in dem Fall, dass keine der Parteien die für die Appellation oder collatio bonorum notwendige Kaution erbringen könne: In diesem Fall sei die Sache bei einem sequester zu hinterlegen, der die Verwaltung des streitigen Vermögens übernehme (f).

Schon dieser Textauszug ${ }^{203}$ ) zeigt, dass Papinians Vergleich auf den abweichenden Vollstreckungsmöglichkeiten der cognitio im Verhältnis zum Formularverfahren beruht: Während der praetor dem Berechtigten nur sicherungsweise (und ohne tatsächlichen Sachbesitz) in die custodia der Erbschaft einweist, erhalten die Parteien in der Appellation einen realen Sachzugriff, der durch entsprechende Kautionen zugunsten des Gegners abgesichert wird (vgl. unter (d) qui optinuit in possessionem per praetorem aut praesidem inducitur $)^{204}$ ).

Führt man das Reskript zur Wirkung der cautio fideicommissorum servandorum causa und Papinians Vergleich dieser Kaution mit den Appellationskautionen zusammen, lässt sich das hier in Frage stehende Verfahren wie folgt skizzieren ${ }^{205}$ ): Ein Fideikommissar hat im Rahmen einer cognitio obsiegt; nunmehr müsste der Erbe - notfalls durch Zwang des Beamten - die fideikommissarische Sache herausgeben, weshalb er Berufung einlegt. Zur Sicherung seiner Forderung gegenüber anderen Erbschaftsgläubigern hat der

$\left.{ }^{202}\right) \mathrm{Zu}$ den Kautionen im Rahmen der collatio bonorum vgl. A. Guarino, Collatio bonorum, Neapel 1937, 150-154; A. Caballé Martorell, La collatio emancipati, Madrid 1997, $170 \mathrm{f}$.

${ }^{203}$ ) Zum Fortgang des Textes, der sich mit der Frage befasst, wie bei Ausbleiben jeglicher Kaution zu verfahren ist; vgl. B abu si a u x, Papinians Quaestiones (Fn. 85) 40 und G. Aricò Anselmo, Sequestro omittendae possessionis causa, AUPA 40 (1988) 217-341, 249.

${ }^{204}$ ) In ähnlichem Sinne wird iurisdictio gebraucht in C. 2,12,3 Sev./Ant. (a. 204) pr. Eum, qui res agit heredum, a quibus tibi deberi fideicommissum dicis, evoca ad praetorem virum clarissimum, qui aut respondere tibi cogetur aut administratione negotiorum secundum formam iurisdictionis prohibebitur. 1. Deliberabit autem praetor, si non defendat heredes, debeatne te mittere in possessionem, secutus iurisdictionem, quae exerceri adversus indefensos solet; dazu bereits A rcaria (Fn. 95) 265f., der das Fragment als Beleg für die Bevorzugung des praetor urbanus in der imperialen Rechtspolitik ansieht.

${ }^{205}$ ) Anders Röhle (Fn. 6) 419f. 
Fideikommissar vor dem für das Formularverfahren zuständigen praetor eine cautio fideicommissorum causa erwirkt, deren Bestand vom Ausgang der cognitio extra ordinem abhängt. Mit der Annahme paralleler Verfahren lässt sich die Differenz zwischen Ulpian und Papinian hinsichtlich der Wirkungen der litis contestatio auf die cautio fideicommissorum servandorum ganz einfach erklären: Ulpians Ansicht, die litis contestatio hebe die Kaution auf, ist allein auf das Formularverfahren zu beziehen; Papinian hingegen behandelt vorrangig die Frage, ob die (im Formularverfahren) abgegebene cautio fideicommissorum servandorum causa durch das Urteil in der cognitio, gegen das zudem Berufung eingelegt wurde, ihre Wirkung verliert. Dass dies - solange die Appellation nicht entschieden ist - dem Schutz des Fideikommissars zuwiderlaufen würde, ist einleuchtend, woraus sich die Aufrechterhaltung der Kaution auch nach der pronuntiatio erklärt.

Die hier angenommene Parallelität von cognitio und cautio fideicommissorum servandorum causa im ordentlichen Verfahren lässt sich auch an anderen Fragmenten beobachten.

a. Zur prozessualen Parallelität von cognitio und Formularverfahren mit Blick auf die cautio legatorum vel fideicommissorum causa:

So belegt ein Fragment aus Ulpians Ediktskommentar die praktische Relevanz der verfahrensrechtlichen Dualität $\left.{ }^{206}\right)$ :

D. 36,4,3pr.-1 Ulp. 52 ad ed. pr. Si is, a quo satis petitur, offerat cognitionem et dicat: ,hodie constet de fideicommisso, hodie agamus', dicendum est cessare satisdationem, cum possit ante de fideicommisso quam de satisdatione constare. $1 \mathrm{Nec}$ non illa cognitio imploranda erit ab herede, si forte dicatur per calumniam satis peti: hoc enim commune est omnium satisdationum. Divus enim Pius rescripsit eum, apud quem satis petitur, debere explorare, num per calumniam satis petatur: de qua re summatim debet cognoscere.

Im principium stellt der Jurist fest, dass die Kautionspflicht erlischt, wenn der Erbe, von dem Sicherheitsleistung ${ }^{207}$ ) verlangt wird, die cognitio anbietet, sich also bereit erklärt, noch am selben Tag (hodie) vor dem Beamten über die Wirksamkeit des Fideikommisses zu verhandeln. §1 dagegen betrifft umgekehrt das Verlangen einer cognitio durch den auf Kautionsleistung angegangenen Erben. Ulpian betont, dass auch der Erbe die Durchführung einer cognitio verlangen kann, wenn die Einforderung der Sicherheitsleistung schikanös ist, und beruft sich dafür auf ein Reskript des Antoninus Pi-

${ }^{206}$ ) Vgl. Le ene1, Palingenesia II (Fn. 36) Sp. 739-742 unter Pal. 1252; zur Exegese des Textes vgl. Simon (Fn. 22) 183-189.

${ }^{207}$ ) Hier satisdatio, die nicht für die Erfüllung im Rahmen der cognitio, sondern auch für die cautio rei servandae causa belegt ist. 
us, nach welchem die calumnia von demjenigen, apud quem satis petitur, in einem summarischen Verfahren festgestellt werden (summatim cognoscere) muss ${ }^{208}$ ). Die Feststellung der calumnia causae cognitio ist als Kompetenz des praetor im Formularverfahren auch andernorts belegt ${ }^{209}$ ): Das Reskript erstreckt diese Befugnis des ordentlichen Gerichtsmagistraten auch auf die Frage, ob das Verlangen einer Sicherheitsleistung für das Fideikommiss als Schikane anzusehen ist, etwa weil das Fideikommiss offensichtlich nicht besteht oder weil die Kautionspflicht erlassen wurde ${ }^{210}$ ).

Ulpians Gegenüberstellung ist in verschiedener Hinsicht aufschlussreich: Während der Begriff cognitio im principium offensichtlich die Befugnis des Beamten meint, der sich mit der Forderung des Fideikommisses zu befassen hat, verweist $\S 1$ auf die causae cognitio des Gerichtsmagistraten ${ }^{211}$ ). Das Fragment zeigt damit die bereits für Pap. 28 quaest. D. 36,5,3,1 angenommene Verfahrensteilung, denn die im principium ersichtliche Zusage des Beschwerten, die cognitio durchzuführen, lässt sich nur als Einverständnis zur Ladung vor den zuständigen Beamten auslegen. Hingegen wird dem ordentlichen Gerichtsmagistraten in $\S 1$ nur dann ein summarisches Prüfungsrecht für das Bestehen oder Nichtbestehen des Fideikommisses gewährt, wenn der Erbe calumnia des Fideikommissars behauptet.

${ }^{208}$ ) Für interpoliert hält dies noch Lemosse (Fn. 8) 144 Fn. 6; vgl. aber D. 36,3,14pr.-1 Ulp. 79 ad ed. pr. Haec stipulatio et in fideicommissis locum habet, sive pure fideicommissum sit relictum sive ex die certa vel incerta vel sub condicione, sive res aliqua sive hereditas sive ius aliquod relictum est. 1. Divus quoque Pius rescripsit, quotiens evidens res est, ut certum sit nullo modo fideicommisso locum esse, perquam iniquum esse supervacua cautione onerari heredem. Das Fragment lässt es möglich erscheinen, dass der Gerichtsmagistrat auch eine summarische Prüfung der Wirksamkeit des Fideikommisses durchführen konnte, bevor er den Erben zur Kaution zwang. Die Verdächtigung von summatim cognoscere als byzantinisch hat schon A. Steinwenter, Das Verfahren sine scriptis im justinianischen Prozeßrechte, ZRG RA 76 (1959) 306-323, 316 Fn. 28, zutreffend mit der Begründung zurückgewiesen, dass die Basiliken keine einheitliche Terminologie für den Begriff kennen; umfassend jetzt Simon (Fn. 22).

209) Vgl. Martini (Fn. 171) 143f. (mit zu weitreichenden Interpolationsannahmen). Zudem ist die causae cognitio für die Feststellung der calumnia auch sonst als ,ordentliche cognitio“ vor dem Gerichtsmagistraten belegt; vgl. Simon (Fn. 22) $170-183$.

${ }^{210}$ ) Der Vorwurf der calumnia ist nicht auf strafrechtliche Anklagen beschränkt, sondern findet sich auch in privatrechtlichen Zusammenhängen; vgl. D. 5,3,43 Paul. 2 ad Plaut. (zur hereditatis petitio); dazu A.M. Giom a ro, Per lo studio della calumnia, Aspetti di ,deontologia' processuale in Roma antica, Turin 2003, 95f.

${ }^{211}$ ) So auch Giomaro (Fn. 210) 99f., die dies allerdings als Argument gegen den Text verwendet. 
Die derart beschränkte Zuständigkeit des über die cautio fideicommissorum servandorum causa entscheidenden Magistraten wird durch ein Codexfragment bestätigt ${ }^{212}$ ):

C. 6,54,1 Divus Pius Salvio (s.a.) Imperator Pius. Quoniam nihil actor amplius postulat, quam ut fideicommissi nomine satisdetur, non debet is qui iuri dicendo praeest subtiliter cognoscere, debetur nec ne fideicommissum, sed tantum decernere, ut satisdetur.

Das nach der Inskription auf Antoninus Pius zurückzuführende Reskript betont, dass derjenige, qui iuri dicendo praeest, nur über den Antrag des Klägers auf Sicherheitsleistung entscheiden könne, keineswegs aber die Wirksamkeit des Fideikommisses umfassend prüfen dürfe. Die Deutung der Stelle ist von der Auslegung der Kompetenzumschreibung des Rechtsprechungsorgans is, qui iuri dicendo praeest abhängig. Die Formulierung iuri dicundo praeesse ist neben den Digesten auch in der lex Salpensana belegt, deren 26. Kapitel die Kompetenz der duoviri als Gerichtsmagistrate mit dieser Wendung beschreibt ${ }^{213}$ ). Vor allem aber wählt Pomponius ${ }^{214}$ ) den Ausdruck, um die Tätigkeit der Gerichtsmagistrate der Stadt Rom zu kennzeichnen. Schon diese beiden Parallelen sprechen gegen die häufig vertretene Ansicht, welche das Codexfragment auf den praetor fideicommissarius oder die consules bezieht ${ }^{215}$ ). Erkennt man nämlich mit Palazzolo an, dass kaiserliche Reskripte gerade auch in die Tätigkeit des Gerichtsmagistraten im Formularverfahren eingreifen konnten ${ }^{216}$ ), lässt sich aus der Zusammenschau von D.36,4,3,1 Ulp. 52 ad ed. und C.6,54,1 Divus Pius (s. a.) ein Grundsatz für die Prüfung des Fideikommisses vor der Erteilung der cautio fideicommissorum servandorum causa durch den praetor urbanus formulieren: So ist es dem Gerichtsmagistraten zwar erlaubt, summatim, namentlich die calumnia des beantragenden Fideikommissars zu prü-

${ }^{212}$ ) Wie hier Si mon (Fn. 22) 189f., der das Fragment als „Erläuterung des Kaisers zu seinem in D. 36,4,3,1 überlieferten Reskript" liest.

$\left.{ }^{213}\right)$ Lex Salpensana XXVI. Duoviri qui in eo municipio iure dicundo praesunt, item aediles qui in eo municipio sunt, item quaestores qui in eo municipio sunt, eorum quisque in diebus quinque proximis post hanc legem datam.

$\left.{ }^{214}\right)$ D. 1,2,2,13 Pomp. 1. s. ench. Post originem iuris et processum cognitum consequens est, ut de magistratuum nominibus et origine cognoscamus, quia, ut exposuimus, per eos qui iuri dicundo praesunt effectus rei accipitur: quantum est enim ius in civitate esse, nisi sint, qui iura regere possint? (...)

${ }^{215)}$ Vgl. Röhle (Fn. 6) 419 mit Fn. 66 zum Text: „Derpr. fid. soll nur darüber entscheiden: ist Sicherheit zu leisten oder nicht. Ob das Fideikommiß geschuldet ist, bleibt dahingestellt.“

${ }^{216}$ ) Palazzolo (Fn. 13) allgemein 37-43, 148 zum Text. 
fen, eine tiefergehende Prüfung (subtiliter cognoscere) wird ihm hingegen versagt $\left.{ }^{217}\right)$.

Mit der Annahme, dass der praetor des Formularverfahrens auch über die cautio fideicommissorum servandorum causa entscheidet, lassen sich auch zwei Fallgestaltungen, die Ulpian im weiteren Verlauf des Ediktskommentars diskutiert, prozessual plausibel erklären.

\section{b. Zur cautio bei mit Fideikommissen beschwerten Legataren:}

Die hier zu betrachtende Kommentierung zum Edikt ut in possessionem legatorum servandorum causa esse liceat ${ }^{218}$ ) betrifft die Beschwer von Legataren mit Fideikommissen:

D. 36,4,5,29 Ulp. 52 ad ed. Si Titio pure legatum fuerit et eius fidei commissum sub condicione, ut Sempronio restitueret, non inique praetorem statuturum Iulianus scripsit, si, antequam legatum consequatur legatarius, fideicommissi condicionalis satis non det, ut magis Sempronio det legati persecutionem, ut is legatario satisdet deficiente condicione reddi decem. Sed et si acceperit Titius ab herede decem, aequum esse Iulianus ait cogi eum invicem satisdare aut ipsa decem tradere et Sempronium Titio cavere: et hoc iure utimur, id enim et Marcellus ait.

Ulpian behandelt den Fall, dass Titius unter einer Bedingung gebeten worden ist, das, was er unbedingt durch Legat erworben hat, an den Sempronius herauszugeben ${ }^{219}$ ). Wenn der Legatar die Kaution zugunsten des Fideikommissars verweigert, weil er seine Forderung gegenüber dem Erben selbst noch nicht durchgesetzt hat, habe Julian es für richtig gehalten, wenn der praetor dem Sempronius die Legatsklage (persecutio legati) erteile, vorausgesetzt, dass er dem Legatar umgekehrt Sicherheit in Höhe von zehn für den Fall leiste, dass die Bedingung ausfalle ${ }^{220}$ ). Aber wenn Titius schon zehn vom Erben erhalten habe, sei es richtig, ihn zur Sicherheitsleistung zugunsten des Sempronius zu zwingen oder die zehn dem Sempronius gegen Sicherheitsleistung gegenüber dem Titius zu übergeben.

Aus prozessualer Perspektive, ist erneut eine Verfahrensdualität zu beobachten: Der Legatar kann sein Legat im Formularverfahren gegen den Erben durchsetzen, während der Fideikommissar seine Forderung in der cognitio extra ordinem einklagt. Was aber gilt für den Schutz des Fideikommissars

217) Gleichsinnig auch Müller-Eis elt (Fn. 135) 213 mit Fn. 253.

${ }^{218)}$ Lenel, Palingenesia II (Fn. 36) Sp. 1257.

$\left.{ }^{219}\right)$ Ohne Grund vermutet Röhle (Fn. 6) 411, dass der Text entgegen der Inskription aus den fideicommissis lib. VI Ulpians entstamme.

${ }^{220}$ ) Die Rechtsnatur dieser cautio ist zweifelhaft. Sie erinnert an die cautio de restituendo, wie sie im Formularprozess als cautio iudicialis im Rahmen von actiones in rem belegt ist; vgl. dazu A.M. Giomaro, ,Cautiones iudiciales' e ,officium iudicis', Mailand 1982, 39-70. 
gegenüber dem Legatar? Erneut nennt der Text den praetor als zuständigen Magistraten, womit prima facie der Gerichtsmagistrat des Formularverfahrens gemeint sein muss. Diese Lösung erscheint auch deshalb wahrscheinlich, weil Julian annimmt, dass der praetor dem Fideikommissar die Legatsklage erteilen kann ${ }^{221}$ ), wenn der Legatar die Leistung der cautio fideicommissorum servandorum causa verweigert ${ }^{222}$ ).

Anders liegt die Entscheidung in der Variante, die von einer traditio der dem Legatar vom Erben übergebenen decem auf den Fideikommissar spricht. Da hier die Realleistung an den Fideikommissar gegen entsprechende Rückgabestipulation als Rechtsfolge angenommen wird ${ }^{223}$ ), findet dieses Verfahren offenbar vor einem Beamten der cognitio statt. Diese prozessuale Scheidung lässt die bereits skizzierte Funktionsteilung zwischen Formularverfahren und cognitio extra ordinem mit Blick auf Einzelfideikommisse deutlich hervortreten: Sucht der Fideikommissar Sicherung gegen Zwischenverfügungen oder Vermögensverfall des Beschwerten, wird er die cautio fideicommissorum servandorum causa wie ein Legatar verlangen, das heißt den Erben oder Legatar vor dem praetor urbanus auf Kautionsleistung belangen. Soweit die Durchsetzung des (bedingten) Fideikommisses in Frage steht, wird der Begünstigte dagegen im Wege der cognitio vorgehen, da ihm diese - sofern der Legatar schon über erbschaftliches Vermögen verfügt einen sofortigen Sachzugriff auf die Sache verspricht.

Diese Aufteilung der Kompetenzen findet sich auch im anschließenden, von Ulpian selbst gebildeten Fall, in dem auch das Legat unter einer Bedingung hinterlassen worden ist:

D. 36,4,5,30 Ulp. 52 ad ed. Quid ergo, si et legatum sub condicione sit relictum et fideicommissum, neque fideicommissi satisdetur? Aequissimum erit fideicommissarium nomine legati satis accipere ab herede, si ei legatarius non caveat, scilicet ut et ipse legatario caveat. Quod si iam accepit legatarius ab herede satis, decernendum erit ex ea satisdatione magis fideicommissario quam legatario dandam actionem, in eum scilicet casum, quod fideicommissi eius condicio extitit: ipsius

${ }^{221)}$ Vgl. auch D. 36,4,10 Paul. 3 sent. Si nullae sint res hereditariae, in quas legatarii vel fideicommissarii mittantur, in rem quidem heredis mitti non possunt, sed per praetorem denegatas heredi actiones ipsi persequuntur; dazu De Robertis (Fn. 78) $21 f$.

222) Diese Fiktion ist gerade ein Merkmal des prätorischen Rechts und muss nicht auf die cognitio extra ordinem weisen; vgl. Ka se r/Hackl (Fn. 2) 329-331 zu verschiedenen Erscheinungsformen.

223) Dass es hier um ein anderes Verfahren geht, zeigt sich auch in der Formulierung: aequum esse Iulianus ait cogi eum invicem satisdare aut ipsa decem tradere et Sempronium Titio cavere. 
etiam legati persecutio danda erit fideicommissario, si nondum solutum est et condicio eius extitit, scilicet si fuerit fideicommissarius paratus cavere legatario.

Für diese Konstellation sind nach Ulpian drei Varianten zu unterscheiden: Im ersten Fall hat der Erbe noch keine cautio legatorum servandorum causa geleistet, weshalb der Fideikommissar nomine legati vom Erben Kaution verlangen kann, wenn er seinerseits bereit ist, Sicherheit zu leisten. Im zweiten Fall hat der Erbe dem Legatar schon die cautio versprochen, weshalb der Fideikommissar aus der Kaution vorgehen kann, wenn die Bedingung für das Fideikommiss eingetreten ist ${ }^{224}$ ). Im dritten Fall schließlich wird dem Fideikommissar die Legatsklage erteilt, wenn der Legatar das Fideikommiss trotz Bedingungseintritt nicht erfüllt hat, und der Fideikommissar seinerseits Sicherheit leistet.

Im Einklang mit dem vorangehenden Beispiel von Julian kann - sofern der praetor dem Fideikommissar die dem Legatar zustehenden Klagen zugesteht - auch für Ulpians Fälle vom ordentlichen Verfahren ausgegangen werden. Über Julian hinaus reicht allein die erste Variante Ulpians, in dem der Fideikommissar die cautio legatorum servandorum causa gegen den Erben erheben kann, also ein prätorisches Zwangsmittel übertragen erhält. Allerdings gibt es auch für diese Fallgestaltung keinen Anlass, von einer cognitio extra ordinem auszugehen, da der Gerichtsmagistrat auch in anderen Zusammenhängen Berechtigte austauschen und durch formulare Fiktion die Aktiv- und Passivlegitimation anpassen kann ${ }^{225}$ ).

Alle betrachteten Fragmente untermauern mithin Arcarias These, dass die cautio fideicommissorum servandorum causa - genau wie die cautio legatorum servandorum causa - im Formularverfahren vor dem ordentlichen praetor geltend zu machen war und damit kein Vollstreckungs-, sondern ein Sicherungsmittel gegenüber dem durch das Fideikommiss beschwerten Erben oder Legatar darstellte.

Diese Annahme einer Sicherung des Fideikommissars im Formularverfahren wirft allerdings die Frage auf, wie sich diese Kautionspflicht und die mit ihr verbundene missio zu der bereits oben untersuchten exekutorischen missio des Kognitionsverfahrens, insbesondere zur sog. missio Antoniniana,

${ }^{224}$ ) Umstritten ist, ob persecutio legati auf die cognitio extra ordinem weist. Zur Diskussion (ablehnend) F. Sturm, Stipulatio Aquiliana, Textgestalt und Tragweite der Aquilianischen Ausgleichsquittung im klassischen römischen Recht, München 1972, 154f.; zum umfassenderen Gehalt des Begriffs vgl. auch Giodice-Sabbatelli (Fn. 3) 183-187 und 201-218.

${ }^{225}$ ) L. Di Lella, Formulae ficticiae, Contributo allo studio della riforma giudiciaria di Augusto 1984, bes. 33-47. 
verhält (s. o. II.3b/c). Indizien zur Abgrenzung verspricht Ulpians weitergehende Kommentierung der missio Antoniniana (D. 36,4,5,21-30 Ulp. 52 ad ed.), welche Divergenzen zwischen dem außerordentlichen Rechtsmittel und der missio rei servandae causa des Formularverfahrens thematisiert.

3. Zum Vergleich von missio Antoniniana und missio rei servandae causa in Ulpians Ediktskommentar, D. 36, 4, 5, 21-30 Ulp. 52 ad ed.:

Dieser Teil des ulpianischen Ediktskommentars hat wenig Beachtung gefunden, vermutlich, weil man die Ausführungen meist pauschal für interpoliert gehalten hat $\left.{ }^{22}\right)$. In der Tat ist der Abschnitt schwer verständlich, was vor allem daran liegt, dass der Jurist scheinbar willkürlich zwischen fideicommissum und legatum hin- und herzuspringen scheint ${ }^{227}$ ). Gerade dieser Wechsel kann jedoch als Indiz dafür angesehen werden, dass Ulpian ursprünglich einen Vergleich zwischen exekutorischer missio der cognitio und missio rei servandae causa intendierte. Da die missio in rem im justinianischen Recht aufgehoben (vgl. oben II.3.a) und der Unterschied zwischen exekutorischer und sichernder missio durch die einheitliche Geltung des Kognitionsverfahrens entfallen war $^{228}$ ), ist weiter vorstellbar, dass Ulpians Vergleich von den Kompilatoren zu einer Gesamtdarstellung einer scheinbar einheitlichen missio gekürzt wurde. Tritt man mit dieser Prämisse an den Text heran, ergeben sich erstens weiterführende Klärungsmöglichkeiten zu dessen Inhalt, zweitens lassen sich Anhaltspunkte dafür finden, dass die Dualität von exekutorischer missio und missio rei servandae causa vor allem mit Blick auf die das Schuldnervermögen betreffende missio Antoniniana zu schwierigen Abgrenzungsproblemen führen konnte ${ }^{229}$ ).

a. Fruchtziehungsrecht bei der missio Antoniniana und der missio rei servandae causa:

In den ersten beiden Abschnitten der hier zu betrachtenden Kommentierung $(\S \S 21,22)$ behandelt Ulpian das Fruchtziehungsrecht des in den Besitz eingewiesenen Vermächtnisnehmers, wobei er einerseits vom Legatar und legatum, andererseits vom Fideikommissar und fideicommissum spricht. Un-

${ }^{226}$ ) Nachweise zu D. 36,4,5,16-30 Ulp. 52 ad ed. bei Kaser/Hackl (Fn. 2) 428 Fn. 13; Interpolationsverdächtigungen insbes. bei Röhle (Fn. 6) 410.

${ }^{227}$ ) Fehlgehend daher die Emendationen bei Röhle (Fn. 6) 412f.

$\left.{ }^{228}\right)$ Zum justinianischen Kognitionsverfahren vgl. Kaser/Hackl (Fn. 2) 623-630 mwN.

${ }^{229}$ ) Die missio rei servandae causa führt ja ebenfalls zur Einweisung des Legatars/Fideikommissars in den Besitz ,gemeinsam mit dem Erben', erstreckt sich also auch auf das Erbenvermögen; vgl. Lepri (Fn. 99) 113-118. 
terstellt man, dass legatum idealtpyisch für die sichernde missio, fideicommissum hingegen für die missio Antoniniana verwendet wird, handelt $\S 21$ von der missio Antoniniana:

D. 36,4,5,21 Ulp. 52 ad ed. Quaeri poterit, an in vicem usurarum hi fructus cedant, quae in fideicommissis debentur. Et cum exemplum pignorum sequimur, id quod ex fructibus percipitur primum in usuras, mox, si quid superfluum est, in sortem debet imputari: quin immo et si amplius quam sibi debetur perceperit legatarius, exemplo pigneraticiae actionis etiam utilis actio ad id refundendum dari debebit. Sed pignora quidem quis et distrahere potest, hic autem frui tantum ei constitutio permisit, ut festinetur ad sententiam.

$\S 22$ ist hingegen der der ediktalen missio in possessionem gewidmet:

D. 36,4,5,22 Ulp. 52 ad ed. Qui legatorum servandorum causa in possessionem mittitur, et fructus custodire et cetera debebit. Et pati quidem heredem colere agros et fructus redigere, sed custodire legatarium fructus oportebit, ne ab herede consumantur: quod si heres fructus nolit cogere, permittendum erit legatario cogere fructus et coactos servare. Quin immo si tales sint fructus, quos primo quoque tempore venire expediat, vendere quoque legatario permittendum est et pretium servare. In ceteris quoque rebus hereditariis missi in possessionem hoc erit officium, ut universas res hereditarias colligat et ibi custodiat, ubi domicilium defunctus habuit, et, si nulla domus sit, habitationem conducat vel horreum quoddam, in quo res collectae custodiantur. Et puto ita legatarium custodire res hereditarias debere, ut neque heredi auferantur neque depereant deterioresve fiant.

Während der Fideikommissar im Rahmen der missio Antoniniana die Früchte aus dem Vermögen des Erben ziehen kann, wobei diese vorrangig auf die geschuldeten Zinsen und sodann auf die Hauptschuld angerechnet werden $\left.(\S 21)^{230}\right)$, ist der Legatar nach $\S 22$ zur sorgfältigen Aufbewahrung (custodia) der Früchte verpflichtet und darf diese nur dann ernten, wenn der Erbe sie nicht selbst einbringen will. Nur wenn die Früchte verderblich sind, darf der Legatar sie auch verkaufen und stattdessen das Geld als Sicherheit verwahren $^{231}$ ). Schon diese Gegenüberstellung der unterschiedlichen Kompetenzen mit Blick auf die Früchte zeigt, dass $\S 21$ und $\S 22$ nicht auf die gleiche Person bezogen werden können.

Dieser Eindruck lässt sich durch einen Blick auf die Passagen mit Personenwechsel erhärten: So wird in $\S 21$ nach der Darlegung der Rolle des Fideikommissars mit quin immo auf den Legatar geschwenkt, indem es heißt, dass der Legatar das, was er zuviel erhalten habe, aufgrund einer an die

$\left.{ }^{230}\right) \mathrm{Zu}$ Anrechnung der Früchte beim Pfand vgl. M. Kaser, Studien zum römischen Pfandrecht, II: Actio fiduciae und actio pigneraticiae, TR 47 (1979) 319-345, 333 Fn. 295

${ }^{231}$ ) Auch G. Wesener, Actiones ad exemplum, ZRG RA 75 (1958) 220-250, 232f. betont, dass in $\S 21$ die beiden Arten der missio zu unterscheiden seien. 
Pfandklage angelehnten Klage (exemplo pigneraticiae actionis etiam utilis actio $)^{232}$ ) herausgeben müsse. Der Anschluss mit quin immo setzt eine Steigerung voraus. Nach der überlieferten Textgestalt ergibt sich diese aus der Weiterführung der Analogie zum Pfandrecht, indem auch die Haftung des Gläubigers nach dem Vorbild des Pfandrechts bestimmt wird. Führt man sich freilich vor Augen, dass der Legatar nur ein Sicherungsrecht am Vermögen des Beschwerten erhält und sich - wie in $\S 22$ deutlich gesagt wird - gerade nicht aus der Sache befriedigen kann, erscheint die Anlehnung an die Pfandrechtsklage auf das superfluum fehlgehend, selbst wenn die missio rei servandae causa mit Blick auf ihre Sicherungsfunktion bisweilen mit einem Pfand verglichen wird ${ }^{233}$ ). Die in $\S 21$ vorgenommene Gleichstellung des missus mit einem Pfandgläubiger passt dagegen ohne weiteres zum Fideikommissar, der zur Befriedigung in das Vermögen des Erben eingewiesen wurde und hierbei zu viel an Früchten gezogen hat. Daher liegt der Schluss nahe, dass der mit quin immo eingeleitete Wechsel vom Fideikommissar zum Legatar auf einer Kürzung beruht, welche die ursprünglichen Unterschiede zwischen den beiden Positionen verdunkelt.

Eine vergleichbare Hypothese lässt sich mit Blick auf $\S 22$ formulieren ${ }^{234}$ ): Der erste Teil des Textes (qui legatorum servandorum causa in possessionem mittitur, et fructus custodire et cetera debebit) beschreibt die Position des Legatars mit Blick auf die Früchte et cetera $^{235}$ ) als custodia, was sich als Bewachungsverpflichtung wiedergeben lässt ${ }^{236}$ ). Hingegen lautet der zweite Teil des Textes: in ceteris quoque rebus hereditariis missi in possessionem hoc erit officium, ut universas res hereditarias colligat et ibi custodiat, ubi domicilium defunctus habuit. Es wird also gesagt, dass die übrigen erbschaftlichen Sachen, die nicht Früchte oder fruchtähnlich sind, vom Eingewiesenen zusammengetragen und am Wohnsitz des Verstorbenen aufbewahrt werden

${ }^{232}$ ) Zu dieser Klage vgl. We sener (Fn. 231) 233 Fn. 70 mwN.

$\left.{ }^{233}\right)$ C. 6,54,3 Sev./Ant. (196); dazu H. Wagner, Die Entwicklung der Legalhypotheken am Schuldnervermögen im Römischen Recht (bis zur Zeit Diokletians), Köln 1974, 70-73 und 100.

${ }^{234}$ ) Solazzi, Concorso I (Fn. 138) 188 beschränkt sich auf die Feststellung, dass der Legatar die Früchte unter bestimmten Voraussetzungen verkaufen könne.

${ }^{235}$ ) Hinter et cetera könnte sich partus ancillae verbergen; vgl. dazu M. Ka ser, Partus ancillae, ZRG RA 75 (1958) 156-200, 193f., der betont, dass die Früchte und der partus ancillae als Vermehrung der Erbschaft das Schicksal der Gesamtsache teilen und daher auch Teil der missio sind.

${ }^{236}$ ) Zur (insofern parallelen) custodia venditoris vgl. M. Pennitz, Das periculum rei venditae, Ein Beitrag zum ,aktionenrechtlichen Denken' im römischen Privatrecht, Wien 2000, 380-408. 
müssen. Nach der überlieferten Textgestalt kommentiert Ulpian also unterschiedliche Gegenstände der missio in possessionem mit Blick auf den Legatar. Indes ist die Unterscheidung von Früchten und sonstigem Vermögen des Erben für die cautio legatorum servandorum causa und die an sie anschließende missio nicht zielführend, da die missio rei servandae causa nicht nach Vermögensbestandteilen unterscheidet, sondern allgemein die erbschaftlichen Sachen, und damit auch Früchte und sonstigen Vorteile, erfasst ${ }^{237}$ ). Diese im Text zugrundegelegte Unterscheidung hinsichtlich der Befugnisse des missus fügt sich hingegen gut zu der für die cognitio extra ordinem beobachteten Differenzierung zwischen der exekutorischen missio in die Sache selbst und der missio Antoniniana in die Früchte des Vermögens des Erben (s. oben II.3a-c). Es besteht daher die plausible Möglichkeit, dass der Anschluss mit in ceteris nicht auf den Legatar, sondern auf den Fideikommissar und die ihm zustehenden missiones zu beziehen ist. Unter dieser Prämisse wäre somit auch für diesen Textteil von einer Kürzung auszugehen, welche dazu diente, die Unterschiede zwischen den missiones der cognitio extra ordinem und der missio rei servandae causa des Formularprozesses zu nivellieren.

Mit dieser Annahme wird auch der unmittelbare Fortgang des Textes einsichtig. So betrifft $\S 23$ der Kommentierung das Zusammentreffen von prätorischer missio in possessione und der missio Antoniniana:

D. 36,4,5,23 Ulp. 52 ad ed. Quod si ex constitutione quis in possessionem mittatur, curandum est, ne vis fiat utenti et fruenti legatario.

Hier betont Ulpian, die missio Antoniniana dürfe nicht dazu führen, dass der Legatar Gewalt erleide, indem der missus ex constitutione die Sache nutze $^{238}$ ) und ihre Früchte ziehe ${ }^{239}$ ). Auch diese Forderung des Juristen erklärt sich am einfachsten aus der Gegenüberstellung des durch die missio Antoniniana geschützten Fideikommissars und des durch die ediktale missio protegierten Legatars: Während der Fideikommissar den tatsächlichen Sachzugriff erhält und sogar die Früchte selbst ziehen kann, ist der Legatar auf den Interdiktenschutz angewiesen. Dieser Schutz wird durch ne vis fiat

${ }^{237}$ ) Vgl. Lenel, ${ }^{3} \mathrm{EP}$ (Fn. 70) 370: „simul cum herede in possessionem bonorum, quae in causa hereditaria erunt ... esse iubebo."

${ }^{238}$ ) Das Deponens uti, utor bedeutet ,nutzen, benutzen'. Utenti ist Dativ Singular des Partizips Präsens Aktiv. Wenn es sich auf die früheren Benutzer beziehen sollte, müsste das Wort im Plural (utentibus) stehen.

$\left.{ }^{239}\right)$ Hulot übersetzt: „(...) que le légataire (...) ne fasse aucun violence et n'empêche pas l'usage ou la jouissance des autres légataires déjà envoyés en possession“. Möglich wäre auch, utenti und fruenti insofern auf den Legatar zu beziehen, dass ihm in seiner Benutzung und Fruchtziehung keine Gewalt geschieht. 
evoziert, womit das Interdikt ne vis fiat ei qui legatorum vel fideicommissorum servandorum causa in possessionem missus erit angesprochen ist (vgl. oben II.3.a $)^{240}$ ).

Für die aufgeworfene Frage des Verhältnisses von missio fideicommissorum servandorum causa und exekutorischer missio ist damit für Ulpians Zeit nicht nur eine gewisse Verunsicherung, sondern vor allem auch ein eindeutiges Übergewicht des zur Befriedigung eingewiesenen missus zu beobachten, welches Ulpian zum Anlass nimmt, die Interessenwahrung der Legatare anzumahnen (§23). Allerdings wirft der Fortgang der ulpianischen Kommentierung die Frage auf, ob nicht Legatare zunehmend auch in den Genuss der Naturalexekution aus der cognitio extra ordinem kommen konnten ${ }^{241}$ ):

D. 36,4,5,27 Ulp. 52 ad ed. Missus in possessionem si non admittatur, habet interdictum propositum: aut per viatorem aut per officialem praefecti aut per magistratus introducendus est in possessionem.

Erneut könnten in diesem Fragment zwei Rechtsbehelfe ineinandergeflossen sein, wenn der Text einerseits betont, dass der missus in possessionem den Interdiktenschutz habe, ihm aber andererseits auch die Einführung in den Besitz durch Gerichtsdiener, Präfekt oder Magistraten verspricht. Diese Vermengung widerspricht Ulpians eigenen Ausführungen an anderer Stelle, die klar zwischen cognitio extra ordinem und Formularverfahren unterscheiden (D. 43,4,3pr. Ulp. 68 ad ed., dazu oben II.1.a). Der Vergleich zum Ausschnitt aus dem 68. Buch der ulpianischen Kommentierung spricht daher mit aller Deutlichkeit dafür, dass der hier zitierte Auszug aus dem 52. Buch von Ulpians libri ad edictum gekürzt und dadurch verfälscht wurde. Vor allem aber führen beide Fragmente zur Frage, ob nicht die cognitio extra ordinem in der späten Servererzeit auch auf Legate Anwendung finden konnte.

4. Rechtsschutz in der cognitio extra ordinem für Legate?

Die späte Severerzeit ist durch einen Zuwachs an Bürokratie und durch eine Professionalisierung des Ämterwesens gekennzeichnet ${ }^{242}$ ). In diesem Zusammenhang hat sich - wie Coriat gezeigt hat - auch der Zugriff des

${ }^{240}$ ) Das Interdikt wird von L. Labruna, Vim fieri veto, Alle radici di una ideologia, Camerino 1971, nicht behandelt; knapp zu diesem zuletzt del Pilar Pérez Álvarez (Fn. 138) 177f.

${ }^{241}$ ) Nachweise zum Text bei Ra madier (Fn. 66) 76-78; Palazzolo (Fn. 13) 167 Fn. 106; Betancourt, AHDE 52 (Fn. 66) 483-487.

242) Vgl. P. Eich, Zur Metamorphose des politischen Systems in der römischen Kaiserzeit, Die Entstehung einer personalen Bürokratie im langen dritten Jahrhundert, Berlin 2005, bes. 370-383. 
princeps auf Rechtsprechung und Rechtssetzung intensiviert ${ }^{243}$ ). Einen klaren Beleg für diese Tendenz bilden die bereits gestreiften Verweise auf die cognitio extra ordinem in Ulpians Kommentar zum Edikt, wobei namentlich der Hinweis, ein prätorischer Rechtsbehelf sei angesichts eines neuen, in der cognitio verfügbaren Rechtsmittels ${ }^{244}$ ) entbehrlich geworden ${ }^{245}$ ), bezeichnend ist.

\section{a. Per omnia exaequata sunt legata fideicommissis:}

In einem solchen Vergleichskontext fällt auch die meist als justinianische Interpolation angesehene Bemerkung Ulpians: per omnia exaequata sunt legata fideicommissis ${ }^{24}$ ), welche auf den ersten Blick an Inst. 2,20,3 necessarium esse duximus omnia legata fideicommissis exaequare, ut nulla sit inter ea differentia ${ }^{247}$ ) erinnert. Bei näherer Betrachtung ist die Annahme einer Interpolation allerdings nicht zwingend, denn Justinians Reform zielt nicht auf die Gleichsetzung der Legate mit den Fideikommissen, sondern auf die Beseitigung aller noch bestehender Unterschiede zwischen beiden Vermächtnisarten. Daher liegt nahe, dass Ulpians Satz aus dem Zusammenhang gerissen wurde und möglicherweise spezifischeren Gehalt hatte. Allerdings scheint der palingenetische Kontext dieser Annahme zunächst nicht günstig, weil Ulpians Bemerkung auf das Interdikt quod legatorum bezogen ist und damit auf einen Rechtsbehelf gegen den Legatar ${ }^{248}$ ), der allenfalls umgekehrt

${ }^{243}$ ) Zu dieser vgl. J.- P. Coriat, Le prince législateur, La technique législative des Sévères et les méthodes de création du droit impérial à la fin du principat, Paris 1997, bes. 453-458.

${ }^{244}$ ) Es gibt keinen Grund, wie Berger (Fn. 71) bes. 176f. sowie ders., s. v. interdictum, in: RE IX,2, Stuttgart 1916, Sp. 1609-1707, Sp. 1704f., die Überschneidung von Rechtsbehelfen extra ordinem und Interdikten als Interpolation zu verdächtigen; zutreffend bereits G.I. Luzzat to, Il problema d'origine del processo extra ordinem, I: Premessi di metodo, I cosiddetti rimedi pretori, Bologna 1965, 305f.

${ }^{245}$ ) Dies gilt namentlich für das Interdikt de migrando, das dem inquilinus erlaubt, wegzugehen: D. 43,32,1,1-2 Ulp. 73 ad ed. 1 Hoc interdictum proponitur inquilino, qui soluta pensione vult migrare: nam colono non competit. 2 Cui rei etiam extra ordinem subveniri potest: ergo infrequens est hoc interdictum.

${ }^{246}$ ) D. 30,1 Ulp. 67 ad ed.; dazu Voci (Fn. 135) 237: ,una celebre interpolazione“; vorsichtiger Johnston, Law of Trusts (Fn. 3) 256-260.

${ }^{247}$ ) Der Kontext der justinianischen Aussage ist umstritten; vgl. S. Riccobono, Legati e fedecommessi, Verba e voluntas, in: Mélanges Cornil II, Paris 1926, 348-374, 349-352; K. - H. S ch ind ler, Justinians Haltung zur Klassik, Köln 1966, 233; Voci (Fn. 135) 235-237 Fn. 57; weitere Nachweise bei Johnston, Law of Trusts (Fn. 3) 251f. Fn. 89.

$\left.{ }^{248}\right)$ D. 43,3,1,2 Ulp. 67 ad ed. Est autem et ipsum apiscendae possessionis et continet hanc causam, ut, quod quis legatorum nomine non ex voluntate heredis occupa- 
auf den Fideikommissar übertragen worden sein könnte ${ }^{249}$ ). Allerdings ist auch vorstellbar, dass der für die cognitio typische Sachzugriff deshalb in der Kommentierung des Interdikts quod legatorum erwähnt wird, weil er sich auf dessen Geltendmachung auswirkt ${ }^{250}$ ). Zwar eignet sich die cognitio extra ordinem nicht als alternativer Rechtsschutz zum Interdikt quod legatorum $^{251}$ ); ein Zusammenhang zwischen beiden besteht aber insofern, als ein Legatar, der den unmittelbaren Sachzugriff erhalten will, im Wege der cognitio die Herausgabe verlangen könnte. Ulpian könnte also gemeint haben, dass die Vollstreckung nach den Grundsätzen des Kognitionsverfahrens, den Anwendungsbereich und die Funktion des Interdikts quod legatorum veränderte. Durch die Einzelvollstreckung zugunsten des Legatars würde nämlich die für das Formularverfahren Zuweisung von Besitz und Parteirollen gestört.

Diese Annahme lässt sich anhand des palingenetischen Kontextes ${ }^{252}$ ) erhärten: Nach Lenel beginnt Ulpians Kommentierung mit dem Ediktslob ${ }^{253}$ ), welches den Zweck des Interdikts darin sieht, den Erben vor der Eigenmacht des Legatars zu schützen. Der Vermächtnisnehmer soll vielmehr gezwungen sein, gegen den Erben gerichtlich vorzugehen. Nachdem Ulpian (§3) betont hat, dass das Interdikt auch dem Erbeserben und dem bonorum possessor zusteht ${ }^{254}$ ), nicht aber sonstigen Rechtsnachfolgern ${ }^{255}$ ),

vit, id restituat heredi (...); dazu zuletzt Y. González Roldán, Il diritto ereditario in età adrianea, Legislazione imperiale e senatus consulta, Bari 2014, 169 mit Fn. 3. Zum Interdikt vgl. ausführlich F. Betancourt, El libro anonimo ,de interdictis', Codex Vaticanus Latinus No 5766, Sevilla 1997, 525-579.

${ }^{249}$ ) So in der Tat Lotmar (Fn. 184) 123f., und auch noch Johnston, Law of Trusts (Fn. 3) 256-259.

${ }^{250}$ ) Eine abweichende Rekonstruktion des Zusammenhangs bei A. Palermo, Il procedimento cauzionale nel diritto romano, Milano 1942, 93; dagegen bereits Luzzatto (Fn. 244) 304 Fn. 1.

${ }^{251}$ ) Rekonstruktion bei Lenel, ${ }^{3} \mathrm{EP}$ (Fn. 70) 453: Quod de his bonis, quorum possessio ex edicto meo illi data est, legatorum nomine non voluntate illius possides quodque dolo malo fecisti quo minus possideres, id, si eo nomine satisdatum est sive per illum non stat ut satisdetur, illi restituas.

252) Lenel, Palingenesia II (Fn. 36) Sp. 802, ordnet die Aussage in Pal. 1467 als Zwischenstück zwischen D. 43,3,1,4 Ulp. 67 ad ed. und D.43,3,1,5-15 Ulp. 67 ad ed. ein.

$\left.{ }^{253}\right)$ D. 43,3,1,2 Ulp. 67 ad ed. Etenim aequissimum praetori visum est unumquemque non sibi ipsum ius dicere occupatis legatis, sed ab herede petere: redigit igitur ad heredes per hoc interdictum ea, quae legatorum nomine possidentur, ut perinde legatarii possint eum convenire.

${ }^{254}$ ) Für interpoliert hält dies Berger (Fn. 244) 1661f.

${ }^{255}$ ) Bei dieser letzten Bemerkung ist namentlich an den Erbschaftsfideikommissar zu denken, der ja - wie gesehen (s. o. I.2) - ediktal in mancher Hinsicht dem 
fragt er sodann (§4), wie zu verfahren sei, wenn Unsicherheit über den Besitztitel des Inhabers der Sache bestehe. In seiner Antwort bezieht sich Ulpian zunächst auf Arrianus, der dem Erben empfiehlt, sowohl die hereditatis petitio als auch das interdictum quod legatorum $\mathrm{zu}$ erheben ${ }^{256}$ ). Und genau an diese prozesstaktische Erwägung knüpft nun der severische Jurist seine Bemerkung zur Gleichsetzung von Legaten mit Fideikommissen an. Aufgrund dieses Zusammenhangs könnte damit in der Tat gemeint sein, dass Legate wie Fideikommisse durch unmittelbaren Zwang gegenüber dem Erben durchgesetzt werden können und zur Einzelvollstreckung führen. Damit aber könnte der Legatar mithilfe der cognitio extra ordinem die dem Erben im Formularverfahren zustehenden Rechtsbehelfe (hereditatis petitio; interdictum quod legatorum) entwerten. Wenn der Legatar durch ein Kognitionsverfahren unmittelbaren Zugriff auf die Sache erhält, erscheint es widersprüchlich, dem Erben seinerseits Interdiktenschutz gegen den Legatar zur Rückforderung der Sache zu gewähren ${ }^{257}$ ). Soweit dem Legatar also Rechtsschutz in der cognitio extra ordinem zustände, wäre das interdictum quod legatorum gegenstandslos, was der von Ulpian allgemein beobachteten Tendenz, ediktale Rechtsbehelfe durch cognitio extra ordinem zu verdrängen, entspräche.

$\mathrm{Zu}$ ergänzen ist, dass anders als die Erstreckung der für Legate geltenden formularen Rechtsbehelfen auf Fideikommisse, die Erweiterung des Rechtsschutzes der Kognition auf Legate wegen der Formlosigkeit der kaiserrechtlich anerkannten Vermächtnisse keiner besonderen Begründung bedurfte; vielmehr konnte der im Legat zum Ausdruck gekommene Wille genauso Grundlage der Rechtsfolgenbestimmung des Beamten sein wie der im Fideikommiss formlos ausgedrückte Wunsch ${ }^{258}$ ).

bonorum possessor angenähert wird, den Schutz des Interdikts aber offensichtlich deshalb nicht benötigt, weil ihm ja das Recht zur Restitution aus dem SC Pegasianum zukommt.

${ }^{256}$ ) D. 43,3,1,4 Ulp. 67 ad ed. Quia autem nonnumquam incertum est, utrum quis pro legato an pro herede vel pro possessore possideat, bellissime Arrianus scribit hereditatis petitionem instituendam et hoc interdictum reddendum, ut, sive quis pro herede vel pro possessore sive pro legato possideat, hoc interdicto teneatur: quemadmodum solemus facere, quotiens incertum est, quae potius actio teneat: nam duas dictamus protestati ex altera nos velle consequi quod nos contingit.

${ }^{257}$ ) Dazu passt, dass D. 43,3,1,9 Ulp. 67 ad ed. die Passivlegitimation des missus in possessionem für das Interdikt quod legatorum bejaht; vgl. B et a n c ourt, AHDE 52 (Fn. 66) 400-402.

${ }^{258}$ ) Vgl. auch D. 32,11,12 Ulp. 2 fideicomm.; dazu Riccobono, Legati e fedecommessi (Fn. 247) 353f.; Jo h n st on, Law of Trusts (Fn. 3) 264-269. 


\section{b. Legate vor dem praetor fideicommissarius:}

Dass in der Tat jedenfalls in der Severerzeit Legate bisweilen auch vor dem praetor fideicommissarius geltend gemacht wurden, belegt:

D. 32,78,6 Paul. 2 ad Vitell. Cum vir ita legasset: ,quae uxoris causa parata sunt, ei do lego', ego apud praetorem fideicommissarium petebam etiam res aestimatas, quarum pretium in dotem erat ${ }^{259}$ ), nec optinui, quasi testator non sensisset de his rebus. atquin si in usum eius datae sint, nihil interest, ab ipsa an ab alio comparatae sunt (...)

Der aus den ad Vitellium libri $I V^{260}$ ) stammende Fall betrifft ein nach den traditionellen Regeln formuliertes Vindikationslegat, das ein Ehemann zugunsten seiner Ehefrau ausgesetzt hat ${ }^{261}$ ). Der Inhalt des Legates wird dabei so umschrieben, dass alles, was für die Ehefrau erworben worden ist (parata sunt), vermacht sein soll262). Ego als Vertreter der Vermächtnisnehmerin klagt daraufhin ${ }^{263}$ ) beim praetor fideicommissarius auch die Sachen ein, die dem Mann als dos aestimata überlassen wurden. Er verliert den Prozess, weil der praetor fideicommissarius entscheidet, nach der Intention des Erblassers umfasse das genannte Legat diese Sachen nicht. Entscheidend sei nämlich, dass die als Mitgift gegebenen Sachen nicht in ihrem (ausschließlichen) Gebrauch gestanden hätten, sondern - wie für die Mitgift vorausgesetzt wird - dem Unterhalt beider Ehegatten gedient hätten. Das Fragment zitiert im Fortgang zugunsten des Ego eine gleichsinnige Entscheidung des Alburnius Valens ${ }^{264}$ ), der die Mitgiftsachen nur dann als von einem derartigen Legat erfasst ansieht,

$\left.{ }^{259}\right)$ R. Röhle, Neue Lesarten zum Text des Codex Florentinus, ZRG RA 122 (2005) 62-90, 71 Nr. 16 liest ,quarum pretium in dotem erant“.

${ }^{260}$ ) Der Titel des Werkes lautet Ad Masuri Sabini libros Ad Vitellium libri IV. Es handelt sich mithin um einen Kommentar zu den libri ad Vitellium des Sabinus; vgl. D. Liebs, § 423.B.3 Iulius Paulus, in: K. Sallmann (Hg.), Die Literatur des Umbruchs, Von der römischen zur christlichen Literatur, 117 bis 284 n. Chr., München 1997, $152 \mathrm{f}$.

$\left.{ }^{261}\right)$ Zum hohen Alter des legatum quod uxoris causa paratum est vgl. R. A stolfi, Studi sull'oggetto dei legati in diritto romano II, Padua 1969, 232-240.

262) A stolfi (Fn. 261) 235 beschreibt den Inhalt wie folgt: „,on le parole quae eius causa parata sunt e simili, che l'oggetto del lascito era costituito proprio da quelle cose, che la vedova aveva adoperato vivo il testatore."

263) Der Hinweis ego petebam gilt als Beleg für eine Karriere des Paulus als Anwalt; vgl. K. Tschirner, Zum Leben des Iulius Paulus, Zeitschrift für Rechtsgeschichte 12 (1876) 149-160, 149; F.P. Bremer, Rechtslehrer und Rechtsschulen im Römischen Kaiserrecht, Berlin 1868, 60 mit Fn. 250; Lie b s, § 423.B.3 (Fn. 260) 151.

${ }^{264}$ ) Zu diesem Juristen vgl. D. Lieb s, Hofjuristen der römischen Kaiser bis Justinian, München 2008, 35f., 42f. unter Hadrian und Antoninus Pius. 
wenn der Mann sie in sein Eigentum überführt und sodann an die Frau herausgegeben habe.

Das interpretatorische Missverständnis des Vermächtnisnehmers rührt daher, dass er die Formel parata auch auf die Sachen bezieht, die zum Schätzpreis in die Mitgift gegeben wurden. Die aestimatio dotis bedeutete die Schätzung der in die Mitgift einfließenden Naturalleistungen, die vor allem dazu dienen sollte, die Rückforderung zu erleichtern ${ }^{265}$ ). Durch den Empfang der Sachen zum Schätzpreis steht der Ehemann zwar als emptor dar ${ }^{266}$ ), was vor allem bedeutet, dass er das Risiko des zufälligen Sachuntergangs trägt ${ }^{267}$ ). Während die parata dem persönlichen Gebrauch der Ehefrau dienen und daher den andernorts als parapherna benannten Sachen nahestehen ${ }^{268}$ ), erfolgt die Mitgiftbestellung aber gerade nicht zum Nutzen der Frau, sondern dient der Eheeingehung und dem Unterhalt der Ehegatten ${ }^{269}$ ). Der praetor $f$ deicommissarius befürwortet daher wie der im Nachgang zitierte Jurist eine enge Auslegung der Formel parata, was eine Anwendung auf die Mitgift, deren Legat traditionell mit den Worten erteilt wird, ausschließt. Dies ist auch deshalb angemessen, weil das Legat der Mitgift eine andere Formulierung hätte ${ }^{270}$ ) und die für die Frau erworbenen Sachen gerade von der Mitgift abzugrenzen sind ${ }^{271}$ ).

$\left.{ }^{265}\right) \mathrm{Zu}$ den (geld)wirtschaftlichen Funktionen der aestimatio dotis vgl. v.a. A. Bürge, Geld- und Naturalwirtschaft im vorklassischen und klassischen römischen Recht, ZRG RA 99 (1982) 128-157, 145f.

$\left.{ }^{266}\right)$ Vgl. D. 23,3,10,5 Ulp. 34 ad Sab. (...) quia aestimatio venditio est; dazu zuletzt F.M. Mazzante, Dos aestimata, dos vendita? Die geschätzte Mitgift im römischen Recht, Marburg 2008, 47-76.

${ }^{267}$ ) Zur aestimatio dotis vgl. H.J. Wolff, Zur Stellung der Frau im klassischen römischen Dotalrecht, ZRG RA 53 (1933) 297-371, 335f.; E. Volterra, In tema di aestimatio dotis, Rendiconti dell'Istituto Lombardo, Accademia di scienze e lettere 64 (1933) 1014-1032 = Scritti giuridici I, Neapel 1991, 429-447; A. Burdese, Aestimatio dotis, in: Studi Emilio Betti II, Mailand 1961, 167-207, bes. 179-187 (mit zu weitgehender Textkritik); eine knappe Synthese zuletzt bei Mazzante (Fn. 266) bes. $5-18$.

${ }^{268}$ ) Zur Parapherna (res extra dotem) vgl. U. Yiftach-Firanko, Marriage and Marital Agreements. A History of the Greek Marriage Document in Egypt. $4^{\text {th }}$ century BCE -4 the century CE, München 2003, 129-164.

${ }^{269}$ ) Zum Text vgl. v. a. A. Calonge, Aestimatio dotis, AHDE 35 (1965) 5-57, 38, der betont, dass die parata dem Zweck dienen, der Frau zu nutzen. Dagegen dient die Mitgift dem Unterhalt der Ehe, vgl. zuletzt J. St a g 1, Favor dotis, Die Privilegierung der Mitgift im System des römischen Rechts, Wien 2009, 22-25.

$\left.{ }^{270}\right) \mathrm{Zu}$ diesem Zweck vgl. Stagl (Fn. 269) 112-114 zu D. 31,77,9 Pap. 8 resp., in dem das Fideikommiss zugunsten der Frau ausgelegt wird.

${ }^{271}$ ) Zum Legat „quod eius causa emptum paratumve esset“ vgl. auch D. 34,2,10 
Während sich die Entscheidung des praetor fideicommissarius somit offenbar in den anerkannten Auslegungsgrenzen des ius civile bewegt, stellt sich die Frage seiner Zuständigkeit für die Klagen aus Legaten. Während Jörs von einem Fideikommiss ausging ${ }^{272}$ ), hat Röhle aus dem Fragment geschlossen, der Sonderbeamte sei in der späten Severerzeit auch für Vindikationslegate zuständig gewesen ${ }^{273}$ ). Beide Deutungen gehen von einer zu engen Zuständigkeitsregelung aus und vernachlässigen die bekannte Tatsache, dass in der späten Kaiserzeit auch förmlich errichtete Testamente und nach ius civile stilisierte Legate als Fideikommisse angesehen und erhalten werden können ${ }^{274}$ ). Im Sinne einer Klagestrategie des Legatars wäre in diesem Fall der Gang vor den praetor fideicommissarius durchaus zielführend, denn die Auslegung von Fideikommissen orientiert sich allein am Testatorwillen, wobei hier ins Gewicht fällt, dass der Legatar eine vom traditionellen Verständnis abweichende Auslegung des Vermächtnisses vertritt. Vor allem aber erlaubte die cognitio extra ordinem den unmittelbaren Sachzugriff, was in dem von Paulus weiter berichteten Fall, in dem der Mann die Mitgift beim Tod der Frau herauszugeben hat, von besonderer Bedeutung sein könnte ${ }^{275}$ ).

c. Die missio Antoniniana im Legatsrecht:

Zuletzt ist die Frage aufzuwerfen, ob die missio Antoniniana (II.3.c) auch auf Legate Anwendung finden konnte. Wenn Ulpians Bericht zur Einführung außerordentlicher Rechtsmittel anstelle des Interdiktenverfahrens (III.4.a) und Paulus' Darstellung einer Legatsklage vor dem praetor fideicommissa-

Pomp. 5 ad Q. Muc.; dazu U. John, Die Auslegung von Sachgesamtheiten im römischen Recht bis Labeo, Karlsruhe 1970, 97-101, der allerdings den historischen Kontext unbeachtet lässt. Zur Abgrenzung von emptum und paratum vgl. ferner D. 32,47,1 Ulp. 22 ad Sab.; dazu A stolfi (Fn. 261) 265 f.

272) Jörs (Fn. 36) 42.

$\left.{ }^{273}\right)$ Röhle (Fn. 6) 425f., der von einer ,zeitweisen Zuständigkeit“ des praetor fideicommissarius spricht; gleichsinnig schon Samter (Fn. 15) 89, der von einer „Personalunion“ ausgeht.

${ }^{274}$ ) Vgl. zum Beispiel D. 5,2,13 Scaev. 3 resp. für die Aufhebung des Testaments nach Erhebung der querela inofficiosi testamenti; D. 29,1,19pr.-1 Ulp. 4 disp. zur Wirksamkeit zweier Soldatentestamente. Hinzu kommt die zwischen Ehegatten verbreitete Praxis, Schenkungen durch Fideikommisse bestätigen zu lassen; vgl. D. 24,1,54 Pap. 8 resp.

${ }^{275}$ ) In diese Richtung weist der Fortgang des Textes; vgl. D. 32,78,6 Paul. 2 ad Vitell. (...) Postea apud Aburnium Valentem inveni ita relatum: mulier res aestimatas in dotem dederat ac deinde maritus ei legaverat his verbis: ,Quae eius causa comparata emptaque essent. 'D ixit emptorum paratorumque appellatione non contineri ea, quae in dotem data essent, nisi si maritus eas res, posteaquam ipsius factae essent, in uxoris usum convertisset. 
rius authentisch sind, wofür sich anführen lässt, dass die von beiden Juristen im Detail hervorgehobenen Unterschiede für das justinianische Recht kaum von Relevanz gewesen sein dürften, gibt ein Codextext Anlass, die im Wortlaut von D. 36,4,5,16 Ulp. 52 ad ed. mitgeteilte Erstreckung der missio Antoniniana auf Legate ${ }^{276}$ ) in Frage zu stellen ${ }^{277}$ ):

C. 6,54,6 Alex. (a. 225) Certa est forma iurisdictionis, qua fideicommissi servandi causa in possessionem rerum, quae in causa hereditaria sunt aut dolo malo esse desierint, is, cui legati vel fideicommissi nomine satis non datur, mittitur vel in proprias res heredis, si fideicommisso satis non fit post sex menses, quam peti coeperit, secundum divi Antonini patris mei constitutionem.

Auch dieses Reskript stellt die certa forma iurisdictionis, das heißt das prätorische Edikt mit der missio rei servandae causa für Legate und Fideikommisse, der missio Antoniniana als Spezialfall der cognitio extra ordinem gegenüber ${ }^{278}$ ). Dabei wird insbesondere hervorgehoben, dass die missio Antoniniana auch den Zugriff auf das Eigenvermögen des Erben ermöglicht. Während der ediktale Rechtsschutz Fideikommiss und Legate erfasst ${ }^{279}$ ), scheint sich die missio Antoniniana auf Fideikommisse zu beschränken: si fideicommisso satis non fit post sex menses ${ }^{280}$ ).

Die Annahme einer Interpolation von D. 36,4,5,16 Ulp. 52 ad ed. ist dennoch keineswegs zwingend: Wie die Gegenüberstellung von ediktaler missio und missio Antoniniana durch Ulpian gezeigt hat (s. oben VI.3.a-c), ist dem severischen Juristen der grundsätzliche Unterschied zwischen Legaten und Fideikommissen sehr bewusst, denn er verwendet legatum/legatarius und fideicommissum/fideicommissarius geradezu idealtypisch, um die beiden Arten der missio zu unterscheiden. Dies bedeutet jedoch nicht, dass die prätorische missio rei servandae causa auf Legate und die missio Antoniniana auf Fideikommisse beschränkt sein muss; vielmehr steht fest, dass der ediktale Rechtsschutz auch auf Fideikommisse erstreckt wurde. Angesichts der günstigen Vollstreckungsmöglichkeiten des Fideikommisses ist umgekehrt vorstellbar, dass die kaiserliche Rechtsadministration die cognitio extra or-

${ }^{276)}$ Etiam in propria bona heredis legatarios et fideicommissarios esse mittendos.

277) Ausführlich hierzu A rcaria (Fn. 95) 293-298 (mit abweichenden Ergebnissen).

${ }^{278}$ ) Palazzolo (Fn. 13) 160f.; anders Arcaria (Fn. 95) 297, der von einem Bezug auf die cognitio extra ordinem ausgeht.

${ }^{279}$ ) Qua fideicommissi servandi causa (...) cui legati vel fideicommissi nomine satis non datur.

${ }^{280}$ ) Vgl. D. 43,4,3,1 Ulp. 68 ad ed., der an den unmittelbaren Zwang zugunsten des missus anknüpft und sich auf den Fideikommissar beschränkt; vgl. Pa lazzolo (Fn. 13) 168 Fn. 108. 
dinem auch auf Legate erstreckte (s. o. IV.3.a). Hierbei ist zu beachten, dass aufgrund der Formlosigkeit des Fideikommisses ${ }^{281}$ ) durchaus die Möglichkeit besteht, Legate als Fideikommiss auszulegen, was nichts anderes bedeutet, als den Erblasserwillen gegenüber der gewählten Form zu privilegieren ${ }^{282}$ ). Unterstellt man dieses Vorgehen auch für die missio Antoniniana, wäre der Einbezug von Legaten in den Rechtsschutz der cognitio extra ordinem nicht an die Nennung des legatum oder legatarius gebunden, sondern könnte auch stillschweigend unter dem Stichwort fideicommissum oder fideicommissarius erfolgen, sofern das Legat die Qualitäten eines Fideikommisses erfüllt und etwa die Verpflichtung zur Auskehr der Früchte beinhaltet.

Sicherheit ist in dieser Frage angesichts der Quellenlage nicht zu erzielen; dennoch scheint eine nuancierte Beschreibung der severischen Rechtslage gegenüber Interpolationsannahmen vorzugswürdig. In dieser Hinsicht lassen sich die zitierten Belege zur Gleichsetzung von Legaten mit Fideikommissen, zur Klage aus einem Legat vor dem praetor fideicommissarius und die Unsicherheit mit Blick auf die missio Antoniniana zu einem Bild verdichten, dass die schrittweise Auflösung der Grenzen zwischen Legat und Einzelfideikommiss nahelegt ${ }^{283}$ ). Unter dieser Prämisse wäre die durch Augustus begründete Konkurrenzsituation zwischen Erbeinsetzungen und Legaten einerseits und Fideikommissen andererseits an dieser Stelle zu einem gewissen Abschluss gekommen, da die cognitio fideicommissaria mit all ihren Besonderheiten fortan auch für Legate offengestanden hätte. Für die hier untersuchte Frage wäre damit gleichzeitig der Wendepunkt gefunden, an dem das Formularverfahren gegenüber der cognitio extra ordinem tatsächlich seine Bedeutung eingebüßt hätte. Der so rekonstruierte Zeitpunkt für den Wechsel der Verfahrensart liegt deutlich später als die oftmals als Wendepunkt angesetzte Augusteischen Reform, mit welcher die cognitio extra ordinem für Fideikommisse eingeführt wurde (s. o. II.1.a), und wäre zudem als Pro-

${ }^{281}$ ) Treffend insoweit Riccobono, Legati e fedecommessi (Fn. 247) 364: „Il termine ,legatum' non poteva sparire, chè discendeva dalla più nobile tradizione giuridica, ma la sua sostanza è ora quella stessa del fedecommesso.“

282) Das beste Beispiel ist D. 32,11,12 Ulp. 2 fideicomm.; weitere Beispiele und Diskussion hierzu bei Johnston, Law of Trusts (Fn. 3) 260-271.

$\left.{ }^{283}\right) \mathrm{Zu}$ einzelnen Entwicklungen der Angleichung vgl. auch Johnston ibid. 258 Fn. 3. Ergänzend sei darauf verwiesen, dass auch die epigraphische Überlieferung in diese Richtung zu weisen scheint. So finden sich seit Caracalla Inschriften, die nicht länger vom praetor fideicommissarius, sondern vom praetor ultimae voluntatis sprechen, was man im Sinne eines Bedeutungszuwachses und einer Allzuständigkeit für Forderungen aus dem Willen des Erblassers deuten könnte; vgl. dazu Nachweise bei Jörs (Fn. 36) bes. 40f. und Röhle (Fn. 6) 400f. 
zess schrittweiser Ablösung zu verstehen. Die Entwicklung könnte dabei so zusammengefasst werden, dass zunächst Fideikommissare Rechtsschutz im Formularverfahren erhielten, bis der Rechtsschutz der cognitio extra ordinem von den Fideikommissen auf die Legate übergriff.

\section{Gesamtergebnis}

Die Schwierigkeiten der Abgrenzung von cognitio extra ordinem und Formularverfahren beruhen nicht nur auf der verzerrten Überlieferung in der justinianischen Kompilation, sondern sind auch auf die Tatsache zurückzuführen, dass das Formularverfahren auch nach der Einführung der Klagbarkeit der Fideikommisse als regelmäßige Verfahrensart für die Rechtsfolgen aus Fideikommissen fungierte. Die fortdauernde Bedeutung des ordo iudiciorum neben dem neuen kaiserlichen Verfahren ist auch deshalb völlig einleuchtend, weil dieses der für Legate und Testamente eröffnete Rechtsweg blieb. Erst die Severerzeit führte vermutlich zu einer stärkeren Verdrängung des Formularverfahrens durch das Kognitionsverfahren, welches sich nicht mehr auf Fideikommisse beschränkt, sondern - durch das Mittel der Auslegung - auch die Legate erfasst haben mag.

\section{Zusammenfassung der Ergebnisse und Schlussfolgerungen}

Abschließend seien die verschiedenen Einzelergebnisse in Thesen zusammengefasst:

1. Die cognitio extra ordinem aus Fideikommissen beschränkt sich auf die materielle Frage, ob das Fideikommiss besteht, welchen Inhalt und Umfang es hat und welche Verpflichtung sich daraus für den Beschwerten ergibt.

2. Die wichtigste Neuerung der cognitio extra ordinem für Fideikommisse gegenüber dem Formularverfahren für Legate und Erbeinsetzungen liegt in der Möglichkeit der Einzelvollstreckung in die hinterlassene Sache, welche auch mit einem Folgerecht gegenüber Dritten einhergeht. Diese Eigenheit der cognitio beruht auf der Auslegung des erblasserischen Willens, ist also das Ergebnis des vom cognoszierenden Beamten festgestellten Inhalts der rogatio.

3. Der unmittelbare Sachzugriff des Fideikommissars, der sich auch gegenüber Dritten durchsetzt, wird in der Literatur bisweilen als missio in rem bezeichnet; dieser Beleg ist aber nicht quellenmäßig und führt zu Verwirrung mit Blick auf andere Erscheinungen, namentlich zur missio rei servandae causa (s.u. 8) und zur missio Antoniniana (s. u. 4). Vielmehr ist auch die 
Drittwirkung als Folge der „materiellrechtlichen“ Betrachtung des Fideikommisses und damit als Ausdruck der Auslegung der letztwilligen Verfügung anzusehen.

4. Die missio Antoniniana ist eine von Caracalla im Rahmen der cognitio extra ordinem geschaffene Möglichkeit, nicht nur den unmittelbaren Sachzugriff auf die hinterlassene Sache zu erhalten, sondern zusätzlich Zugriff auf das Vermögen des Erben, um Forderungen auf Früchte und Zinsen zu befriedigen. Diese missio ist exekutorischer Natur; sie ist nicht auf Fideikommisse beschränkt und wird von Justinian abgeschafft.

5. Der Konflikt zwischen Formularverfahren und cognitio extra ordinem stellt sich bei Universalfideikommissen, die dem Beschwerten die Herausgabe der gesamten Erbschaft auferlegen, mit besonderer Dringlichkeit, woraus sich die intensive legislative Aktivität der frühen Kaiserzeit (SC Trebellianum und SC Pegasianum) in diesem Bereich erklärt.

6. Beide Senatsbeschlüsse (SC Trebellianum und SC Pegasianum) des 1. Jahrh. n. Chr., welche sich der Problematik der Erbschaftsfideikommisse annehmen, regeln die Rechtsfolgen von Universalfideikommissen im Formularverfahren.

7. Sowohl der Aktionentransfer des SC Trebellianum als auch der Antrittszwang des SC Pegasianum werden vor dem ordentlichen Gerichtsmagistraten durchgesetzt. Während der Aktionentransfer des SC Trebellianum vom praetor im Wege der formularen Fiktion erreicht wird, lässt sich der Antrittszwang des SC Pegasianum als Variation des Verfahrens aus der venditio bonorum deuten, das ebenfalls dem praetor zugewiesen ist.

8. Vermögensrechtliche Einzelfideikommisse werden nach dem Vorbild der Legate dem Schutz der cautio fideicommissorum servandorum causa sowie der missio rei servandae causa unterstellt. Auch diese beiden Sicherungsmittel sind im Formularverfahren (gegen den Erben) anzusiedeln und liegen in der Kompetenz des ordentlichen Gerichtsmagistraten. Verwirrung entsteht in den justinianischen Quellen allein dadurch, dass der Begriff missio bisweilen auch für die Vollstreckung im Rahmen der cognitio extra ordinem verwendet wird, wie namentlich die missio Antoniniana (s. o. 4) zeigt.

9. Dass die Sicherung des Fideikommissars im Formularverfahren durchgesetzt wird, der Anspruch des Fideikommissars hingegen in der cognitio extra ordinem eingeklagt wird, ergeben auch die Fragmente, die eine Konkurrenz von cautio und cognitio erkennen lassen und den Fideikommissar - je nach Sachlage - auf das eine oder andere Verfahren verweisen.

10. Die Einführung der missio Antoniniana führt - wie der Ediktskommentar Ulpians zeigt - zu Abgrenzungsschwierigkeiten mit Blick auf die 
missio rei servandae causa. Die vom severischen Juristen herausgearbeiteten Hauptunterschiede betreffen den Sachzugriff, den sichernden bzw. exekutorischen Charakter der Maßnahme sowie den Umfang der Haftung des Erben.

11. $\mathrm{Zu}$ Überschneidungen von formularer Kautionspflicht und cognitio extra ordinem kommt es namentlich dort, wo die Position des missus rei servandae causae nicht nur durch Interdikt, sondern auch durch unmittelbaren Zwang geschützt wird. Seit der Severerzeit ist von einer schrittweisen Ersetzung der formularen Schutzmechanismen durch die wirkungsvollere Sacheinweisung der cognitio auszugehen.

12. Die Attraktivität der cognitio extra ordinem mit Blick auf den Sachzugriff könnte auch erklären, warum sich gerade für die späte Severerzeit Belege für den Rechtsschutz von Legaten im Rahmen der cognitio extra ordinem finden lassen. Ulpians Bemerkung, dass die Legate den Fideikommissen angepasst seien, könnte gerade auf diese Tatsache hinweisen; auch die missio Antoniniana spricht in ihrem Wortlaut von Legaten und Fideikommissen. 